\title{
XXII. THE EPIDEMIOLOGICAL OBSERVATIONS MADE BY THE COMMISSION IN BOMBAY CITY.
}

I. Introduction.

II. Description of Bombay.

III. Methods adopted for studying the disense.

IV. The epizootic.

I. The rodents of Bombay, habits and breeding season.

II. The rat epizootics in relation to time and place.

III. The relation of the decumanus epizootic to the rattus epizootic.

IV. Plague in other rodents.

V. Summary.

V. The epidemic and its relation to the epizootics.

I. General account of the epidemic of 1905-1906.

II. The relation of the epidemic to the epizontics in time and place.

III. Summary.

VI. The sanitary circumstances in Bombay City which influence the spread of epidemic plague.

Appendix I. Tables, charts and maps of the occurrence of rat and human plague in the different sections of Bombay City.

Appendix II. Statistical report on certain rat figures, by M. Greenwond, Esq.

\section{INTRODUCTION.}

One of the first duties which the present Commission had to undertake was to decide where the epidemiological observations which were necessary to be made should be carried out. After various parts had been visited, it was decided that the headquarters of the Commission should be in Bombay, and that Bombay City and Island should, in the first instance at least, be put under observation for epidemiological purposes.

Three considerations rendered Bombay a suitable locality. In the first place Bombay City had suffered from plague since the autumn of 1896, each year seeing a fresh epidemic. The seasonal prevalence was well marked, and it was recognised that any hypothesis of the etiology of plague, if a true hypothesis, would have to explain adequately this phenomenon. 
Secondly, there was already in existence in Bombay an excellent Municipal Department, with a large staff under the direction of an experienced Medical Officer of Health, Dr Turner. Long before the Commission was formed the Bombay Municipality, at the instigation of their Health Officer, had made a representation to Government, asking that a scientific Commission be appointed to investigate plague in co-operation with their Health Department. The Commission, therefore, anticipated that every assistance would be given to them by Dr Turner and his entire department, and this anticipation was soon proved to be correct.

Thirdly, Bombay possessed at Parel on the outskirts of the City a Government laboratory complete in every way and well suited for the requirements of the Commission. Through the kindness of the Director Lt. Col. W. B. Bannerman, I.M.S., accommodation was given to the Commission in its buildings, and the whole resources of the laboratory were freely placed at their disposal.

While these advantages were apparent, it was also seen that Bombay possessed several disadvantages for an epidemiological study of plague. The population is large, nearly a million, varied and scattered over a wide area. Further, it was recognised that during the plague epidemic, when from 200 to 300 cases would occur daily, it would be impossible for the members of the Commission themselves to collect detailed information concerning every plague case, and that the general density of both rat and human plague would in all probability somewhat obscure the relationship between them.

It was therefore considered desirable to choose a few isolated villages of from 1000 to 5000 inhabitants, in which plague had periodically recurred, and to endeavour to make in these places a more complete epidemiological study. Arrangements were accordingly made to undertake the study of rat and human plague in four villages on the outskirts of the city of Bombay and within easy motor distance of the Parel laboratory. It was also arranged that two villages in the Amritsar district of the Punjab should be treated in the same way, one of the members of the Commission with a separate staff being told off for this duty. It was anticipated that the general relationships of the epizootic and epidemic would be obtained from Bombay city, some errors being corrected by the very large number of plague rats and of human cases dealt with, and that the more minute details would be elucidated in some of these six villages. 
We propose first to deal with Bombay and then to pass on to the villages.

\section{DESCRIPTION OF BOMBAY ISLAND AND CITY ${ }^{1}$. (Map I.)}

Bombay is a large island lying with its long axis almost due north and south.

The general shape is seen from the accompanying map. It has a length of about 10 miles and its greatest breadth is about three miles. Its total area is about 22.4 square miles. As regards the configuration of the Island it may be said in general terms that it is low lying. There are a few hills, such as Malabar Hill, Parel Hill, etc. but the greater part of the town is built on low ground, a considerable portion of which has been reclaimed in recent years from the sea.

At the last census (February, 1906) the total population was found to be 977,822 which, divided over an area of $14,385.89$ acres, gives a general density for the whole Island of 67.97 persons per acre. The population is however very irregularly distributed, the density varying from $7 \cdot 1$ per acre in one section to $711 \cdot 7$ per acre in another.

Lying as it does within the tropics on the coast of the Indian Ocean, Bombay comes under the influence of the seasonal monsoons. During the months of November to April the north-east monsoon blows, while from May to October the south-west monsoon prevails. In the former months there is, as a rule, no rain, while during the south-west monsoon there is an average rainfall of from 60 to 80 inches; the bulk of this falls in the months of June and July. The humidity is fairly high all the year, but is increased during the rainy season. The mean daily range of temperature is at no time large; in the winter months it is from $10^{\circ}$ to $12^{\circ} \mathrm{F}$, in the hot months about $7^{\circ}$ or $8^{\circ} \mathrm{F}$., while in the rains it is only $3^{\circ}$ to $5^{\circ} \mathrm{F}$.

In the cold season (November-March) the maximum temperature is on the average about $87^{\circ} \mathrm{F}$., the minimum $65^{\circ} \mathrm{F}$. and the mean $75^{\circ} \mathrm{F}$. The temperature gradually increases during the months of March, April and May until at the beginning of June the maximum is on an average $90^{\circ}$ to $95^{\circ} \mathrm{F}$, the minimum about $75^{\circ} \mathrm{F}$. and the mean about $85^{\circ} \mathrm{F}$.

1 The statistical information which we propose to give has been obtained from the Census Report of Bombay for 1906, issued by the Municipal Commissioner, and from Parts V. and VI., Vol. XI. of the report of the Census of India for 1901. These parts were compiled and written by Mr S. M. Edwardes, I.C.S. for Bombay eity. 
Reports on Plague Investigations in India 727

MaP I. Bombay. Town and Island showing division into sections.

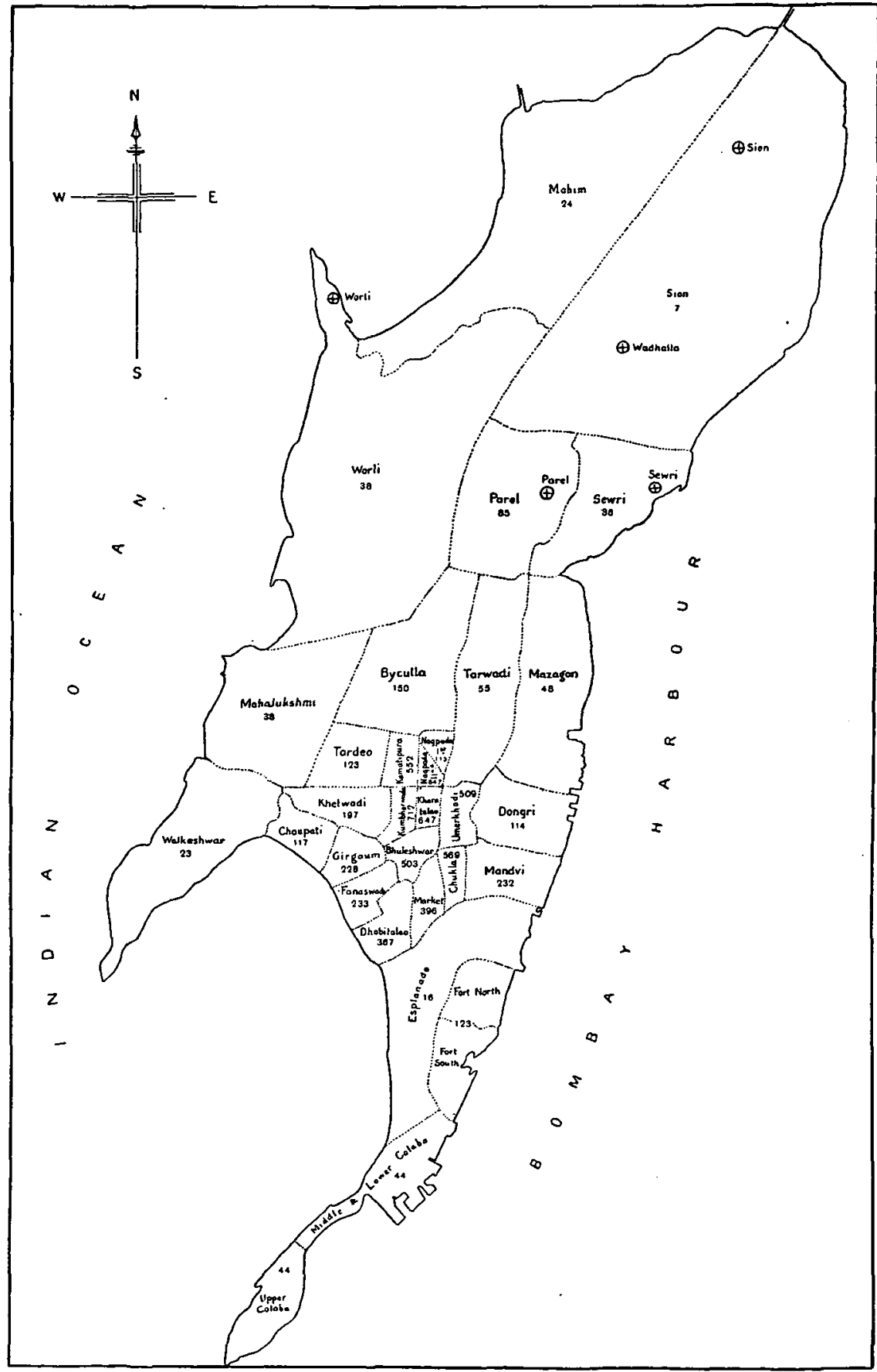

The numbers show the population per acre.

The villages specially noticed are indicated $\oplus$. 
There is a considerable fall of temperature in the rains, the mean, however, still remaining about $80^{\circ} \mathrm{F}$. There is a slight rise again in October during the time the south-west monsoon is being driven back by the north-east. On the whole, therefore, the climate of Bombay may be described as hot and moist, especially during the months of May to October inclusive.

We shall have occasion to give below a more or less detailed description of the sanitary arrangements and habits of the people of Bombay.

\section{METHODS ADOPTED FOR STUDYING THE DISEASE.}

It will be best to describe in two parts the methods adopted by us for studying the epidemiology of plague in Bombay city: (1) those relating to the epidemic, and (2) those relating to the epizootic amongst rats.

\section{The Epidemic.}

The arrangements for the purpose of observing the epidemic were made on a large scale, our aim, indeed, being to collect information regarding every plague case throughout a whole year. Observations were carried on during a longer period, namely, from 1st July, 1905, to 30 th September, 1906, but the data presented in this report fall within the 12 months from the 1st October, 1905, to 30th September, 1906.

It would have been impossible for the members of the Commission alone to cope with the enormous amount of work involved in this attempt, but we were fortunate in being helped greatly by the Medical Officer of Health for Bombay, Dr J. A. Turner. To his cordial co-operation and ready concurrence in our suggestions the scheme owes much, for he placed at the disposal of the Commission a large part of the sanitary and medical staff of the Health Department of the City under his charge.

The following account gives a description of the sanitary organisation of the City, in so far as it is concerned with our study of the epidemic.

The City and Island of Bombay is divided into ten districts, to each of which a qualified medical practitioner-the District Registrar -is appointed. Each of these ten districts is divided for the purposes of the Health Department into two or three sections. These sections, and not the districts, are the areas, which we have chosen for 


\section{Reports on Plague Investigations in India}

description in our account of the epidemic and epizootic in Bombay (vide Map I.).

The duties of the District Registrars are mainly in connection with the registration of the births and deaths, but they also have charge of a dispensary where poor patients are treated. In addition they attend the poorer class of patients in their homes. The District Registrars have a particularly thorough and extensive knowledge of their districts, and, moreover, their familiarity with the various languages ${ }^{1}$, habits and customs of the people gives them unrivalled advantages in obtaining as accurate information regarding the mortality from plague as is possible in a city like Bombay. It may be noted, also, that they have an unusually wide experience of the disease on its clinical side-such indeed as can only be acquired in a city affected to the extent that Bombay has been for the past ten years. Each is assisted in the general duties of his office by two sub-registrars who are usually Hospital Assistants ${ }^{2}$. Each District Registrar has also charge of a Disinfecting Staff, which is under the direct supervision of an Inspector.

The District Registrars, their sub-registrars and the Inspectors of Disinfection were entrusted with the task of collecting the information which we desired. The whole of this staff was supervised on our behalf by two selected medical officers of the Health Department of the City, Dr D. A. Turkhud and Dr J. S. Nerurkar, themselves familiar with its work and with special knowledge of the local conditions in the various districts.

Finally, the whole of the work carried out by the District Registrars and their subordinate staff was superintended daily by the members of the Commission, who personally checked the accuracy of their work.

We may now describe by what means the District Registrars become aware of the plague cases and of deaths from plague.

(1) Since in Bombay plague is a notifiable disease, medical practitioners in attendance on cases report them to the Medical Officer of Health. The information is immediately forwarded to the District Registrars, who in turn inquire personally into the cases.

(2) For each district of Bombay a considerable number of men are employed by the Health Department, whose sole duty it is to obtain information with regard to births and deaths in the district. Each man is told off to supervise a small area,

1 "Some idea can be formed of the cosmopolitan character of our city and island by observing that 62 different languages or dialects are spoken within its limits." Edwardes" Census Report, Bombay, p. 39.

2 A Hospital Assistant is a man who has undergone a three years' medical training in a Government Medical College. 
so that in course of time he becomes familiar with all the inhabitants living in this area. This staff is so organised that men are on duty both by day and night. For the whole of Bombay there are 62 of these men who are styled "birth registration karkoons," and 90 styled "death registration ramosis," besides a group of 34 "death registration karkoons," the last named being on special duty at cemeteries and burning ghats. Each man in the two former groups is provided with a book of printed slips in triplicate.

When a "death registration ramosi" observes a funeral party he fills up from information supplied by it the address of the deceased person together with other particulars. He then gives one of the copies to the funeral party, by whom it must be handed over to the karkoon on duty at the cemetery before the body can be buried or burned. A second copy of the slip is sent at once to the Iistrict Registrar, who, if the case has not been already notified, makes inquiries into it by visiting the house. If the body was not examined before death by a practitioner, the District Registrar arrives at a conclusion as to the cause of death by eliciting information regarding the history and symptoms of the illness from the neighbours and from the relatives or friends.

(3) When a suffering case of plague in a large building, e.g. a chawl, comes to the notice of the District Registrars or of his sub-registrars, they inquire into other suspicious cases of sickness in the building. Evacuation of a tenement in a large building during the epidemic is naturally regarded by them as a suspicious circumstance, and frequently leads to the discovery of plague cases in the other parts of the building.

(4) Certain influential men in the various communities, e.g. Hindu or Mahomedan, have acted for years as voluntary plague workers and give valuable aid by furnishing information regarding plague cases to the registration authorities.

(5) Many cases suffering from plague are not attended by medical practitioners but by unqualified native physicians or "hakims." These cases are occasionally reported to the sub-registrars by hakims or by the neighbours. When this happens the cases are verified by the District Registrars.

We may now proceed to describe how the District Registrars and their staff were utilised by us for the purpose of collecting the necessary epidemiological data.

Printed cards with headings relating to the various points on which information was required and arranged in a convenient form were distributed amongst the District Registrars (Form I.). A printed copy of instructions for filling up these case cards was also supplied to each individual whose duty it was to help us in this direction. These cards were filled up by them on the spot when visiting a plague case.

Comment may be made on two of the headings on this card.

(1) At the outset we entertained the idea that it might be possible to trace the source of infection, if not in all the cases at least in a considerable number. Difficulties, however, soon arose in obtaining 
Reports on Plague Investigations in India 731

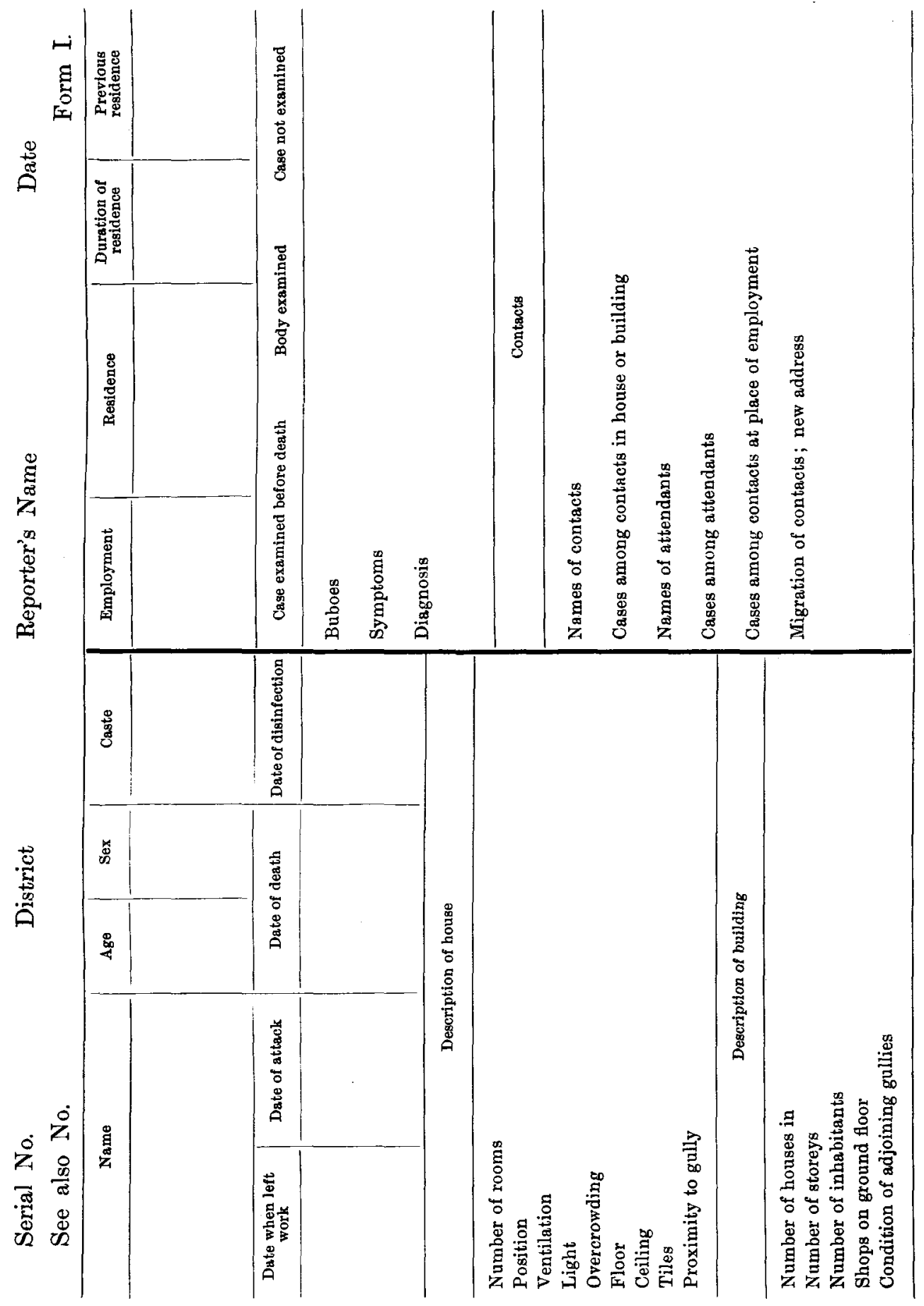


(Form I: back)

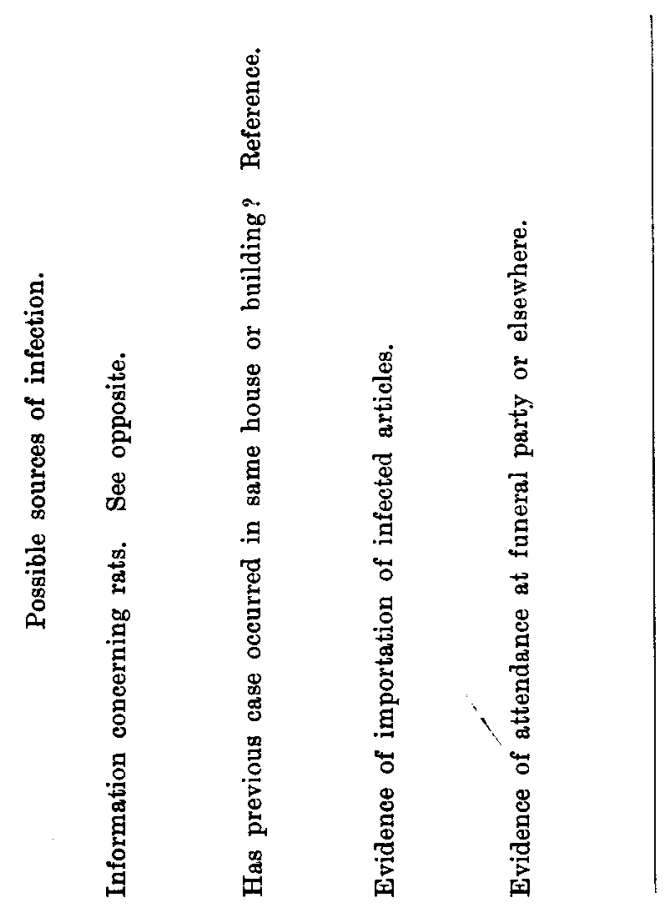

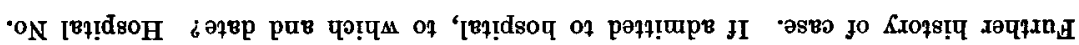

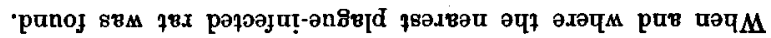

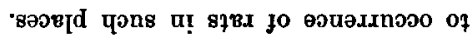

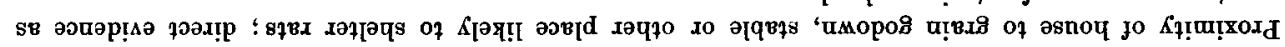
'oqa 'sqsau 'smoxing 'sвәซ ' 
information on this point. From personal investigation of a large number of cases we became convinced, that with the conditions which exist in Bombay it was impossible to arrive at any definite conclusion as to the exact source of infection in even a small proportion of the cases. The reason for this is twofold. First, the majority of the people conceal the occurrence of dead rats in their house largely from fear that disinfection will follow the avowal of the fact, and also on account of a habit of suspicion which is characteristic of the native of India. In the second place, even when the people freely gave whatever information they possessed, it was difficult in the epidemic period to narrow down the possibilities of infection to a particular source, since the infection was widely spread all over the City.

(2) The information derived from the portion of the card relating to "contacts" has given disappointing results. The work involved in following up and correlating cases amongst attendants on plague patients proved to be too great, since the attendants occasionally migrated to other quarters of the City where it was impossible to trace them. Moreover, the remarks we have just made on the question of the source of infection apply with equal force in this case.

Reference may be made to certain sources of error which are unavoidable in the collection of epidemiological data in an oriental city like Bombay. These may be summarised thus :-

(i) Cases which recover and which have not been attended by a medical practitioner are occasionally overlooked.

(ii) Undoubtedly in a number of instances plague deaths are falsely stated by the relatives to be due to other causes. The District Registrars are of course aware of this source of error and are able, in some instances at least, to make the necessary corrections.

(iii) Difficulties in the diagnosis of plague from other diseases, notably relapsing fever, must be considered.

We do not for a moment contend that errors due to these causes may not have crept into the information amassed on our behalf. We recognise, also, that the cases of plague recorded in detail on the cards are only a sample, although undoubtedly a very large one, of the total cases which actually occurred. Evidence however, which will be given later, shows that these errors are for practical purposes nullified by the large numbers of plague cases investigated (over 10,000). Further, we hope to show that the sample in almost all the districts was an extremely good one, so much so that it has amply fulfilled our main purpose, namely, the correlation of human and rat plague. 
Besides the "human case" cards another method of studying the epidemic remains to be described. Maps of every section in Bombay were specially prepared for us. These are essentially street-maps, unnecessary details being avoided, and the streets and lanes being shown in plain black outline. Most of them are on a scale of 200 feet to the inch, the average size of the original maps being $24^{\prime \prime} \times 18^{\prime \prime}$. Each District Registrar was supplied with copies of maps of the sections in his district. Every plague case, as it came to his notice, was represented by him on the map by a conventional sign together with the date when the case was reported to the Health Officer. The sign and date were allocated to a position on the map corresponding as nearly as possible to the house in which the patient was found. Distinctive signs were adopted to indicate a suspicious case of plague and a case which was imported either from outside Bombay or from another section. As a rule one map was used for the plague cases occurring during one month, but in some sections during the epidemic period it was found necessary in order to avoid overcrowding to use a fresh map every fortnight. The maps and case cards were checked by Drs Turkhud and Nerurkar and by members of the Commission.

Before bringing to a close this account of our methods of observing the epidemic in Bombay, we may refer to certain advantages which accrued from the system adopted, apart from the results which have emerged from an analysis of the case cards and maps.

(1) The scheme gave us abundant opportunities of observing with our own eyes the actual conditions in which the inhabitants of Bombay live, an experience which has assisted us greatly in coming to a conclusion as to the part played by these conditions in the spread of plague in the city.

(2) By the co-operation of the District Registrars we were enabled to obtain early information regarding incidents of special interest which occurred throughout the city, e.g. the occurrence of severe outbreaks in certain localities and buildings.

(3) It was possible to carry out special experiments in certain badly infected houses, which were brought to our notice by the District Registrars. Some of these have already been recounted in previous volumes of these reports, namely, those dealing with the infectivity of certain plague houses and the nature of the infecting agent within them. 


\section{Reports on Plague Investigations in India}

\section{The Epizootic.}

The methods adopted for studying the epizootic may be described under three headings: (1) the collection of the rats, (2) the examination of the rats at the laboratory, and (3) the arrangements made to correlate the epizootic with the epidemic.

\section{The collection of the rats.}

Arrangements were made for a daily supply of several hundred rats (alive and dead) from all over the city. The rats were collected on our behalf by the Sanitary and Cleansing Department of the City.

In connection with the work of this Department there are eight Municipal stables or dépôts situated in the different districts. Each of these is in charge of an European Inspector, who is assisted by one or two sub-inspectors. The actual cleansing staff consists of 4800 "sweepers"-men and women. These persons are grouped into batches of 10 or 12, each of which is supervised by a "muccadum" or overseer, a man who is able to write the vernacular. The sweepers remove all refuse from the houses and gullies and sweep the streets. The gullies are cleaned by them at least once a day. Each man is allotted to a very small area so that the work may be efficiently done. The sweepers are the persons who are most likely to find dead rats, because if a rat is found dead in a house the occupants throw it out into the adjoining gully or into the street.

The sweeper when he found a dead rat took it to his muccadum, who attached to it a note stating the exact locality where the rat was found. The rat was then taken by the sweeper to the stable in his district, where roll call is held every morning, and he was paid $\frac{1}{4}$ anna for every dead rat.

At the stable all the dead rats found at one address were put into a tin box, on the lid of which was a number.

The details concerning all the dead rats brought were entered into a form showing (1) the number of the box, (2) the number of rats in the box, (3) the address where the rats were found and (4) the name of the sweeper who found them. All the tins were then packed into carts and were sent with the corresponding form to the laboratory.

With regard to the capture of the live rats a number of traps were kept by the officials at each stable and these were distributed daily amongst selected sweepers (rat catchers), who set them in gullies, godowns, houses, stables, etc. Each trap was numbered and this number and other 
particulars were entered on the form already described. The form was sent to the laboratory with the traps. A reward of $\frac{1}{2}$ anna was given for each live rat.

\section{Examination of the rats at the laboratory.}

On arrival at the laboratory the rats were dealt with on the following scheme, which was so arranged that the rats passed through the hands of a series of unskilled native assistants, each of whom, however, was trained to his particular item of work and was competent to perform it.

The procedure differed slightly in the case of dead and live rats.

Dead rats. A card partly filled up by a clerk from the form sent from the stable was attached to the fore-leg of every dead rat. The details on this card are reproduced (II.). The rat was then dipped into an antiseptic solution in order to diminish the nuisance from flies in the subsequent operations. The next step was to weigh the rat on a spring balance and to enter the weight in grammes on the card. The rat was then pinned upon a small wooden board and taken to the man who dissected them. As will be seen from Plates XIX and XX the pinned-out rats were laid in rows on a series of long tables. A "cutter up" and a clerk were allotted to each table. The work of dissecting the rats was performed by three disciplined European soldiers on the staff of the Plague Research Laboratory, specially chosen for their intelligence and good conduct and trained for this particular duty by members of the Commission.

The "cutter up" opened the rat by an incision which included the groin, axilla and neck on both sides so as to expose the glands in these regions. He dictated to the clerk who accompanied him the species and sex of each rat and the presence or absence of pregnancy in the females. These facts were noted on the rat cards by the clerk.

The methods pursued in the diagnosis of plague-infected rats have been already fully described ${ }^{1}$, so that it is unnecessary to do more than briefly refer to them. Diagnosis of plague rats by naked-eye examination was chiefly relied upon, since it has been our experience that in the hands of competent observers it is the best single method of diagnosis. Every rat dissected throughout the entire investigation, without exception, whether infected or apparently healthy, was examined by a member of the Commission, who decided as to the diagnosis. Microscopical

1 Vol. vir. p. 339. 
JOURNAL OF HYGIENE (PLAGUE NO.), VOL. VII. NO. 6

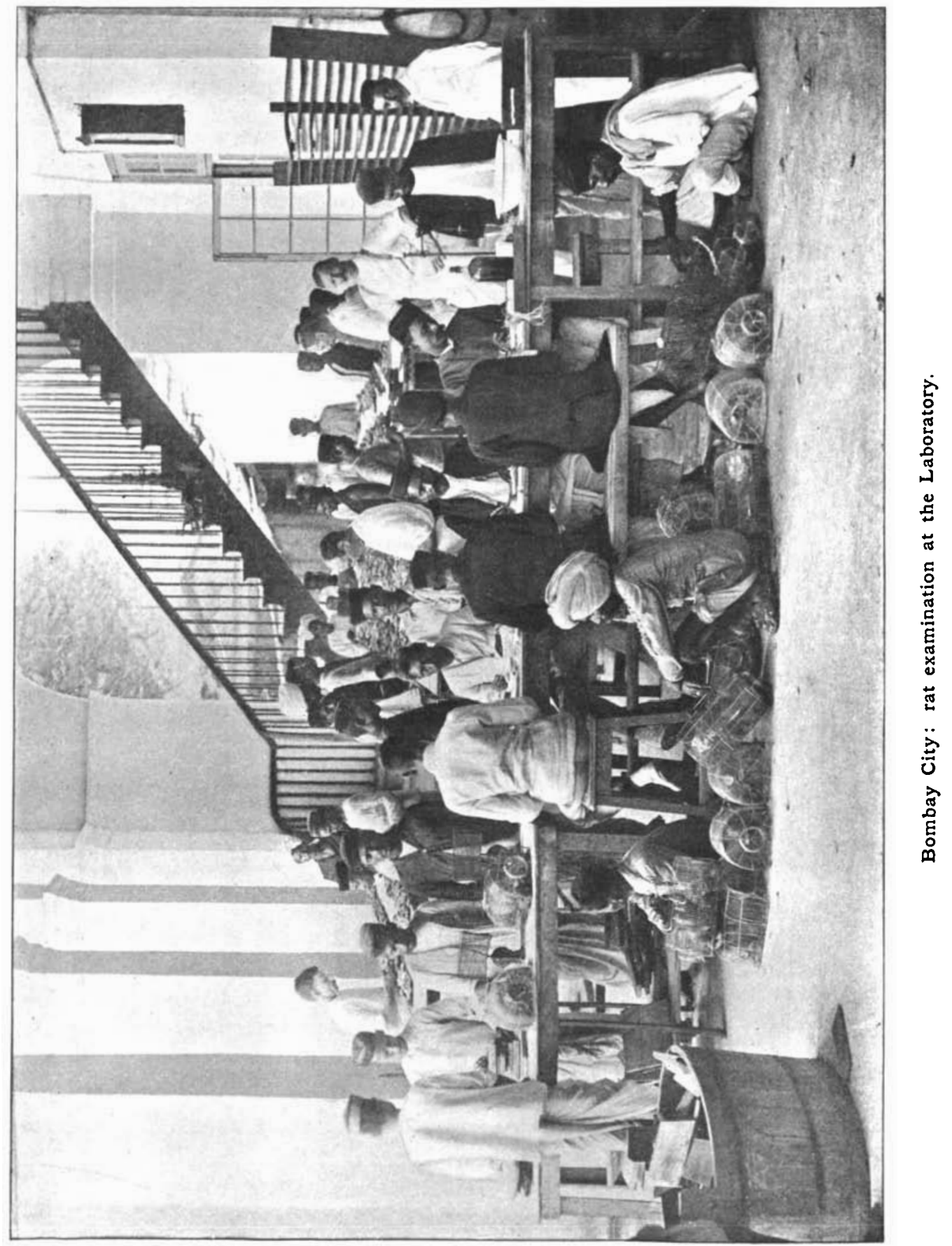




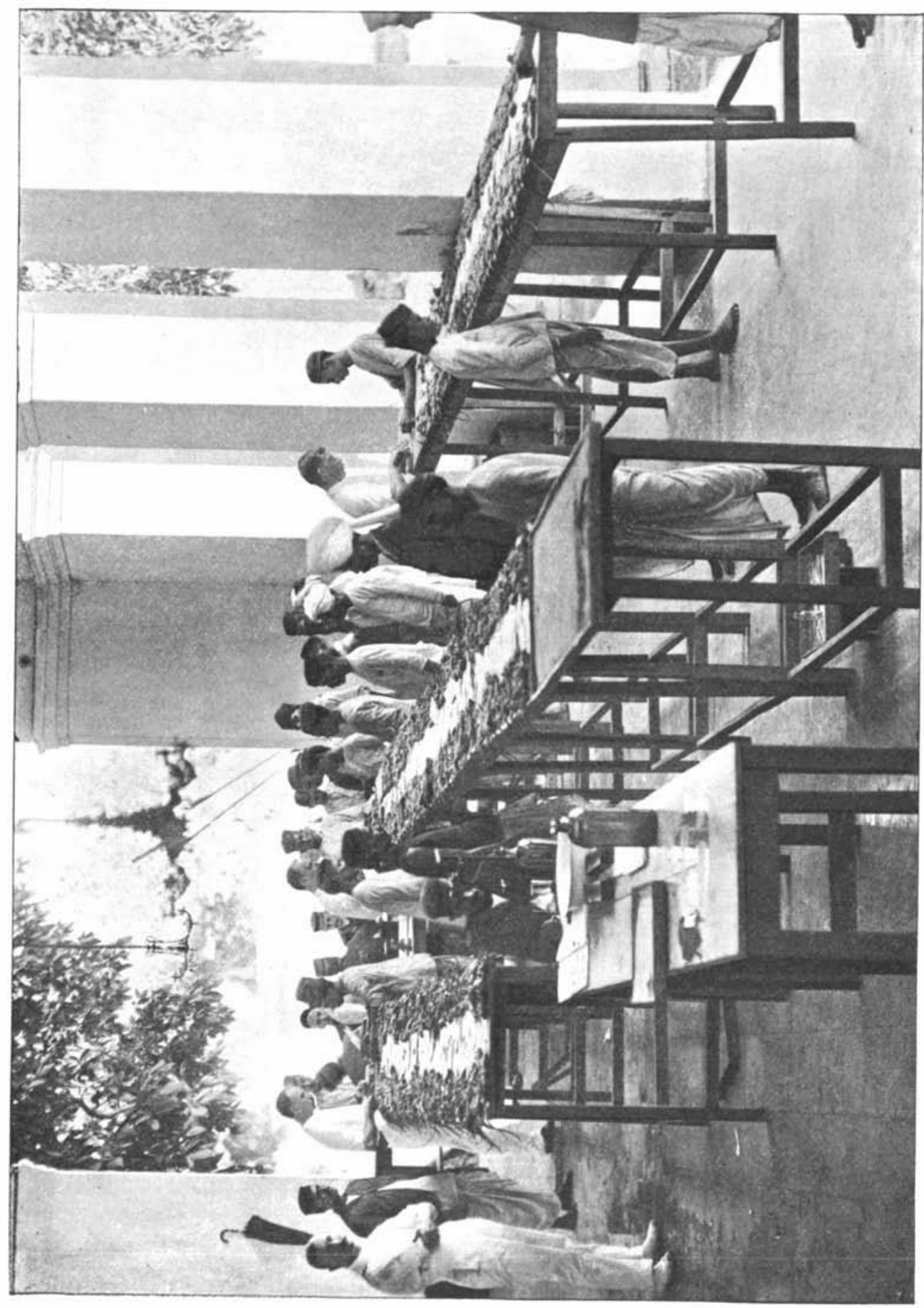




\section{Reports on Plague Investigations in India 737}

Form II.

Date Number

Catcher

Locality

Where \& how caught

Weight Number of fleas

Species

Sex Pregnant

Infected

Initials.

Form III.

Date

District

Section

Catcher

Address

No. of rats in cage Species

(Total No. of fleas $\left\{\begin{array}{r}\text { Average No. } \\ \text { for rat }\end{array}\right.$

Gully

House

Stable

Godown

Remarks :- 
examinations of organ-smears and animal tests were used only when the diagnosis was uncertain.

Live rats. The procedure adopted in the case of the rats caught alive in traps was as follows. The rats first of all were cleared of their fleas (Plate XXI). At an early period of the investigation an attempt was made to obtain a daily average flea-count, but as the arrangements were somewhat defective in several respects we need only describe an improved method (Plate XXII) which was commenced in October 1906. The arrangements at this later period were made so as to fulfil two purposes: (1) the exact allocation of each trap containing rats to a particular part of an inhabited building, e.g. the ground floor, first floor, etc. or to a godown, stable or gully, and (2) an average flea-count, not only for the total rats but for each species of rat and for the rats found in particular classes of buildings, e.g. houses, godowns, etc. This scheme was entrusted to specially selected men at the municipal stables and on the District Registrars' staff who distributed traps to selected sweepers.

The traps were purposely placed in various situations and when a "take" was made, the man in charge wrote on the back of a specially designed card (III.) the exact situation where the trap was found. The trap was then taken to the stable or to the District Registrar's office, where this information, if in the vernacular, was translated and written on the printed side of the card. The traps were afterwards sent to the laboratory. In this scheme we adopted the device of enclosing the whole trap, immediately after it was found to contain rats, in a stout canvas bag made for the purpose and bearing a number. The card referred to above was attached to the neck of this bag.

The object of the bag was in order to secure more uniform results in the flea-counts. It would appear that in the journey to the laboratory fleas on rats in open wire traps exposed to the sunlight dropped off in considerable numbers. By comparison with the old method it was proved that more uniform flea-counts were obtained by the use of this device and that the average number of fleas found per rat was higher.

When the traps arrived at the laboratory each trap was removed from the bag and both trap and bag were at once put into a tin box, to which chloroform was added. Four of these boxes were in constant use during the flea examination. Each of thein had a metal tray resting on the bottom, on which tray the trap and bag were placed. The tray and its contents were removed en bloc after the rats were killed by the chloroform. The fleas on the tray were then counted and those on each rat separately, a note of the results being made on the card and on a form. 


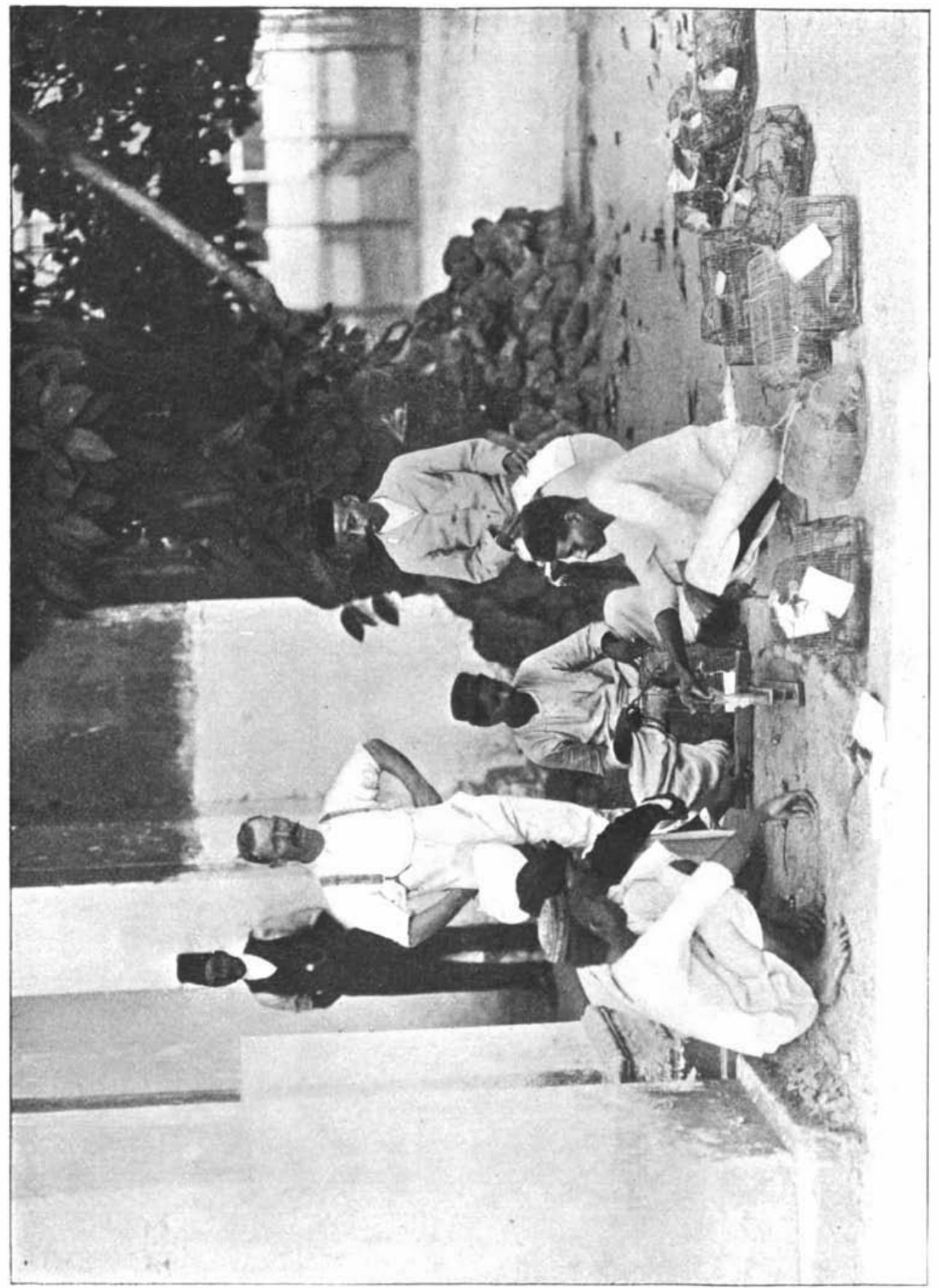




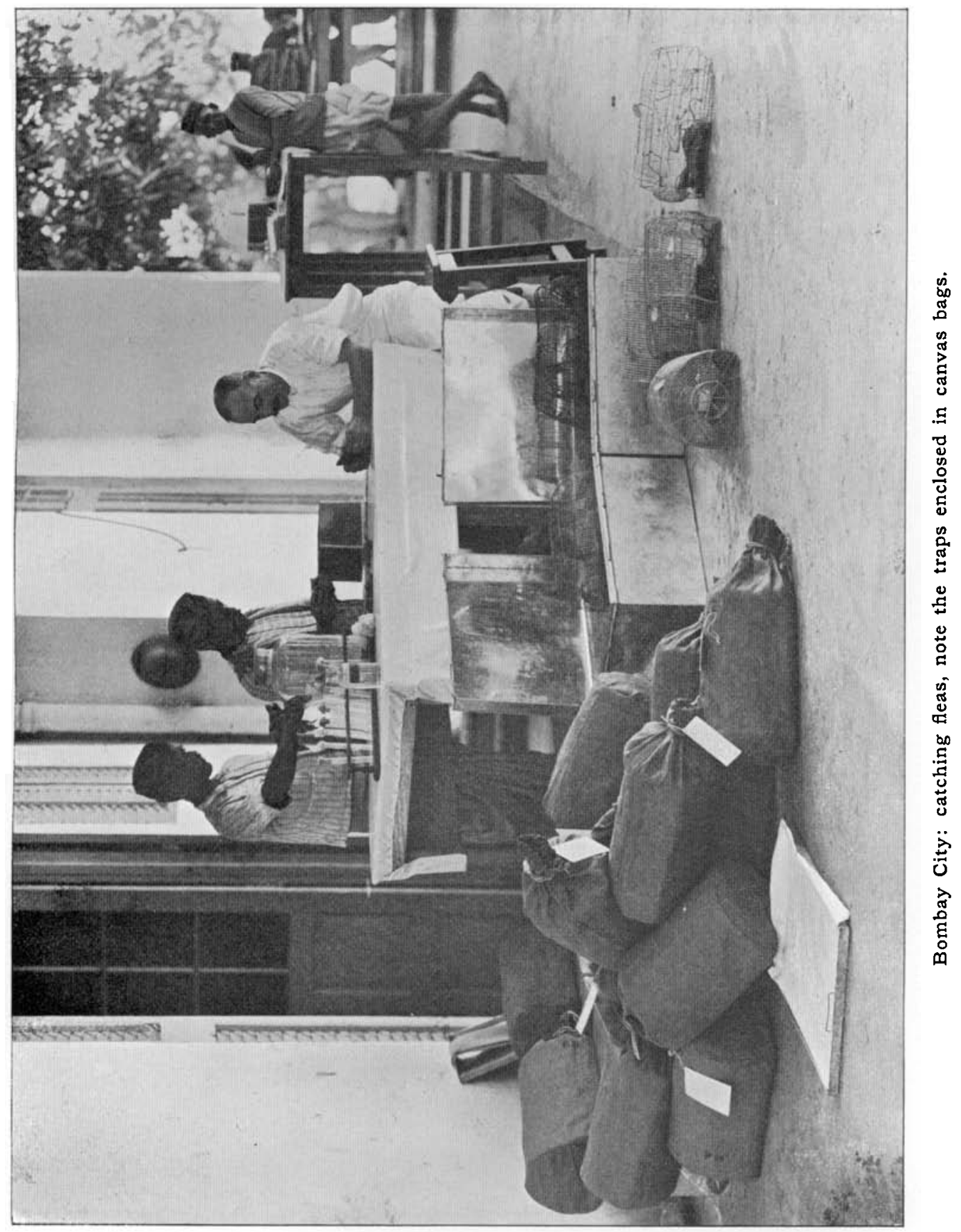


Reports on Plague Investigations in India 739

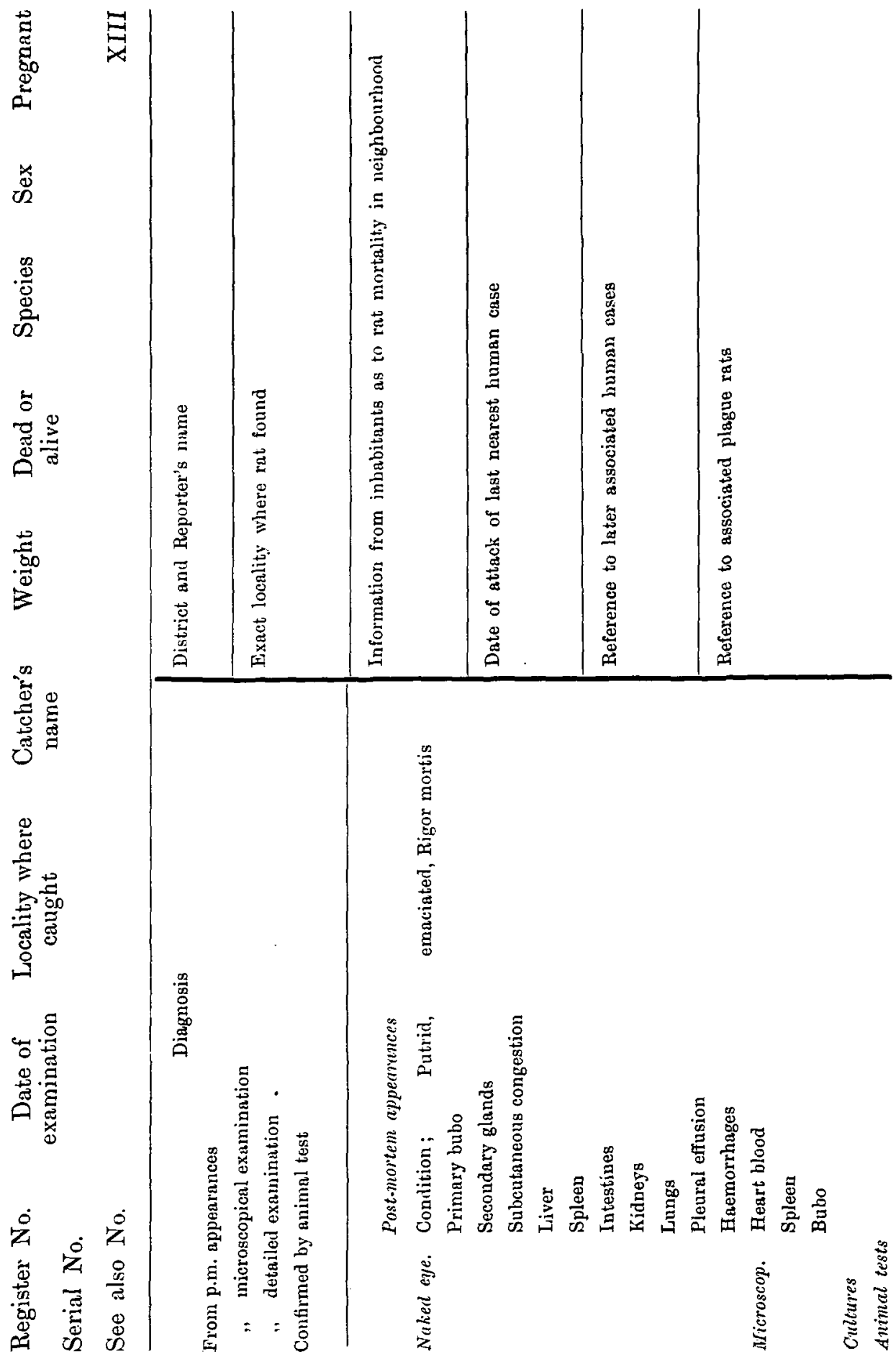


(Form XIII : back)

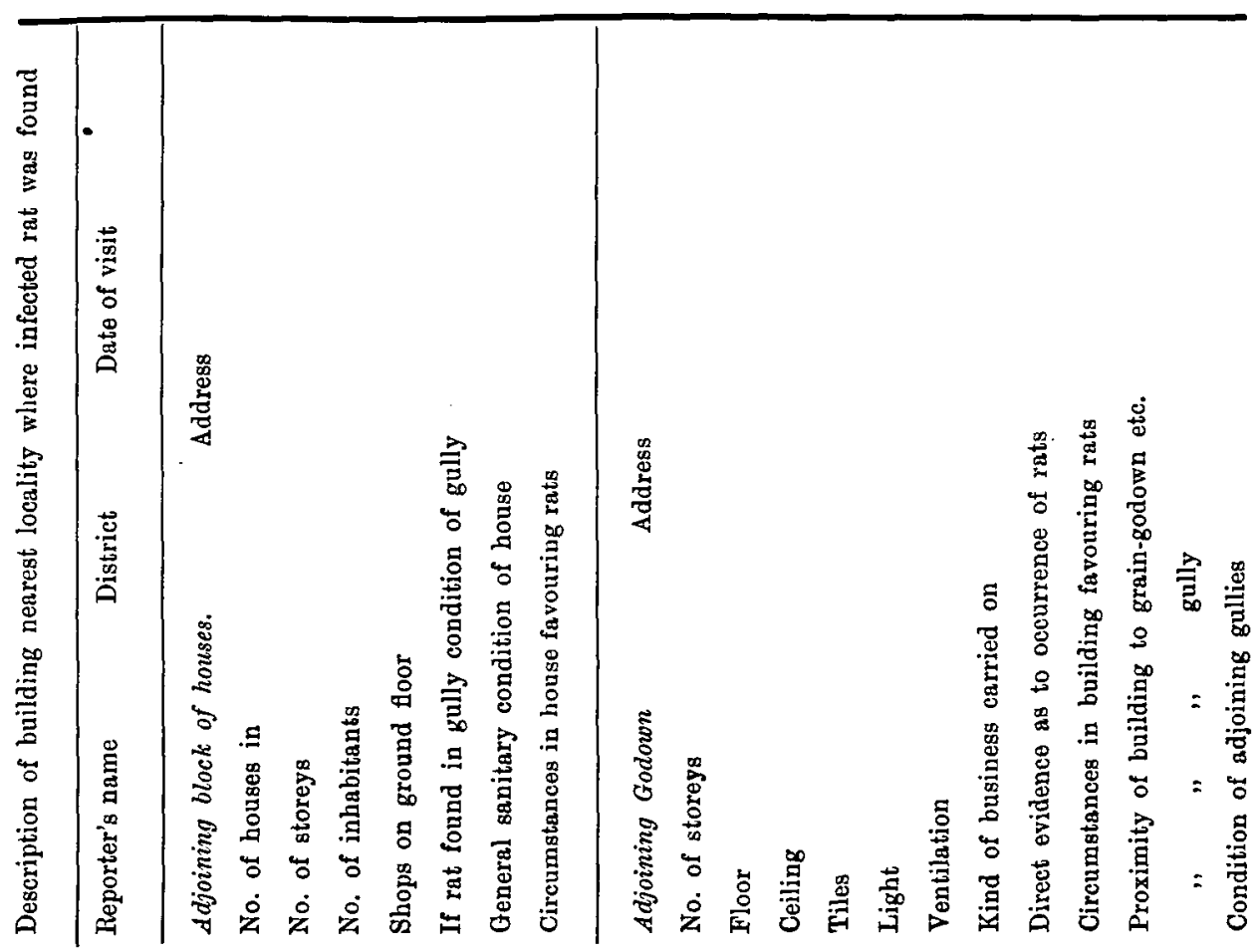


A complete record of the information obtained in this way was kept in a ledger.

The subsequent treatment of the trapped rats was the same as has been described in the case of the dead rats.

It remains to be said that the whole of the information noted on the rat cards was daily recorded in ledgers. In addition daily, weekly and monthly summaries of the rat and flea statistics were prepared.

\section{The arrangements for correlating the epizootic with the epidemic.}

A list of plague-infected rats for each day was sent as soon as possible to each District Registrar and to the Inspectors at each stable. On the same evening or next morning the sweepers who picked up the plague rats pointed out the exact locality where they had found them to the muccadums, who marked the place with a sign "P. R." and the date in red paint (see Plate XXVI.).

The District Registrar or his sub-registrar on visiting the place later in the day recognised it from this sign and filled up, on the spot, a specially designed "plague rat" card which had been sent him from the laboratory already partially filled up, i.e. giving the species of the rat, address where it was found and the name of the catcher. The Registrar at the same time allocated the plague rat to its proper position on the map of the section which we described in the account of the epidemic.

A distinctive sign was used for each species, Mus rattus and Mus decumanus, and the date when the rat was sent to the laboratory was placed alongside. After being filled up the cards were returned to the laboratory where they were copied by clerks into duplicate cards (XIII.) with additional headings (already entered) relating to details of the post-mortem examination and diagnosis of the rat. The maps and cards were checked by members of the Commission, assisted by Drs Turkhud and Nerurkar.

Although the methods for allocating the plague-infected rats were apparently the best that could be used under the circumstances, yet we cannot pretend that absolute accuracy was secured in placing every rat. We have good reason to believe, however, that the accuracy of the methods although only approximate was sufficient for the purpose of comparing the plague rats with the human cases in each section and even over smaller areas than sections. 


\section{THE EPIZOOTIC.}

\section{An Account of the Rodents met with in Bombay.}

Before entering upon a description of the epizootic it is necessary to give a brief account of the rodents which have been met with in the course of our work in Bombay.

(1) The species of rodents found infected with plague in nature.

These are: Mus rattus (the house rat), Mus decumanus (the socalled brown, gray or sewer rat), Mus musculus (mouse), Nesokia bengalensis and Nesokia bandicota (bandicoot).

On account of the large numbers of rodents brought daily to the laboratory for examination it was necessiry to come to a conclusion regarding their species from external appearances alone. The mouse and the bandicoot offered no difficulty in identification. With regard to Mus rattus and Mus decumanus, the most important of all in relation to the epidemic, it was soon found that with practice no difficulty was experienced in differentiating them. We have satisfied ourselves that it is always possible to distinguish rats of the type of Mus rattus from rats of the type of Mus decumanus. Since rats of an intermediate type have never been found by us it would appear that the species do not interbreed.

Nesokia bengalensis on superficial examination resembles Mus decumanus so closely that its occurrence amongst the rats was overlooked during the earlier period of the investigation. Nevertheless after the recognition of this rodent as a distinct species we were able with a little practice readily to identify it from its external appearances alone. It may be added that for reasons which will appear later the error introduced into our work by the confusion of Nesokia bengalensis with Mus decumanus may be said to be negligible.

In the following description of Mus rattus, Mus decumanus and Nesokia bengalensis we shall confine ourselves to the points of distinction on which we relied throughout our work.

Mus rattus.-Tail longer than the body and head together; dark in colour compared with the tail of Mus decumanus and uniform in colour all round. The scales on the tail are arranged in rings; these rings are better marked than in Mus decumanus. The ears are larger in proportion to the size of the rat than in Mus decumanus. The colour of the fur, especially on the ventral aspect of the body, is very variable. Mfus rattus is frequently called the black rat, but the commonest 
type in Bombay is a brown variety. The black variety is somewhat rarely seen in rats taken from the City, though it occurs more commonly amongst rats trapped from ships in Bombay harbour. The belly is invariably of a lighter colour than the back. Rarely the belly is unusually light coloured; rats with this peculiarity are considered by some workers as a variety (Mus alexandrinus), but no distinction was made by us on this account. We have met with pure and partial albinos but they are very rare. Spines in the fur of the back are common.

Mus decumanus. - Tail shorter than body and head together. The ventral aspect of the tail is lighter coloured than the dorsal aspect. The ears are smaller in proportion to the size of the rat than in Mus rattus. The colour of the fur is much more constant than in Mfus rattus. It is brownish-gray on the back and a lighter gray on the belly. Pure and partial albinos have been rarely met with.

Nesokia bengalensis'. - Tail shorter than head and body, in this respect resembling that of Afus decumanus, but in appearance resembling that of Mrus rattus, i.e. the rings are well marked. The hairs on the tail are shorter and less numerous than in Mus decumanus and there is no brush of hairs projecting beyond the tip of the tail as there is in Mus decumanus. The head when looked at from above is broader and shorter than in Mus decumanus. The ears are somewhat larger in proportion to the size of the animal than in Mus decumanus. The fur is coarse with wellmarked spines on the back. The colour of the fur is uniformly darker than in Mus decumanus and this colour is very constant. Nesokia grunts when alarmed, whereas Mfus decumanus squeals. There is a well-marked bony tubercle on the external surface of the ramus of the lower jaw contrasting with a similar but rudimentary tubercle in the case of Mus decumanus.

Musk rats were trapped in considerable numbers from all parts of the Island. This animal (Crocidura coerulea: order-Insectivora) is not a rat but a shrew. It is recognised with great ease chiefly by its long head and pointed snout.

(2) General distribution and abundance of each species in the rodent population.

In Bombay city Mus rattus and Mus decumanus both occur in prodigious numbers. In the country villages, however, Mus decumanus is very rarely found (see Table III.). This is doubtless correlated with the absence of any sewerage system in those villages.

There can be no doubt that the species of rodents which are most numerous in Bombay are Mus rattus and Mus decumanus. It is difficult from the figures given in Tables I, and II. to arrive at a definite conclusion as to whether Mus rattus or Mus decumanus is the predominating

1 "It is doubtful whether this (genus Nesokia) should rank as more than a subgenus of Mus." The Fauna of Britisl India: Mammalia: W. T. Blanford, F.R.S., London, 1888-1891, p. 422. 
species, since the "takes" depend to a great extent on the number of traps set in situations frequented by each species. More than twice as many Mus rattus were trapped alive as decumanus, while the proportion is reversed in the case of rats found dead. This fact may be explained by the habits of each species, which are such that dead decumanus would be much more likely found than dead rattus.

However this may be, the point is of little practical importance, since it is certain that enormous numbers of each species exist in Bombay and that both species are very liable to plague infection.

The number of mice brought for examination during the year was small, probably for the reason that the rat traps used were not well suited for trapping mice. From our observations in the City, however, we are inclined to think that the mouse population is a small one, relatively at least to that of Mus rattus and Mus decumanus, and that

\section{TABLE I.}

Showing the result of rat trapping in Bombay for three months, November-January.

\begin{tabular}{|c|c|c|c|c|c|c|c|c|c|c|c|c|c|}
\hline & \multirow[b]{2}{*}{ Takes } & \multirow[b]{2}{*}{ Rats } & \multicolumn{2}{|c|}{ rattus } & \multicolumn{2}{|c|}{ decumanus } & \multicolumn{2}{|c|}{ Nesokia } & \multicolumn{2}{|c|}{ Musk rats } & \multicolumn{2}{|c|}{ Mice } \\
\hline & & & & $\begin{array}{l}\text { Total } \\
\text { No. }\end{array}$ & $\begin{array}{l}\text { \%oto } \\
\text { Total }\end{array}$ & $\begin{array}{l}\text { Total } \\
\text { No. }\end{array}$ & $\begin{array}{l}\% \text { to } \\
\text { Total }\end{array}$ & $\begin{array}{c}\text { Total } \\
\text { No. }\end{array}$ & $\begin{array}{l}\% \text { to } \\
\text { Total }\end{array}$ & $\begin{array}{c}\text { Total } \\
\text { No. }\end{array}$ & $\begin{array}{l}\% \text { to } \\
\text { Total }\end{array}$ & $\begin{array}{c}\text { Total } \\
\text { No. }\end{array}$ & $\begin{array}{l}\text { \% to } \\
\text { Total }\end{array}$ \\
\hline \multicolumn{2}{|c|}{ Total Number } & 2901 & 12856 & 8332 & $66 \cdot 2$ & 3618 & $28 \cdot 7$ & 123 & $1 \cdot 0$ & 294 & $2 \cdot 3$ & 219 & $1 \cdot 7$ \\
\hline \multicolumn{2}{|c|}{ Gullies } & 278 & 1254 & 701 & $55 \cdot 9$ & 485 & $38 \cdot 7$ & 22 & $1 \cdot 7$ & 26 & $2 \cdot 0$ & 20 & $1 \cdot 6$ \\
\hline \multicolumn{2}{|c|}{ House-- } & 2253 & 9247 & 6466 & $69 \cdot 9$ & 2386 & $25 \cdot 8$ & 75 & 0.8 & 181 & $2 \cdot 0$ & 139 & 1.5 \\
\hline \multicolumn{2}{|c|}{ Compound } & 16 & 104 & 33 & $31 \cdot 7$ & 62 & $59 \cdot 6$ & - & - & 5 & $4 \cdot 8$ & 4 & $3 \cdot 8$ \\
\hline \multicolumn{2}{|c|}{ Ground floor } & 1384 & 5855 & 3805 & $65 \cdot 0$ & 1774 & $30 \cdot 0$ & 69 & $1 \cdot 2$ & 132 & $2 \cdot 3$ & 75 & 1.2 \\
\hline 1 st &, & 479 & 1971 & 1536 & $77 \cdot 9$ & 390 & $19 \cdot 8$ & $\mathbf{3}$ & 0.1 & 24 & $1 \cdot 2$ & 18 & 0.9 \\
\hline $2 n d$ &, & 234 & 845 & 720 & $85 \cdot 2$ & 105 & $12 \cdot 4$ & - & - & 10 & $1 \cdot 2$ & 10 & $1 \cdot 2$ \\
\hline $3 r d$ & , & 80 & 260 & 224 & $86 \cdot 2$ & 36 & $13 \cdot 8$ & - & - & - & - & - & - \\
\hline 4 th &, & 15 & 71 & 43 & $60 \cdot 6$ & - & $\ldots$ & - & - & 2 & $2 \cdot 8$ & 26 & $36 \cdot 6$ \\
\hline 5 th & , & - & - & - & - & - & - & - & - & - & - & - & - \\
\hline 6 th & , & 1 & 1 & - & - & - & - & 一 & - & 1 & $100 \cdot 0$ & - & - \\
\hline Top & & 16 & 54 & 48 & $88 \cdot 9$ & - & - & - & - & - & - & 6 & $11 \cdot 1$ \\
\hline Not & & 28 & 86 & 57 & $66 \cdot 3$ & 19 & $22 \cdot 0$ & 3 & $3 \cdot 5$ & 7 & $8 \cdot 1$ & - & - \\
\hline Stable & & 170 & 944 & 484 & $51 \cdot 3$ & 352 & $37 \cdot 3$ & 18 & $1 \cdot 9$ & 54 & $5 \cdot 7$ & 36 & $3 \cdot 8$ \\
\hline Hors & & 118 & 669 & 321 & $47 \cdot 9$ & 276 & $41 \cdot 3$ & 1 & 0.1 & 38 & $5 \cdot 7$ & 33 & $4 \cdot 9$ \\
\hline Bulle & & 16 & 59 & 25 & $42 \cdot 3$ & 10 & $16 \cdot 9$ & 17 & $28 \cdot 8$ & 7 & $11 \cdot 8$ & - & - \\
\hline Not & & 36 & 216 & 138 & 63.9 & 66 & 30.5 & - & - & 9 & $4 \cdot 2$ & $\mathbf{3}$ & $1 \cdot 4$ \\
\hline Godov & & 136 & 846 & 540 & $63 \cdot 8$ & 268 & $31 \cdot 7$ & $\mathbf{3}$ & 0.4 & 16 & 1.9 & 19 & $2 \cdot 2$ \\
\hline Food & & 32 & 305 & 228 & $74 \cdot 7$ & 63 & $20 \cdot 7$ & - & - & 6 & $2 \cdot 0$ & 8 & $2 \cdot 6$ \\
\hline Not & & 97 & 517 & 290 & $56 \cdot 0$ & 203 & $39 \cdot 2$ & $\mathbf{3}$ & $0 \cdot 6$ & 10 & 1.9 & 11 & $2 \cdot 1$ \\
\hline Gunt & Bags & 1 & 3 & $\mathbf{3}$ & $100 \cdot 0$ & - & - & - & - & - & - & - & - \\
\hline Not & & 6 & 21 & 19 & 90.5 & 2 & $9 \cdot 5$ & - & - & - & - & - & - \\
\hline Food, & shops & 50 & 247 & 108 & $43 \cdot 7$ & 117 & $47 \cdot 4$ & 1 & 0.4 & 16 & $6 \cdot 4$ & 5 & $2 \cdot 0$ \\
\hline Uncla & ied & 14 & 48 & $\mathbf{3 3}$ & $68 \cdot 7$ & 10 & $20 \cdot 8$ & 4 & $8 \cdot 2$ & 1 & $2 \cdot 0$ & - & - \\
\hline
\end{tabular}




\title{
Reports on Plague Investigations in India 745
}

\author{
TABLE II.
}

Showing relative distribution of $M$. rattus and $M$. decumanus in Bombay-trapping for three months, November-January.

\begin{tabular}{|c|c|c|c|c|c|c|}
\hline & & \multicolumn{2}{|c|}{ Rattus } & \multicolumn{2}{|c|}{ Decumanus } \\
\hline & & Rats & Total No. & $\begin{array}{c}\% \text { to } \\
\text { total rats }\end{array}$ & Total No. & $\begin{array}{l}0 / 9 \text { to } \\
\text { total rats }\end{array}$ \\
\hline \multicolumn{2}{|c|}{ Total Number } & 11950 & 8332 & $69 \cdot 7$ & 3618 & $30 \cdot 3$ \\
\hline \multicolumn{2}{|c|}{ Gullies } & 1186 & 701 & $59 \cdot 1$ & 485 & $40 \cdot 9$ \\
\hline \multicolumn{2}{|c|}{ House } & 8852 & 6466 & $73 \cdot 0$ & 2386 & $27 \cdot 0$ \\
\hline \multicolumn{2}{|c|}{ Compound } & 95 & $\mathbf{3 3}$ & $34 \cdot 7$ & 62 & $65 \cdot 3$ \\
\hline \multicolumn{2}{|c|}{ Ground floor } & 5579 & 3805 & $68 \cdot 2$ & 1774 & $31 \cdot 8$ \\
\hline lot & , & 1926 & 1536 & $79 \cdot 7$ & 390 & $20 \cdot 3$ \\
\hline 2nd & , & 825 & 720 & $87 \cdot 3$ & 105 & $12 \cdot 7$ \\
\hline 3 rd & $"$ & 260 & 224 & $86 \cdot 2$ & 36 & $13 \cdot 8$ \\
\hline 4th & , & 43 & 43 & $100 \cdot 0$ & - & - \\
\hline 5th & , & - & - & - & - & 一 \\
\hline 6th & , & - & - & - & 一 & - \\
\hline Top & 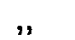 & 48 & 48 & $100 \cdot 0$ & 一 & 一 \\
\hline \multicolumn{2}{|c|}{ Not stated } & 76 & 57 & $75 \cdot 0$ & 19 & $25 \cdot 0$ \\
\hline \multicolumn{2}{|c|}{ Stables-. } & 836 & 484 & $57 \cdot 9$ & 352 & $42 \cdot 1$ \\
\hline \multicolumn{2}{|c|}{ Horse } & 597 & 321 & $53 \cdot 8$ & 276 & $46 \cdot 2$ \\
\hline Bull & & 35 & 25 & $71 \cdot 4$ & 10 & $28 \cdot 6$ \\
\hline \multicolumn{2}{|c|}{ Not stated } & 204 & 138 & $67 \cdot 6$ & 66 & $32 \cdot 4$ \\
\hline \multicolumn{2}{|c|}{ Godowns- } & 808 & 540 & $66 \cdot 8$ & 268 & $33 \cdot 2$ \\
\hline \multicolumn{2}{|c|}{ Food } & 291 & 228 & $78 \cdot 3$ & 63 & $21 \cdot 6$ \\
\hline \multicolumn{2}{|c|}{ Not food } & 493 & 290 & $58 \cdot 8$ & 203 & $41 \cdot 2$ \\
\hline \multicolumn{2}{|c|}{ Gunny Bags } & 3 & $\mathbf{3}$ & $100 \cdot 0$ & $一$ & - \\
\hline \multicolumn{2}{|c|}{ Not stated } & 21 & 19 & $90 \cdot 5$ & 2 & $9 \cdot 5$ \\
\hline \multicolumn{2}{|c|}{ Food, Tea shops } & 225 & 108 & $48 \cdot 0$ & 117 & $52 \cdot 0$ \\
\hline \multicolumn{2}{|c|}{ Unclassified } & 43 & 33 & $76 \cdot 7$ & 10 & $23 \cdot 3$ \\
\hline
\end{tabular}

TABLE III.

Showing number and species of rodents trapped alive in four villages in Bombay island.

\begin{tabular}{|c|c|c|c|c|c|c|c|}
\hline Village & $\begin{array}{l}\text { No. of } \\
\text { M. rattus } \\
\text { trapped }\end{array}$ & $\begin{array}{l}\text { M. decumanus or } \\
\underset{\text { Nesolia bengalensis }}{\text { M }}\end{array}$ & $\begin{array}{l}\text { Mice } \\
\text { apped }\end{array}$ & $\begin{array}{c}\text { Musk rats } \\
\text { trapped }\end{array}$ & Period of trapping & $\begin{array}{c}\text { Human } \\
\text { Population }\end{array}$ & $\begin{array}{l}\text { No, of } \\
\text { buildings } \\
\text { in village }\end{array}$ \\
\hline Parel & 1762 & $\begin{array}{l}2 M . \text { decumanus } \\
3 \text { Nesokia beng. } \\
1 ?^{1}\end{array}$ & 91 & 182 & 20. xi. $05-15$. vii. 06 & 3718 & 150 \\
\hline Worli & 2127 & $2 ?^{1}$ & 8 & 592 & 22. xi. $05-15$. vii. 06 & 2500 & 440 \\
\hline Wadhaia & 1120 & 3 Nesokia bengalensis & 6 & 173 & 23. xi. $05-15$. vii. 06 & 1922 & 192 \\
\hline Sion & 528 & $1 ?^{1}$ & 2 & 96 & 4. xii. $05-15$. vii. 06 & 950 & 102 \\
\hline Total & 5537 & 12 & 107 & 1043 & 20. xi. 05-15. vii. 06 & 9090 & 884 \\
\hline
\end{tabular}


this is probably dependent upon the presence of Mus rattus in the houses.

Nesokia bengalensis is not, so far as we can ascertain, a common rodent in Bombay, at least near human habitations. In the City it chiefly occurs in those sections containing large areas of waste ground, and on the whole its haunts appear to be similar to those of Mus decumanus (see Table I.). It will be seen from Table I. that $1 \%$ of a total of 12,856 animals trapped alive belonged to this species and that only 123 Nesokia bengalensis were trapped as compared to 3618 Mus decumanus, i.e., they accounted for only $3.2 \%$ of the decumanus-like rodents.

Specimens of the bandicoot were brought to the laboratory very seldom. It is mostly found in open country and palm groves in the northern part of the Island. The musk rat is fairly common in Bombay.

\section{(3) Remarks on the habits of each species.}

Mus rattus in Bombay is essentially a house rat. It is so confiding that it may almost be said to be a domesticated animal. The people regard its presence in their houses with the utmost tolerance, so that it takes up its abode, and even breeds, in their living rooms, amongst the little disturbed accumulations of rubbish so commonly found in native houses. Certain natives not only take no steps to rid their houses of rats but actually secure them from molestation. One sect, for example, the Jains, to whom every form of animal life is sacred, look upon rat destruction, even when adopted as a measure of plague prophylaxis, as an outrage against their religion, and refuse permission to have traps and baits placed in their houses.

Mus rattus, although typically a climbing rat, is able to burrow, e.g., in beaten earth floors. We have frequently made this observation and in one instance (in Parel village) have seen exceptionally large and numerous holes and burrows in the earthen floor of a store-room for grain from which many Mus rattus had been trapped. We may note that Mus rattus appears to be more particular in its choice of food than Mus decumanus. We have found that, when compared with the proportions in which rats are obtained from all over the City, the relative number of Mus rattus trapped increases in food-godowns (chiefly grain and seed godowns) and diminishes in non-food-godowns. The proportions are seen in the following table:- 


\section{Reports on Plague Investigations in India}

\begin{tabular}{|c|c|c|c|c|c|c|c|}
\hline \multirow{2}{*}{\multicolumn{5}{|c|}{ Total number of rats trapped in various situations }} & M. rattus & \multicolumn{2}{|c|}{$\boldsymbol{M}$. decumanus } \\
\hline & & & & & 230 & to & 100 \\
\hline " & " & , & , & food-godowns & $\mathbf{3 7 1}$ & to & 100 \\
\hline 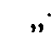 & ", & $"$ & $"$ & non-food-godowns & 141 & to & 100 \\
\hline
\end{tabular}

It is probable that Mus rattus is largely a grain-eating rat.

Whereas the nests of Mus decumanus are almost invariably found in the burrows of this animal, the nests of Mus rattus are chiefly in little disturbed accumulations of material, such as stacks of firewood, cotton waste, etc. or in recesses, such as cupboards.

Mus decumanus, as is well known, is a rat which lives for the most part outside houses in sewers, storm-water drains, stables, etc. It is a burrowing animal with remarkable powers for gnawing through hard materials, e.g., brick and concrete, but it is also a good climber. Mus decumanus, since it lives chiefly in the open, probably makes wider excursions in search of food than Mus rattus.

We have, however, observed nothing to show that these rats are in the habit of migrating, e.g., from one quarter of the City to another. Such a migration would be determined chiefly by a lack of food supply, and it is certain that in Bombay the food supply of Mus decumanus is abundant everywhere at all periods of the year.

The following statements are founded on observations recorded in Table II., in which the results of trapping nearly 12,000 rats of these two species in the native City are summarised.

Mus rattus is apparently much more common in Bombay than Mus decumanus, as we caught, taking all traps set, seven of the former to every three of the latter.

They are found in this proportion in ground floors of houses, but Mus rattus increases relatively to Mus decumanus as one ascends the building. Mus decumanus has never been found above the third floor, so that on the fourth floor and upwards Mus rattus alone is found.

In gullies, compounds of houses, stables, non-food-godowns, and food and tea-shops the number of Mus decumanus relatively increases, so much so in the case of compounds, namely, gardens and open spaces around houses, that we caught in traps set there about twice as many of this species as of Mus rattus.

Further, it is evident that these two species of rats are closely associated with each other, gullies, the lower floors of houses and godowns appearing to be their common meeting ground.

It is necessary to emphasise two important facts concerning the rats of Bombay. The first is the widespread distribution of Mus rattus 
in buildings in the City. We do not think it an exaggeration to state that every inhabited building in Bombay City and Island, not excepting even the better class bungalows, shelters its colony of Mus rattus. The second important fact is, that to a certain extent Mus decumanus in Bombay is a house rat. We have actually seen extensive burrows of Mus decumanus opened up in the "chunam" floor of the living room of a house on the first floor (i.e. above the ground floor) of a typical chawl. Several adults and a large number of newly born rats were captured in the burrows. On another occasion we obtained two plague-infected Mus decumanus from the second floor of an office in the Fort section.

\section{TABLE IV.}

Showing the breeding season of $M$. decumanus.

\begin{tabular}{|c|c|c|c|c|c|c|c|c|c|}
\hline \multirow[b]{2}{*}{ Month } & \multicolumn{3}{|c|}{ Total rats examined } & \multicolumn{3}{|c|}{ Total young rats } & \multicolumn{3}{|c|}{$\begin{array}{l}\text { Percentage of young } \\
\text { rats on total rats }\end{array}$} \\
\hline & Live & Dead & Total & Live & Dead & Total & Live & Dead & Total \\
\hline October & 1702 & 2250 & 3952 & 712 & 395 & 1107 & $41 \cdot 8$ & $17 \cdot 5$ & $28 \cdot 0$ \\
\hline November & 1294 & 2419 & 3713 & 546 & 417 & 963 & $42 \cdot 2$ & $17 \cdot 2$ & $25 \cdot 9$ \\
\hline December & 1824 & 3497 & 5321 & 562 & 553 & 1115 & $30 \cdot 2$ & $15 \cdot 8$ & $21 \cdot 0$ \\
\hline January & 1675 & 11282 & 12957 & 459 & 1645 & 2104 & $27 \cdot 4$ & $14 \cdot 6$ & $16 \cdot 2$ \\
\hline February & 706 & 12790 & 13496 & 196 & 1738 & 1934 & $27 \cdot 7$ & $13 \cdot 6$ & $14 \cdot 3$ \\
\hline March & 520 & 9959 & 10479 & 170 & 1547 & 1717 & $32 \cdot 7$ & $15 \cdot 5$ & $16 \cdot 4$ \\
\hline April & 536 & 6124 & 6660 & 182 & 1159 & 1340 & $33 \cdot 9$ & $18 \cdot 9$ & $20 \cdot 1$ \\
\hline May & 486 & 3635 & 4124 & 149 & 668 & 817 & $30 \cdot 4$ & $18 \cdot 4$ & $19 \cdot 8$ \\
\hline June & 474 & 1802 & 2276 & 168 & 198 & 366 & $35 \cdot 3$ & $11 \cdot 0$ & $16 \cdot 1$ \\
\hline July & 669 & 1818 & 2487 & 221 & 247 & 468 & $33 \cdot 0$ & $13 \cdot 5$ & $18 \cdot 8$ \\
\hline August & 665 & 1820 & 2485 & 270 & 275 & 545 & $40 \cdot 6$ & $15 \cdot 1$ & $21 \cdot 9$ \\
\hline \multirow[t]{4}{*}{ September } & 630 & 2209 & 2839 & 204 & 360 & 564 & $32 \cdot 4$ & $16 \cdot 3$ & $19 \cdot 9$ \\
\hline & & & & & & & $34 \cdot 0$ & $15 \cdot 6$ & $19 \cdot 9$ \\
\hline & \multicolumn{3}{|c|}{ Total adult females } & \multicolumn{3}{|c|}{ Total found pregnant } & \multicolumn{3}{|c|}{ Percentage pregnant } \\
\hline & Live & Dead & Total & Live & Dead & Total & Live & Dead & Total \\
\hline October & 559 & 836 & 1395 & $12 \tilde{5}$ & 112 & 237 & $22 \cdot 3$ & $13 \cdot 4$ & $17 \cdot 0$ \\
\hline November & 395 & 872 & 1267 & 66 & 128 & 194 & $16 \cdot 7$ & $14 \cdot 7$ & $15 \cdot 3$ \\
\hline December & 641 & 1243 & 1884 & 102 & 184 & 286 & $15 \cdot 9$ & $14 \cdot 8$ & $15 \cdot 2$ \\
\hline January & 584 & 4534 & 5118 & 84 & 417 & 501 & $14 \cdot 3$ & $9 \cdot 2$ & $9 \cdot 8$ \\
\hline February & 276 & 4978 & 5254 & 48 & 634 & 682 & $17 \cdot 4$ & $12 \cdot 7$ & $13 \cdot 0$ \\
\hline March & 188 & 3662 & 3850 & 35 & 689 & 724 & $18 \cdot 6$ & $18 \cdot 8$ & $18 \cdot 8$ \\
\hline April & 205 & 2264 & 2869 & 48 & 351 & 399 & $23 \cdot 4$ & $15 \cdot 5$ & $13 \cdot 9$ \\
\hline May & 210 & 1513 & 1723 & 47 & 210 & 257 & $22 \cdot 4$ & $13 \cdot 9$ & $14 \cdot 9 ?$ \\
\hline June & 188 & 758 & 946 & 39 & 96 & 135 & $20 \cdot 7$ & $12 \cdot 7$ & $14 \cdot 3$ \\
\hline July & 254 & 764 & 1018 & 54 & 127 & 181 & $21 \cdot 2$ & $16 \cdot 6$ & $17 \cdot 8$ \\
\hline August & 229 & 702 & 931 & 47 & 111 & 158 & $20 \cdot 5$ & $15 \cdot 8$ & $17 \cdot 0$ \\
\hline \multirow[t]{2}{*}{ September } & 225 & 798 & 1023 & 47 & 100 & 147 & $20 \cdot 9$ & $12 \cdot 5$ & $14 \cdot 4$ \\
\hline & & & & & & & $19 \cdot 5$ & $14 \cdot 2$ & $15 \cdot 1$ \\
\hline
\end{tabular}




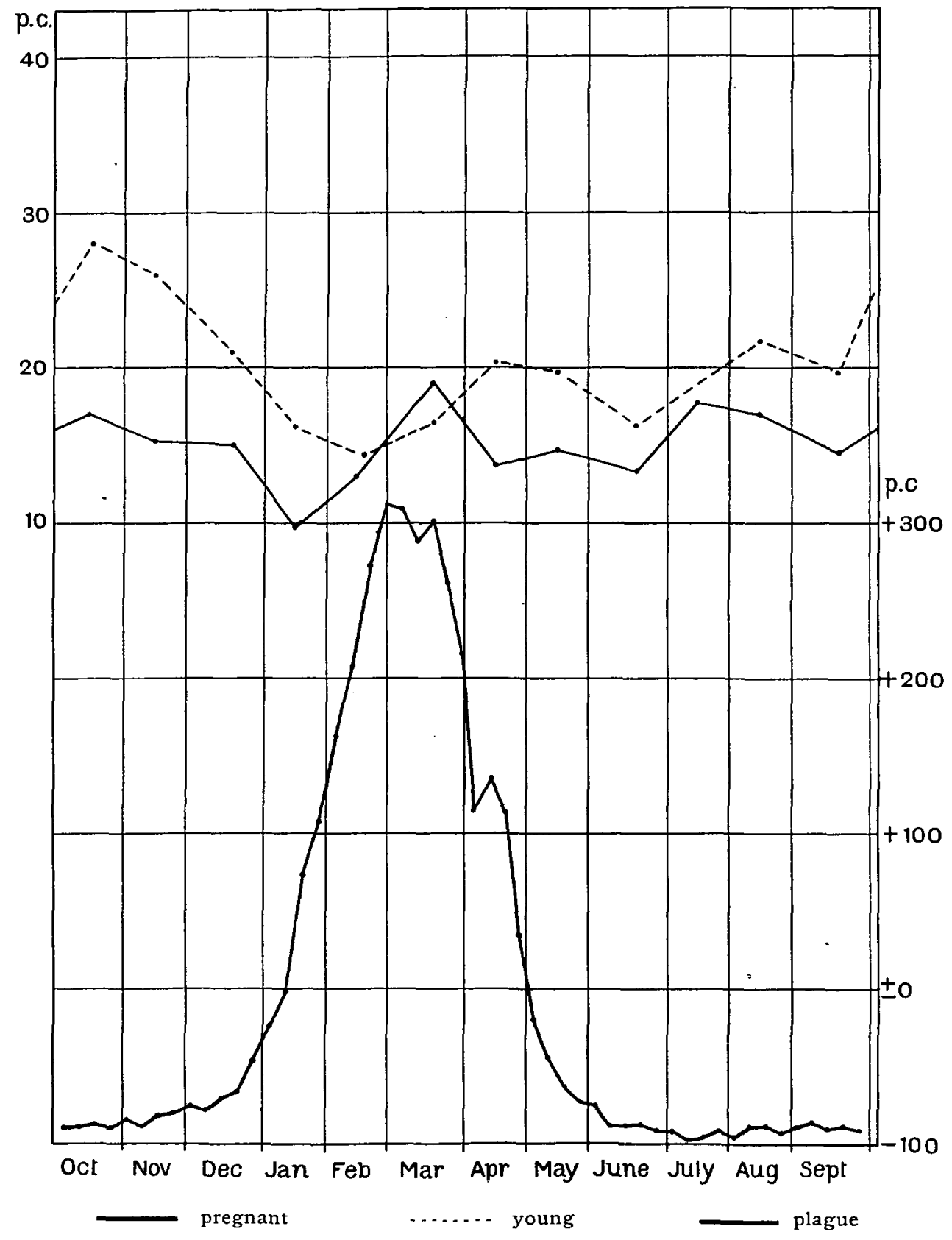

Breeding and plague in Mus decumanus 
BOMBAY CITY II

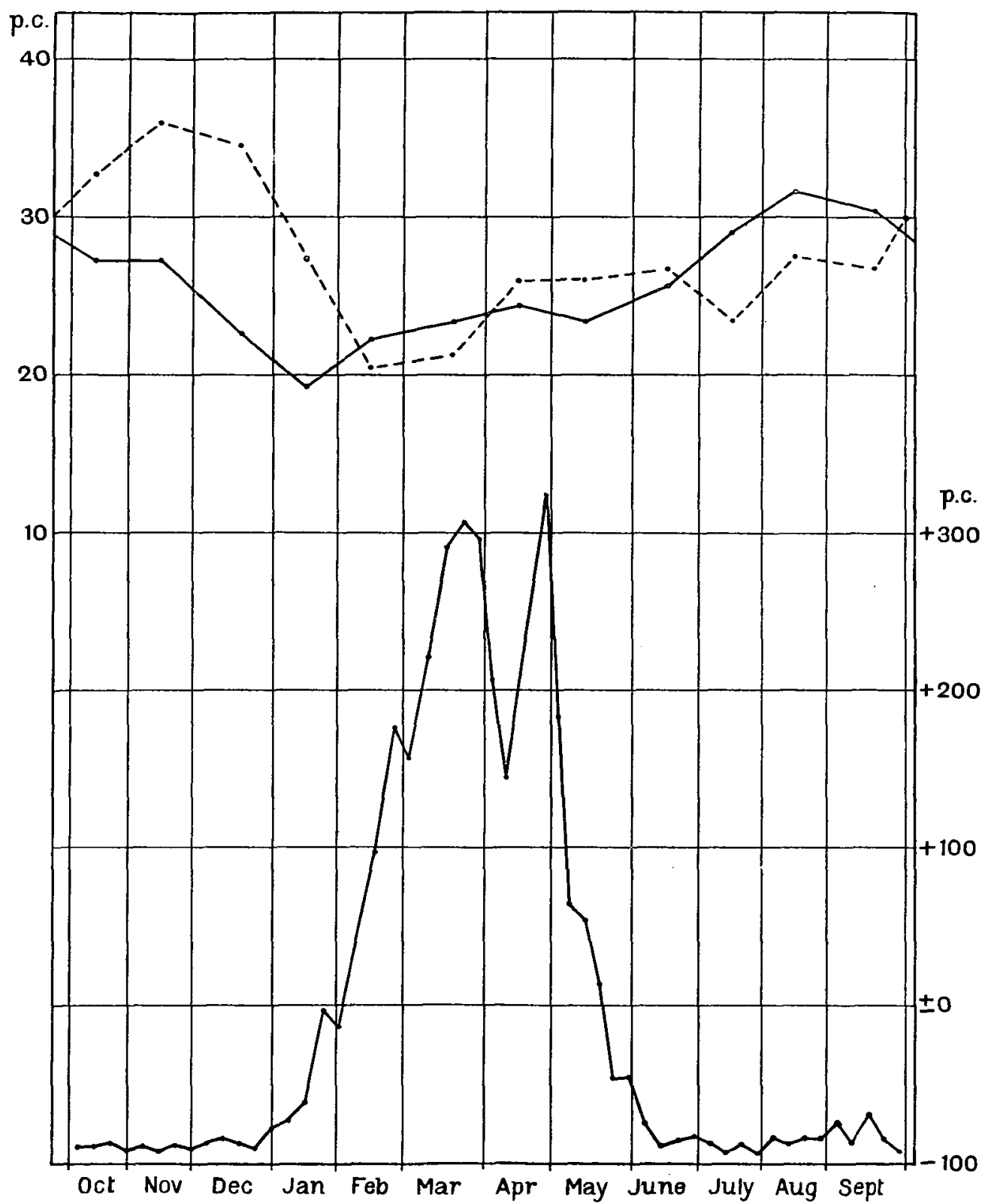

pregnant

young

plague

Breeding and plague in Mus rattus 
(4) The breeding season of Mus rattus and Mus decumanus.

It was sought to investigate this question by considering (1) the percentage of adult females found pregnant, and (2) the proportion of young rats found, at different seasons. For this purpose "young" rattus and decumanus are arbitrarily defined as those weighing 70 and 100 grammes or less respectively; no rats below these weights were found pregnant. The results are shown in Tables IV. and V. and Charts I. and II.

The curves for pregnant females and for young rats correspond fairly well, and indicate that, though in Bombay there is no very definite

TABLE V.

Showing the breeding season of $M$. rattus.

\begin{tabular}{|c|c|c|c|c|c|c|c|c|c|}
\hline \multirow[b]{2}{*}{ Month } & \multicolumn{3}{|c|}{ Total rats examined } & \multicolumn{3}{|c|}{ Young rats } & \multicolumn{3}{|c|}{$\begin{array}{l}\text { Percentage of young } \\
\text { rats on all rats }\end{array}$} \\
\hline & Live & Dead & Total & Live & Dead & Total & Live & Dead & Total \\
\hline October & 2101 & 1071 & 3172 & 739 & 305 & 1044 & $35 \cdot 1$ & $28 \cdot 5$ & $32 \cdot 9$ \\
\hline November & 1678 & 1100 & 2778 & 659 & 342 & 1001 & $39 \cdot 2$ & $31 \cdot 0$ & $36 \cdot 0$ \\
\hline December & 3268 & 1632 & 4900 & 1291 & 392 & 1683 & $39 \cdot 5$ & $24 \cdot 0$ & $34 \cdot 4$ \\
\hline January & 2833 & 3087 & 5920 & 978 & 637 & 1615 & $34 \cdot 5$ & $16 \cdot 5$ & $27 \cdot 3$ \\
\hline February & 1427 & 3864 & 5291 & 418 & 668 & 1086 & $29 \cdot 3$ & $18 \cdot 3$ & 20.5 \\
\hline March & 811 & 4127 & 4938 & 293 & 757 & 1050 & $36 \cdot 1$ & $18 \cdot 3$ & $21 \cdot 3$ \\
\hline April & 1104 & 3445 & 4549 & 413 & 770 & 1183 & $37 \cdot 4$ & $22 \cdot 3$ & $26 \cdot 0$ \\
\hline May & 900 & 2093 & 2993 & 354 & 423 & 777 & $39 \cdot 3$ & $20 \cdot 2$ & $26^{\circ} 0$ \\
\hline June & 1011 & 1135 & 2146 & 375 & 196 & 571 & $37 \cdot 0$ & $17 \cdot 3$ & $26 \cdot 6$ \\
\hline July & 1693 & 1292 & 2985 & 489 & 210 & 699 & $28 \cdot 8$ & $17 \cdot 0$ & $23 \cdot 4$ \\
\hline August & 1864 & 1409 & 3273 & 648 & 251 & 899 & $38 \cdot 7$ & $17 \cdot 8$ & $27 \cdot 5$ \\
\hline \multirow[t]{4}{*}{ September } & 1801 & 1536 & 3337 & 598 & 298 & 896 & $33 \cdot 2$ & $19 \cdot 4$ & $26 \cdot 8$ \\
\hline & & & & & & & $35 \cdot 7$ & $20 \cdot 9$ & $27 \cdot 4$ \\
\hline & \multicolumn{3}{|c|}{ Total adult females } & \multicolumn{3}{|c|}{ Total found pregnant } & \multicolumn{3}{|c|}{ Percentage pregnant } \\
\hline & Live & Dead & Total & Live & Dead & Total & $\overparen{\text { Live }}$ & Dead & Total \\
\hline October & 761 & 364 & 1125 & 224 & 83 & 307 & $29 \cdot 3$ & $22 \cdot 8$ & $27 \cdot 3$ \\
\hline November & 574 & 325 & 899 & 145 & 100 & 245 & $25 \cdot 2$ & $30 \cdot 8$ & $27 \cdot 2$ \\
\hline December & 1056 & 599 & 1655 & 262 & 114 & 376 & $24 \cdot 7$ & $19 \cdot 0$ & $22 \cdot 7$ \\
\hline January & 961 & 1165 & 2126 & 210 & 201 & 411 & $21 \cdot 6$ & $17 \cdot 3$ & $19 \cdot 3$ \\
\hline February & 562 & 1360 & 1922 & 149 & 280 & 429 & $22 \cdot 9$ & $20 \cdot 6$ & $22 \cdot 3$ \\
\hline March & 277 & 1462 & 1739 & 81 & 350 & 431 & $29 \cdot 2$ & $23 \cdot 9$ & $24 \cdot 8$ \\
\hline April & 394 & 1244 & 1638 & 108 & 296 & 404 & $27 \cdot 4$ & $23 \cdot 8$ & $24 \cdot 7$ \\
\hline May & 282 & 968 & 1250 & 95 & 203 & 298 & $33 \cdot 7$ & $21 \cdot 0$ & 23.8 \\
\hline June & 360 & 460 & 820 & 117 & 95 & 212 & $32 \cdot 5$ & $20 \cdot 7$ & $25 \cdot 9$ \\
\hline July & 679 & 464 & 1143 & 225 & 107 & 332 & $33 \cdot 1$ & $23 \cdot 0$ & $29 \cdot 0$ \\
\hline August & 713 & 534 & 1237 & 238 & 154 & 392 & $33 \cdot 3$ & $29 \cdot 4$ & $31 \cdot 7$ \\
\hline \multirow[t]{2}{*}{ September } & 682 & 581 & 1263 & 246 & 134 & 380 & $36 \cdot 0$ & $23 \cdot 0$ & $30 \cdot 1$ \\
\hline & & & & & & & $29 \cdot 1$ & 22.9 & $25 \cdot 6$ \\
\hline
\end{tabular}


breeding season, both species breed most freely in the hottest part of the year (June to October). It will be noted that the fall in fertility begins before the onset of the plague epizootic, though it roughly coincides with it later on.

The average number of foetuses in 114 Mus rattus was $5 \cdot 2$, the largest number found being 9 ; for 71 Mus decumanus the figures were $8 \cdot 1$ and 14 .

(5) Relative incidence of plague in Mus rattus and Mus decumanus.

The percentage of Mus rattus found infected with plague was considerably smaller than that of Mus decumanus.

TABLE VI.

Showing the age and sex incidence of plague among rats.

\begin{tabular}{|c|c|c|c|c|c|c|}
\hline \multirow[b]{2}{*}{ Live rats. } & \multicolumn{3}{|c|}{ M. decumanus } & \multicolumn{3}{|c|}{ M. raitus } \\
\hline & Examined & ${ }_{\text {infected }}^{\text {Plague }}$ & $\begin{array}{c}\text { Per } \\
\text { cent. }\end{array}$ & Examined & $\begin{array}{c}\text { Plague } \\
\text { infected }\end{array}$ & $\begin{array}{c}\text { Per } \\
\text { cent. }\end{array}$ \\
\hline Old males & 3391 & 45 & $1 \cdot 3$ & 5945 & 34 & 0.6 \\
\hline Old females & 3955 & 32 & 0.8 & 7296 & 23 & 0.3 \\
\hline Young males & 1814 & 8 & 0.5 & 3545 & 6 & $0 \cdot 2$ \\
\hline Young females & 2024 & 10 & 0.5 & 3705 & 12 & $0 \cdot 3$ \\
\hline Old rats & 7346 & 77 & $1 \cdot 0$ & 13241 & 57 & 0.4 \\
\hline Young rats & 3838 & 18 & 0.5 & 7250 & 18 & 0.2 \\
\hline Male rats & 5205 & 53 & $1 \cdot 0$ & 9490 & 40 & 0.4 \\
\hline Female rats & 5979 & 42 & 0.7 & 11001 & 35 & $0 \cdot 3$ \\
\hline Total & 11184 & . 95 & 0.85 & 20491 & 75 & 0.37 \\
\hline Dead rats. & & & & & & \\
\hline Old males & 27414 & 6691 & $24 \cdot 3$ & 11299 & 2183 & $20 \cdot 3$ \\
\hline Old females & 22961 & 4377 & $19 \cdot 1$ & 9434 & 1451 & $15 \cdot 7$ \\
\hline Young males & 4303 & 964 & $22 \cdot 4$ & 2520 & 319 & $12 \cdot 7$ \\
\hline Young females & 4927 & 1150 & $23 \cdot 3$ & 2558 & 353 & $13 \cdot 3$ \\
\hline Old rats & 50375 & 11068 & $22 \cdot 0$ & 20733 & 3634 & $17 \cdot 6$ \\
\hline Young rats & 9230 & 2114 & $22 \cdot 9$ & 5078 & 672 & $13 \cdot 3$ \\
\hline Male rats & 31717 & 7655 & $24 \cdot 2$ & 13819 & 2502 & $18 \cdot 1$ \\
\hline Female rats & 27888 & 5527 & $19 \cdot 9$ & 11992 & 1804 & $15 \cdot 0$ \\
\hline Total & 59605 & 13182 & $22 \cdot 2$ & 25811 & 4306 & $16 \cdot 7$ \\
\hline All rats. & & & & & & \\
\hline Old males & 30805 & 6736 & $21 \cdot 8$ & 17244 & 2217 & $12 \cdot 9$ \\
\hline Old females & 26916 & 4409 & $16 \cdot 4$ & 16730 & 1474 & $8 \cdot 8$ \\
\hline Young males & 6117 & 972 & $15 \cdot 9$ & 6065 & 325 & $4 \cdot 9$ \\
\hline Young females & 6951 & 1160 & $16 \cdot 7$ & 6363 & 365 & $5 \cdot 7$ \\
\hline Old rats & 57721 & 11145 & $19 \cdot 3$ & 33974 & 3691 & $10 \cdot 8$ \\
\hline Young rats & 13068 & 2132 & $16 \cdot 3$ & 12328 & 690 & $5 \cdot 7$ \\
\hline Male rats & 36922 & 7708 & $20 \cdot 9$ & 23309 & 2542 & $10 \cdot 9$ \\
\hline Female rats & 33867 & 5569 & $16 \cdot 5$ & 22993 & 1839 & $8 \cdot 0$ \\
\hline Total & 70789 & 13277 & $18 \cdot 8$ & 46302 & 4381 & $9 \cdot 45$ \\
\hline
\end{tabular}




\section{Reports on Plague Investigations in India}

The monthly figures are as follows and show that this difference obtains both during the epizootic and in the off-plague season.

\begin{tabular}{rlrr}
\multicolumn{3}{c}{ TABLE VII. } \\
1905 & October & $1 \cdot 9$ & $0 \cdot 8$ \\
& November & $4 \cdot 3$ & $0 \cdot 7$ \\
& December & $6 \cdot 3$ & $1 \cdot 0$ \\
January & $14 \cdot 4$ & $4 \cdot 6$ \\
February & $25 \cdot 7$ & $14 \cdot 6$ \\
March & $39 \cdot 8$ & $28 \cdot 0$ \\
April & $31 \cdot 4$ & $25 \cdot 2$ \\
May & $14 \cdot 2$ & $15 \cdot 6$ \\
June & $5 \cdot 3$ & $3 \cdot 3$ \\
July & $3 \cdot 9$ & $1 \cdot 6$ \\
August & $5 \cdot 4$ & $2 \cdot 3$ \\
& September & $4 \cdot 6$ & $2 \cdot 3$ \\
Average & $13 \cdot 1$ & $8 \cdot 3$
\end{tabular}

The experimental susceptibility of the two species is about the same. We have many reasons for believing that rats in nature are infected by the agency of fleas. We therefore compared their susceptibilities by adding infected fleas to rats in flea-proof cages, thereby imitating as nearly as possible their natural mode of infection. In every experiment approximately the same number of fleas were used. Some of the experiments were carried out during the epizootic season of 1906, while the remainder were carried out in the epizootic season of 1907. In all 100 experiments have been done with the following results :

$$
\begin{aligned}
& 33 \text { experiments with Mus decumanus } 16 \text { successes }=48 \% \\
& 67, \quad " \text { Mus rattus } 29 \quad=43 \% \\
& \text { Total } \overline{45}, "=45 \%
\end{aligned}
$$

These figures make it clear that the two species of rats show practically no difference in their susceptibility to plague by flea transmission.

It would appear, therefore, that the greater incidence of plague amongst Mus decumanus as compared with Mus rattus cannot be explained on the ground of a difference in susceptibility.

It follows that the explanation must lie in the opportunities for infection being greater in decumanus than in rattus. We have in fact found that the flea infestation of decumanus is much greater, as the following abstract from a complete series of counts to be dealt with later shows. 


\section{TABLE VIII.}

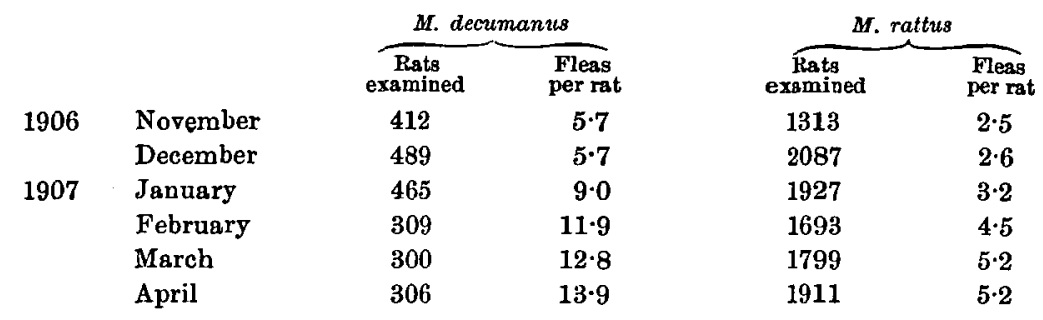

We could not find from our figures that plague was specially incident upon male or female, old or young rats of either species.

\section{The Relation of the Epizootic amongst the Rats to Time and Place.}

It is necessary at the outset to insist upon the fact that in Bombay City there is a Mus decumanus epizootic and a Mus rattus epizootic. That they must be considered as separate epizootics will appear shortly, when we discuss the time and place relations of each. We may add that, although distinct, the epizootics cannot be dissociated, the one having a definite relation to the other. It will be convenient therefore to discuss them together.

\section{The Epizootics in Relation to Time.}

\section{(a) Their seasonal prevalence.}

It will be seen from the charts ${ }^{1}$ of Bombay City (Chart III.), and of certain of the sections (Charts IV.- XV.) which display the relation between rat and human plague, that the epizootics present well defined seasonal variations. Since, as will also be readily observed, the epizootics

\footnotetext{
1 These charts have been drawn up in the following way. In that for Bombay City the data for most of the sections in the island have been collated. The data of certain sections in the north of the island have been omitted on account of a defective rat collection due to the large area and sparse population of these sections. The weekly figures of plagueinfected rats of each species for the remaining sections were corrected for a week of seven days, in order to eliminate variations due to differences in the number of days per week the rat investigation was carried out. The corrected figures for the selected sections for weekly periods having been added together a mean of the resulting figures for the year was taken, and each of the weekly figures was then expressed as a percentage in terms of the mean of the year. The chart was constructed from these percentages. The charts for the sections differ from that of the City only in that the periods are fortnightly instead of weekly. The crude figures actually obtained are shown in Table XXIV. p. 796. There is very little difference between these and the corrected data.
} 


\section{CHART III}

\section{BOMBAY}

October, I905 to September, 1906 


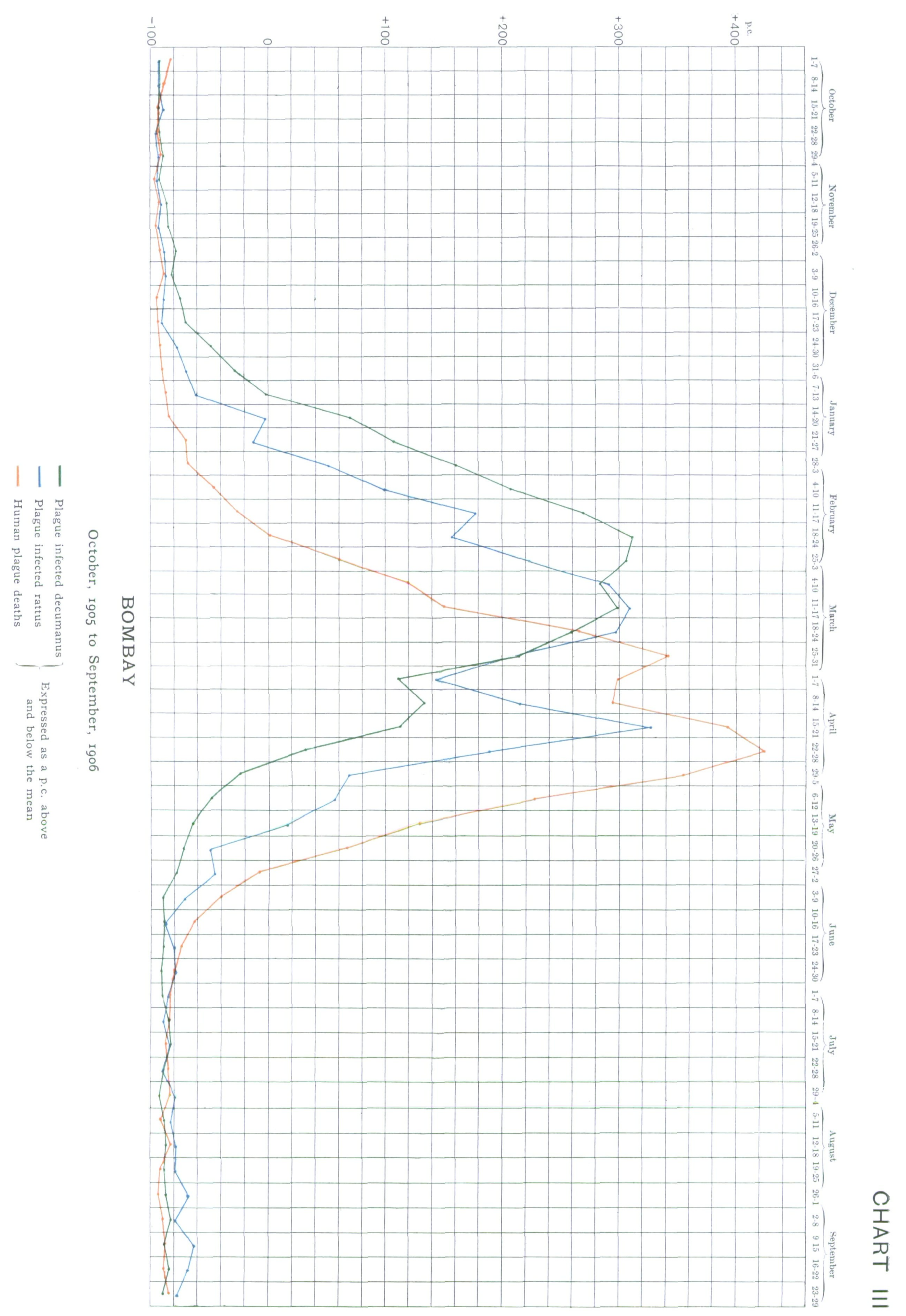


TABLE IX.

Weekly periods

1st to 7 th October

8 th to 14th ,"

15th to 21 st ,"

22 nd to 28 th ",

29th to 4th November

5th to 11th

12 th to 18 th "

19th to 25 th

26th to 2nd December

3rd to 9 th

10th to 16 th "

17th to 23rd ",

24 th to 30 th ,

31st to 6th January

7th to 13th

14 th to 20 th ,"

21 st to 27 th

28th to 3rd February

4 th to 10 th

11 th to 17 th "

18th to 24 th ",

25 th to 3rd March

4th to 10th ",
11 th to 17th "

18th to 24th,

25th to 31st ",

lst to 7th April

8 th to 14th ",

15 th to 21st "

$22 \mathrm{nd}$ to 28 th ,

29 th to 5 th May

6 th to 12th,

13th to 19th"

20 th to 26 th ,

27th to 2nd June

3rd to 9 th

10th to 16th ",

17 th to 23 rd ,

24 th to 30 th ,

18t to 7 th July

8 th to 14th ",

15 th to 21 st "

22nd to 28th ,"

29th to 4th August

5 th to 11th

12 th to 18 th ",

19th to 25th

26th to 1st September

and to 8th

9th to 15th "

16ith to 22 nd "

23rd to 29th "
Bombay.

\begin{tabular}{|c|c|c|}
\hline $\begin{array}{l}\text { Plague } \\
\text { mortality }\end{array}$ & $\begin{array}{l}\text { Plague infected } \\
\text { Rattus } \\
\text { corrected for } \\
\text { week of } 7 \text { days }\end{array}$ & $\begin{array}{l}\text { Plagne infected } \\
\text { Decumanus } \\
\text { corrected for } \\
\text { week of } 7 \text { days }\end{array}$ \\
\hline
\end{tabular}

31

18

12

9

13

6

9

5

9

16

8

8

10

12

16

24

48

51
92

124

178

280

387

442

644

779

702

695

870

925

802

578

404

296

162

106

64

46

35

27

28

24

26

29

17

31

15

14

18

22

22

$\frac{30}{177}$
$5 \cdot 9$

$5 \cdot 9 \quad 19 \cdot 7$

$8 \cdot 2 \quad 23 \cdot 4$

$3 \cdot 5 \quad 18 \cdot 6$

$5 \cdot 9 \quad 30 \cdot 3$

$2 \cdot 8 \quad 21 \cdot 0$

$6 \cdot 9 \quad 42 \cdot 0$

$5 \cdot 9 \quad 47 \cdot 9$

$9 \cdot 4 \quad 67 \cdot 7$

$11 \cdot 7 \quad 60.5$

$9 \cdot 5 \quad 78 \cdot 1$

$7 \cdot 0 \quad 95 \cdot 8$

$19 \cdot 6 \quad 163 \cdot 5$

$28 \cdot 0 \quad 230 \cdot 9$

$38.6 \quad 318.5$

$97.0 \quad 551.9$

$87 \cdot 6 \quad 672 \cdot 0$

$149 \cdot 8.848 \cdot 4$

$203 \cdot 0 \quad 997 \cdot 4$

$282.5 \quad 1201.0$

$261 \cdot 4 \quad 1334 \cdot 2$

$328 \cdot 1 \quad 1320 \cdot 6$

$398 \cdot 7 \quad 1245 \cdot 6$

$416 \cdot 6 \quad 1297 \cdot 6$

$404 \cdot 6 \quad 1166 \cdot 2$

$314 \cdot 7 \quad 1021 \cdot 9$

$248 \cdot 2 \quad 687 \cdot 4$

$321 \cdot 6 \quad 763 \cdot 7$

$432 \cdot 5 \quad 698 \cdot 6$

$294 \cdot 1 \quad 437 \cdot 1$

$171 \cdot 6 \quad 250 \cdot 8$

$158 \cdot 8$

$121.6 \quad 126.0$

$52 \cdot 6$

$54 \cdot 6 \quad 75 \cdot 2$

$28 \cdot 2$

$11 \cdot 7 \quad 37 \cdot 3$

$17 \cdot 7$

$19 \cdot 6$ 29.4

15.2

$9 \cdot 3$

$15 \cdot 3 \quad 25 \cdot 8$

$9 \cdot 4$

$19 \cdot 6 \quad 26 \cdot 6$

$16 \cdot 8$

$20 \cdot 3 \quad 44 \cdot 4$

$19 \cdot 6$

$31 \cdot 6 \quad 42 \cdot 1$

$18.7 \quad 52 \cdot 5$

$36 \cdot 6 \quad 36 \cdot 6$

$30 \cdot 8 \quad 47 \cdot 6$

$21.0 \quad 35.0$

$\overline{102 \cdot 0} \quad \overline{323.9}$ 
are separated only by a short interval of time, the plague season and the off-plague season, as they may conveniently be termed, are for practical purposes the same for both. The off-plague season extends roughly from June to November inclusive, the plague season occupying the remaining months of the year. It will, however, be noted that acute plague was found in both rattus and decumanus in Bombay City in every week throughout the whole year.

\section{(b) The relation in point of time of the decumanus epizootic to the rattus epizootic.}

This is well seen in the chart for Bombay City (III.). It will be noted that the decumanus curve as it ascends crosses the mean line at a point corresponding to the week January 7 th-13th, while the rattus curve crosses the mean line about the end of January.

The decumanus epizootic was at its height approximately between February 21st and March 14th, while the corresponding stage of the rattus epizootic was about ten days later, namely, approximately March 7 th to March 21st.

The curve for Mus rattus shows a second maximum in the week April 15th-21st, the corresponding point in the decumanus curve occurring in the previous week. It is obvious then that the decumanus epizootic precedes the rattus epizootic by a mean interval of about ten days.

This is further apparent by a general study of the corresponding curves made for several of the sections into which Bombay is divided.

\section{The Epizootics in Relation to Place.}

(a) The diffusion of the infection.

It might be expected from the account we have already given of the habits of the two species that Mus decumanus is more important in this connection than Mus rattus on account of its out-of-door life and wandering habits. A study of the maps of the sections ${ }^{1}$ confirms this view and leads us to the conclusion that Mus decumanus is chiefly responsible for the diffusion of the infection amongst the rats throughout the City.

1 Monthly spot maps showing the place incidence of decumanus, rattus and human plague were prepared for all the sections of Bombay City. One set (that of Fort North and South, see Map I.) are reproduced in Appendix $I$. 
In the early months of the epizootic only a few Mus decumanus appear on the maps. Each of these doubtless represents a focus for the spread of the infection, because the succeeding maps show local extensions of the infection amongst Mus decumanus.

The question arises as to whether extension of infection from the badly infected sections to neighbouring little infected sections takes place. It has, we believe, been suggested that the epizootic usually begins in Mandvi (vide map of Bombay) - a notorious plague spot-and spreads in a peripheral manner to the outlying sections. We can find no evidence for this view; indeed a study of the maps and charts entirely opposes it. In Table X. the week corresponding to the climax of each epizootic is given for a certain number of sections. The dates are only approximate, but they show that a definite extension from one section to another is certainly not the rule. Fort North in the Fort section is an interesting example of a badly infected area, isolated from another badly infected section, Mandvi, by a section (Esplanade), which is notably exempt from plague, and yet the epizootic in Fort North and Mandvi followed practically the same course throughout.

TABLE X. Showing weeks corresponding to height of epizootic in various Sections, as judged by the weekly rat figures corrected for a week of 7 days.

Locality

Bombay City except $\mathrm{F}$ and $\mathrm{G}$ wards

Mandvi

Chakla

Oomarkhadi

Dongri

Market

Khara Talao

Khumbharwada

Khetwadi

Fort North and South
Date of climax
of decumanus epizootic

(1) February 18-24

(2) April 8-14

February 18-24

February 25-March 3

February 4-10

February 18-24

March 18-24

February 4-10

March 11-17

March 18-24

February 25--March 3
Date of climax
of rattus epizootic

(1) March 11-17

(2) April 15-21

March 4-10

March 11-17

February 11-17

March 4-10

March 25-31

February 18-24

March 25-31

April 8-14

March 25-31

April 15-21

Moreover, the supposition that the infection spreads in a definite manner from one section to another is rendered unnecessary by the fact, that infection amongst the rats persists during every month of the year in most of the sections.

Lastly, the question of the migration of rats as a factor in the spread of the epizootic may be adverted to. The term, migration, seems to have been used in this connection to mean, that a general movement 
sets in amongst the rats in a place when plague breaks out amongst them. We can only state that we have failed to find the slightest evidence from our observations in Bombay City and in the outlying villages, which might lend support to this idea.

(b) The severity of the epizootics.

The infection amongst the rats of Bombay must be characterised as being exceedingly severe. Table VI. gives sufficient proof of this, but the following statements will enable the reader readily to realise the extreme severity of the epizootics: 4381 Mus rattus and 13,277 Mus decumanus were shown by us to be plague infected during the year: a total of nearly 18,000 plague rats out of a total of 117,000 rats examined. The largest number of infected Mus rattus for one week was 432 , the largest number of Mus decumanus for a similar period being 1334 .

The largest number of plague rats obtained in one day was 277 . On 12th March, 1906, a total of 296 dead Mus decumanus were examined and of these 148 were plague infected, i.e. 50\%. On 20th March, 1906, a total of 219 dead Mus rattus were examined and of these 89 or $40 \%$ proved to be plague infected.

Out of every five decumanus examined tor the whole year, one was infected, and similarly one out of every ten Mus rattus.

The total number of plague rats sent from Mandvi during the year represents an average of $3 \cdot 1$ plague rats for every building in this section. In at least eight sections the average number per building (calculated on the total buildings in each section) ranges from $0 \cdot 1$ to. $3 \cdot 1$ plague rats (Table XI.). Mandvi heads the list of the sections with a total for the year of 1065 infected Mus rattus and 1808 infected Mus decumanus, a total of 2873 plague rats. The comparative severity of the epizootics in the various sections is illustrated in Table XII. Mandvi again has the unenviable distinction of coming first in this Table.

It will be seen that plague rats were obtained every week throughout the year from Mandvi, that infected Mus decumanus were obtained also every week and that in only three weeks in the year were no plague Mus rattus found in this section. It would seem evident that Mandvi is the worst section in the City as regards the severity of the epizootic.

The widespread character of the epizootic was excellently illustrated in the maps for the sections; maps of one section are reproduced. 


\section{Reports on Plague Investigations in India 757}

TABLE XI. Showing comparative severity of epizootic and epidemic in various sections.

\begin{tabular}{|c|c|c|c|}
\hline Sections & $\begin{array}{c}\text { Average number } \\
\text { of plague } \\
\text { deaths per building }\end{array}$ & $\begin{array}{l}\text { Average number } \\
\text { of total plague } \\
\text { rats per building }\end{array}$ & $\begin{array}{l}\text { Plague deaths } \\
\text { per mille }\end{array}$ \\
\hline Dongri & 1.0 & $1 \cdot 9$ & $16 \cdot 4$ \\
\hline Mandvi & $0 \cdot 6$ & $3 \cdot 1$ & $14 \cdot 4$ \\
\hline Khara Talao & 0.6 & $1 \cdot 9$ & $12 \cdot 1$ \\
\hline Bhuleshwar & 0.6 & $1 \cdot 6$ & 17 \\
\hline Khumbharwada & 0.6 & $1 \cdot 6$ & 11 \\
\hline Oomarkhadi & 0.5 & $1 \cdot 7$ & $10 \cdot 7$ \\
\hline II Nagpada & 0.5 & $1 \cdot 0$ & $11 \cdot 2$ \\
\hline Kamathipura & $0 \cdot 5$ & $0 \cdot 6$ & $13 \cdot 1$ \\
\hline Dhobi Talao & 0.5 & $1 \cdot 2$ & $14 \cdot 2$ \\
\hline Girgaum & $0 \cdot 3$ & 0.1 & $9 \cdot 4$ \\
\hline Khetwadi & $0 \cdot 2$ & 0.2 & $8 \cdot 0$ \\
\hline I Nagpada & 0.2 & 0.0 & $3 \cdot 6$ \\
\hline Esplanade & $0 \cdot 1$ & 0.08 & $6 \cdot 7$ \\
\hline Mahalakshmi & 0.08 & 0.01 & $5 \cdot 8$ \\
\hline
\end{tabular}

TABLE XII. Showing comparative severity of epizootics in various sections.

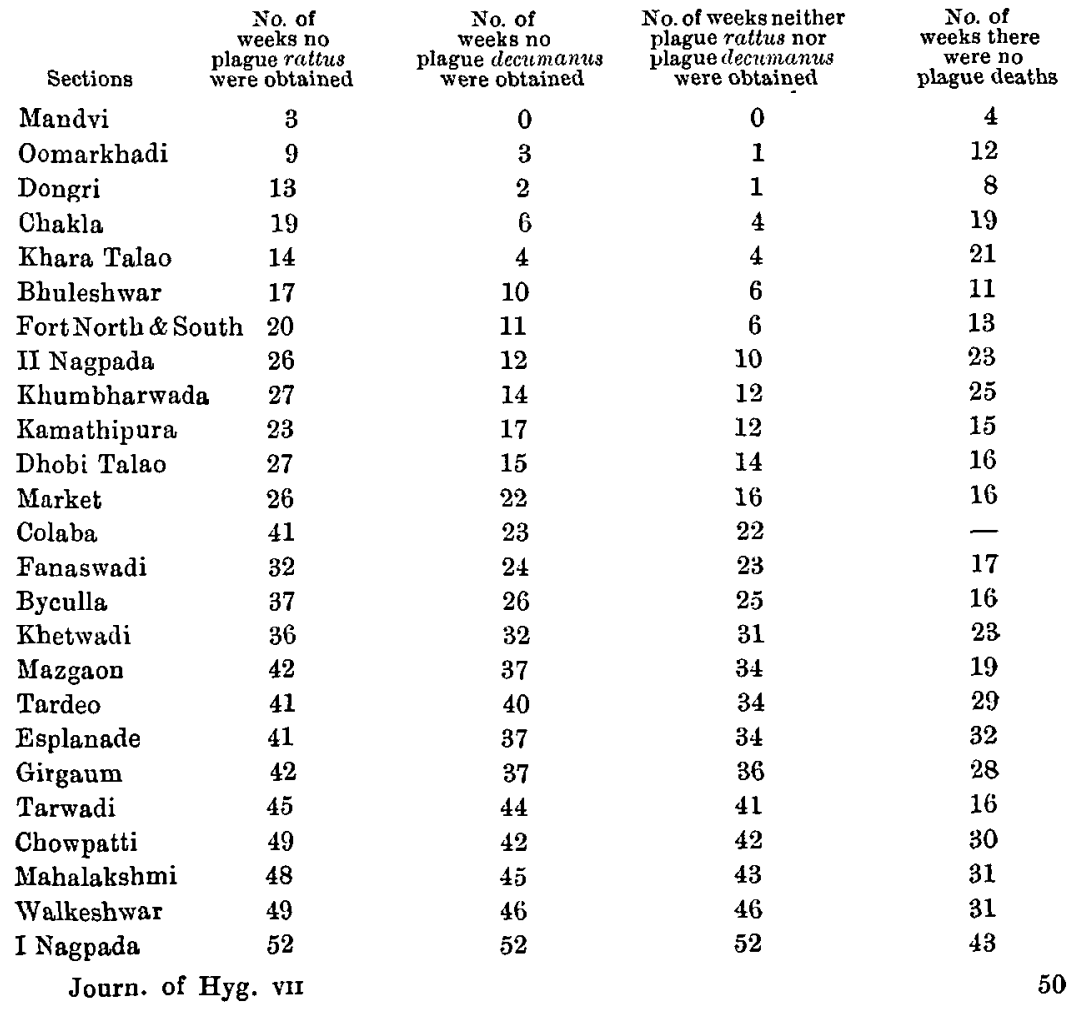


(c) Severely infected foci.

Such a focus is well exemplified in an outbreak which occurred amongst Mus decumanus in Samuel Street and De Souza Street in Mandvi. In these streets there are a large number of gunny bag godowns', a class of godown which is particularly favoured by rats on account of the shelter they afford and on account of the residue of grain in the sacks.

Again, certain gullies in Oomarkhadi section show a severe infection amongst the rats, especially amongst Mus decumanus. In January, for example, 49 plague rats, of which 47 were Mus decumanus, were obtained from two of the gullies.

(d) The persistence of infection in localities.

A good example of the long persistence of infection in a localised area was noted in Mandvi section in the neighbourhood of De Souza Street. The tirst plague rat found was a Mus rattus on 19th September, 1905, the date of finding the last rats (two Mus decumanus) being 29th December, 1905, an interval of at least three months.

(e) The question of the re-infection of houses or buildings by rats.

This is a matter of some importance in relation to prophylaxis. Our data with regard to it are, however, meagre. In an outbreak of plague in Sion Koliwada village we could obtain no evidence that re-infection occurred amongst the rats (Mus rattus) in the houses attacked early. In Bombay City it is possible that re-infection of the house rats in the plague season may take place on account of the widespread and severe infection amongst Mus decumanus and the association of this rat with Mus rattus.

\section{The Relation of the Decumanus Epizootic to THE RATTUS EPIZOOTIC.}

In the consideration of this question a study of the charts and maps for Bombay City and for the sections is essential. On the charts three curves will be noted which in order of time represent the decumanus epizootic, the rattus epizootic and the human epidemic. Each of these curves is separated from the next by a space representing an interval of time, the interspaces, and therefore the time intervals, being very nearly the same. (See Charts III.-XV.)

${ }_{1}$ Gunny bags are used chiefly for grain; the empty bags are stored in these godowns. 
We may state without discussion in this place that the sum of the evidence as amassed by us leads us to the conclusion that the human epidemic is due entirely to the epizootic amongst the rats, and that of the two epizootics the rattus epizootic must be held directly responsible for the epidemic. Accepting this as a just conclusion it naturally suggests itself that similarly the decumanus epizootic is directly accountable for the rattus epizootic.

In this statement we merely wish to express the general relation between the two epizootics. We do not suppose that in every instance Mus rattus received its infection directly from a plague-infected Mus decumanus, because we know that when infection is introduced into a colony of Mus rattus the presence of infected Mus decumanus is not essential for its continuance.

It seems to us from the following considerations that it is impossible to escape from the conclusion mentioned above.

There can be no doubt that the decumanus epizootic precedes the rattus epizootic in time. The maps of the sections bring this out very well. Since, however, each map represents a period of one month, the charts for the sections (fortnightly periods), and especially that for Bombay City (weekly periods), express the time relations more accurately.

It is quite evident from the latter chart that a definite interval exists between the decumanus epizootic and the rattus epizootic, the mean interval of time being about ten days.

If now the interval between the two epizootics corresponds with the mean interval of time, which from actual observation is found to elapse between the exposure to infection of Mus rattus and its death, we shall have good grounds for concluding that the decumanus epizootic is responsible for the rattus epizootic. The following direct evidence is very important in this connection. Thirty successful flea transmission experiments were carried out in the laboratory with Mus rattus. The method employed was to transfer to healthy Mus rattus in flea-proof cages infected fleas which had fed on septicaemic rats. The fleas were transferred from these animals after their death from plague to the healthy Mus rattus. The number of days from the date of exposure to the bites of the fleas to the death of Mus rattus has been computed as accurately as possible and an average has been struck. The average for the thirty experiments is $7 \cdot 2$ days.

This correspondence of the experimental mean with the mean expressed in the chart, when taken in conjunction with the fact that 
the decumanus epizootic precedes the rattus epizootic, appears to us to be strong evidence in support of the conclusion that the decumanus epizootic stands in a causal relation to the rattus epizootic. We have already pointed out that the condition for epidemic spread (i.e. prevalence of fleas) is greater in decumanus than rattus; hence it is not difficult to imagine why the decumanus epizootic precedes that in rattus.

\section{Plague in Mes musculus, Nesokia bengalensis AND NESOKIA Bandicota.}

Mus musculus. Since no special care was taken in the collection of mice we can make no definite statement as to the severity of the infection amongst them. Only 63 infected mice were obtained during the year. The regional distribution of the buboes and the post-mortem appearances generally corresponded with these features as met with in plague rats.

Nesokia bengalensis. The remarks made above with regard to mice apply equally in the case of this rodent. Peripheral buboes were commonly present and were similar in distribution to those in rats, and the pathological appearances, including "granular" liver and pleural effusion, were identical with those met with in plague rats.

Nesokia bandicota. Very few specimens of plague-infected bandicoots have come to our notice.

Musk rat. It is interesting to note that we have never met with a specimen of a plague-infected musk rat, although on account of the habits of this animal it must frequently be exposed to infection. The explanation is simple, namely that the musk rat is highly resistant to plague, as we have proved by experiment. It withstands the subcutaneous inoculation of as large a dose as $\frac{1}{5}$ of an agar-tube culture of a virulent strain of the bacillus.

1 The curves for the epizootics may for practical purposes be said to be calculated on dead rats since the numbers of live rats found infected formed a very small proportion of the total infected rats. The experimental result may therefore with fairness be compared with the time as shown in the Chart. Further, in the experiments the fleas were always fed on a rat which had a large number of bacilli in the blood and a considerable number were used in each experiment. Both these factors would tend to shorten the interval between the death of the rats, in comparison to what occurs in nature. 


\section{Summary.}

It has been shown that Mus decumanus and Mus rattus are by far the most important species of rodent in Bombay in relation to the spread of plague. A short account has been given of the external appearances which we relied upon in distinguishing between the two species. It has been pointed out that Mus rattus is essentially a house rat, that it is very numerous in the native houses, and that it has a universal distribution in Bombay Island. Mus decumanus, although typically an out-of-door wandering rat, is yet found not infrequently in the lower floors of inhabited buildings, and is practically confined to Bombay City. The importance of the close association of the two species in certain common haunts lies in the relation of the decumanus epizootic to the rattus epizootic.

Mus decumanus does not occur in the outlying villages in the Island, a circumstance which is referable to the absence of gullies, drains, etc. in these villages.

Nesokia bengalensis, a rodent closely resembling Mus decumanus, accounts for about $1 \%$ of the rodent population in the City: it is susceptible to plague.

With regard to the epizootic amongst the rats the following conclusions may be formulated:-

(1) Mus decumanus and Mus rattus are equally susceptible to plague.

(2) The incidence of plague is twice as great on the decumanus population as on the rattus population.

(3) Mus decumanus is the species which is chiefly responsible for the diffusion of plague amongst the rats throughout Bombay City.

(4) The decumanus epizootic precedes the rattus epizootic by a mean interval of about ten days.

(5) The rattus epizootic is directly attributable to the decumanus epizootic.

(6) Plague persists in the rats in Bombay City during the off season. This persistence is due chiefly to Mus decumanus.

It seems to us that the last four conclusions can best be correlated, and are adequately explained if it be granted that the conditions for epizootic prevalence are more favourable in the decumanus population than in the rattus population.

The only factor concerned in the severity of epizootic prevalence, which, so far as our knowledge extends, does not affect the two species 
equally, is the degree of flea-infestation of each, Mus decumanus harbouring more than twice as many fleas as Mus rattus. We think, therefore, that in this fact is to be found the key to the elucidation of the relationship of the two epizootics.

\section{THE EPIDEMIC AND ITS RELATION TO THE EPIZOOTICS.}

\section{General Account of the Epidemic of 1905-6.}

(1) Statistical data relating to the severity of the epidemic.

The epidemic of the year under review, when compared with the yearly outbreaks in the City dating from 1897, may be described as being of moderate severity. 12,245 attacks were reported during the year from the whole of the island. Of these 74 were "imported" cases, i.e. a history was obtained that they had recently arrived in the island from an infected locality, where presumably they had received their infection. 11,010 plague deaths were reported during the year. Data concerning 10,880 plague cases, or $89 \%$ of the reported attacks, were entered into the case cards in accordance with the system of which we have already given a description. It was found impossible towards the climax of the epidemic to keep pace with the large amount of work involved in filling up the case cards. In spite of this nearly all the sections are well represented in the cards.

Deaths from plague were reported from the City during every week of the year, the smallest number-five deaths only-being in the week 19th-25th November and the largest number-925-in the week 22nd-28th April. The largest number of plague deaths in one day was 167, viz. on the 30th April 1906. The largest number of deaths in the year for a single section occurred in Byculla (917). Only in four weeks during the year were no plague deaths reported from Mandvi. The death rate from plague was greatest in Bhuleshwar section, in which it reached the high figure of 17 per mille of the population of this section. In 19 sections out of 25 the death rate rose above 10 per mille of the population of each section. 
(2) Statistical data relating to the incidence of plague on the population, classified according to sex, age and religion.

Our data on these points, obtained by an analysis of the case cards, are set forth in Tables XIII., XIV. and XV.

(a) With regard to the incidence on sex it might appear at first sight that males are somewhat more liable to infection than females.

\section{TABLE XIII.}

Incidence of plague on the two sexes.

$$
\begin{gathered}
\text { No. of males } \\
\text { attacked by plague } \\
7,211
\end{gathered}
$$

No. of females attacked by plague 3,669

$$
\begin{gathered}
\text { No. of males in } \\
\text { population (census 1906) } \\
612,965
\end{gathered}
$$

$$
\begin{aligned}
& \text { No. of femsles in } \\
& \text { population (census 1906) } \\
& 364,811
\end{aligned}
$$

$$
\begin{gathered}
\text { Ratio of infected } \\
\text { to non-infected males } \\
\text { 1-85 }
\end{gathered}
$$

\begin{tabular}{|c|c|c|c|c|}
\hline Religion & \multicolumn{2}{|c|}{$\begin{array}{l}\text { Numbers attacked } \\
\text { by plague }\end{array}$} & $\begin{array}{l}\text { No. of each } \\
\text { religion in the } \\
\text { population (census 1906) }\end{array}$ & $\begin{array}{l}\text { Incidence of } \\
\text { perague } \\
\text { per mille }\end{array}$ \\
\hline Brahmins & 456 & & & \\
\hline Jains & 15 & & & \\
\hline Other Hindus & 5,626 & 8,821 & 706,154 & $12 \cdot 4$ \\
\hline Low caste Hindus & 2,724 & & & \\
\hline Parsees & 310 & & $48,8 \geq 4$ & $6 \cdot 3$ \\
\hline Mahomedans & 1,414 & & 168,677 & $8 \cdot 3$ \\
\hline Native Christians & 263 & & & \\
\hline Eurasians & 14 & 296 & 48,508 & $6 \cdot 1$ \\
\hline Europeans & 19 & & & \\
\hline Jews & 32 & & 5,367 & $5 \cdot 6$ \\
\hline
\end{tabular}

Ratio of infected to non-infected females $1-99$

\section{TABLE XIV.}

Incidence of plague on persons of different age-periods.

\begin{tabular}{cccc} 
Age-period & $\begin{array}{c}\text { No. of attacks } \\
\text { for each age-period }\end{array}$ & $\begin{array}{c}\text { No. of population } \\
\text { in each age-period } \\
\text { (census 1906) }\end{array}$ & $\begin{array}{c}\text { Incidence per } \\
\text { mille for } \\
\text { each age-period }\end{array}$ \\
$0-5$ & 239 & 69,775 & $3 \cdot 4$ \\
$6-10$ & 878 & 70,009 & $12 \cdot 6$ \\
$11-20$ & 3,519 & 187,321 & $18 \cdot 7$ \\
$21-40$ & 5,102 & 478,101 & $10 \cdot 6$ \\
$41-60$ & 1,040 & 142,715 & $7 \cdot 2$ \\
Above 60 & 102 & 26,574 & $3 \cdot 8$ \\
\hline Total & 10,880 & 974,495 & -
\end{tabular}

TABLE XV.

Incidence of plague on persons of different religions. 
We do not think that this is actually the case, because it is well known that in Bombay concealment of cases amongst females, especially among Mahomedan women, is more largely practised than amongst males. It seems to us, therefore, very probable that little difference exists in the liability to infection of persons of either sex.

(b) Table XIV. shows that there are marked variations in the incidence of plague on persons of different ages. The incidence increases from birth to the age of 20 and afterwards diminishes. The greatest incidence falls on persons in the age-period 11-20. It would seem difficult to explain these variations on grounds other than a varying susceptibility to the disease at different age-periods.

(c) Table XV. shows that Hindus (including Jains) are most liable to infection. Mahomedans come next in order and are followed by Parsis and a group which includes Native Christians, Eurasians and Europeans. The incidence appears to be least in Jews. The most probable explanation of this variation appears to us to be found in the conditions of life (poverty, habits, etc.) which, as we shall see, greatly influence the liability of the people to exposure to infection from rats.

\section{The Relation of the Epidemic to the Epizootics with regard to Time and Place.}

\section{(1) The time-relations of the epidemic and the rattus epizootic.}

The charts for Bombay City and for the sections show that the epidemic curve has a marked similarity to the curves which represent the epizootics. The seasonal prevalence of the epidemic therefore corresponds to that of the epizootics.

The epidemic curve for Bombay City crosses the mean line in the week 18-24 February. The interspace at this point separating the epidemic from the rattus epizootic represents an interval of $3 \frac{1}{2}$ weeks. As the epidemic curve rises towards a summit in the last week of March it approximates to the epizootic curve so that when it reaches this summit the interval is reduced to a fortnight. The epidemic curve shows a second well-marked apex which is separated by only a week's interval from the corresponding apex of the rattus epizootic. The mean interval between the epidemic and the rattus epizootic curves may therefore be said to be approximately 10 to 14 days. This result is further borne out by a study of the curves for the separate sections.

If the epidemic is directly attributable to the rattus epizootic, it 
becomes necessary to furnish an adequate explanation of the interval of time which elapses between the epidemic and this epizootic. It must be pointed out that this interval, if our conclusions are correct, must be capable of being interpreted, on the view that the rat flea is the transmitting agent of the infection from rat to man. On this view our explanation of the mean interval expressed in the charts is as follows. We consider that this interval is divisible into three periods: $(a)$ a period, which elapses between the death of an infected rat and the communication of the infection from the rat to man by the rat flea, (b) the incubation period of the disease in man, and (c) the period of duration of illness in a fatal case of human plague.

(a) From observations ${ }^{1}$ we have made it would appear that when an opportunity is offered to rat fleas of biting man the best results are obtained when the fleas have starved for about three days, i.e. under these conditions the largest number of fleas are found to bite man. The apparent disinclination of the rat flea to attack man, even when he is the only available host, is naturally explained by the fact that man is not the true host of Pulex cheopis.

(b) The best evidence relating to the average length of the incubation period in human plague has been collected by the Indian Plague Commission and is presented in their report (vol. v. p. 77). From this evidence it would appear that the mean incubation period approximates to three days.

(c) The mean duration of illness in fatal cases of plague may be stated to be $5 \frac{1}{2}$ days. This result has been arrived at as follows: the mean duration of illness of 100 fatal cases reported on the case cards is 3.6 days. The duration of illness in 64 hospital cases, who died from the disease and from whose blood we recovered the $B$. pestis, works out at 7.5 days. The mean of these figures is 5.5 days, so that we may regard the mean duration of illness in a fatal case as approximately $5 \frac{1}{2}$ days.

Summarising the above data we obtain the following results:

\begin{tabular}{lll} 
Time elapsing before the rat flea bites man & $\ldots$ & 3 days. \\
Incubation period of human plague & $\ldots$ & 3 \\
Duration of illness of fatal human plague & $\ldots$ & $5 \frac{1}{2}, "$, \\
\hline & & $11 \frac{1}{2},$,
\end{tabular}

It is evident that the mean period of $11 \frac{1}{2}$ days corresponds fairly satisfactorily to the mean interval of time expressed in the charts.

1 These observations will be published in a later volume. 
The time-relations of the epidemic and the rattus epizootic are well illustrated in the maps for the sections.

(2) The place-relations of the epidemic and the rattus epizootic.

The direct evidence bearing upon this point which we have been able to collect in Bombay is, from unavoidable causes, meagre. We were able to make a search for dead rats in only a small proportion of the total houses and buildings in which plague cases occurred. Still, in a considerable number of instances plague-infected $M$. rattus have been found in houses in association with plague cases.

From indirect evidence, however, there can be not the slightest doubt that the place-infection of man is intimately related to that of $M$. rattus. We refer to the fact-a commonplace doubtless to workers in India, but not perhaps sufficiently appreciated by those who have not visited this country-that $M$. rattus is essentially a house-rat and that it lives in close association with man. It necessarily follows from this association that the place-infection of $M$. rattus must correspond closely to that of man in the sense that both must be referred to inhabited buildings.

(3) The quantitative relation of the incidence of human and of rat plague.

This is well shown for any one section in the charts of the sections, i.e. the epidemic and the epizootics increase and diminish in severity pari passu.

In order to contrast one section with another, from this point of view, Table XI. should be consulted. It will he observed that the first nine sections in this table show an incidence for human plague deaths of over 10 per mille of the population of each section, corresponding to an average of 1 to $3 \cdot 1$ plague-infected rats per building in eight of the sections. In the last five sections in the table, in which the human plague incidence is considerably less, the average number of total plague rats per building is also considerably smaller. Confirmatory evidence is given in the column in this table, in which is set forth the average number of plague deaths per building. Although the figures for the rats are only approximate the figures in the table taken as a whole certainly indicate a quantitative relation between the severity of the epidemic and the severity of the epizootics in the different sections. 
(4) Further remarks on the spread of infection from rat to man.

In an account of the epizootic we have arrived at the conclusion that the rattus epizootic is directly attributable to the decumanus epizootic. At the same time it was pointed out that in this statement we do not wish to imply that in every instance $M$. rattus received its infection directly from $M$. decumanus. Further, from the considerations which have been brought forward in the present discussion, we think it justifiable to conclude that the epidemic is directly attributable to the rattus epizootic.

It would seem impossible, however, to escape from the conclusion that $M$. decumanus occasionally transfers infection directly to man, in view of the fact, to which we have already alluded, that $M$. decumanus is to a certain extent a house-rat. Since $M$. decumanus is not, however, so generally distributed over buildings as $M$. rattus, we do not think that direct infection of man by the former species occurs nearly as frequently as it does by the latter species of rat. The charts unquestionably support this conclusion, since they show that the epidemic is more nearly related in time to the rattus epizootic than to the decumanus epizootic.

\section{Summary and Conclusions.}

With regard to the incidence of plague on different classes of the population we may note that little difference, if any, exists in the liability to infection of males and females; that there is a varying incidence on persons of different age-periods, the greatest incidence being on persons between 11-20 years of age; and that of the different races in Bombay Hindus and Mahomedans suffer most severely from the disease.

We may summarise our conclusions regarding the inter-relations of the epidemic and the epizootics as follows:

(1) The time-relation of the epidemic and the rattus epizootic is explicable on the view that the rat flea is the transmitting agent of the infection from $M$. rattus to man.

(2) From the point of view of place-infection there is an intimate relation between the epidemic and the rattus epizootic.

(3) There is a definite quantitative relation between the incidence of human and of rat plague.

(4) The epidemic is directly attributable to the rattus epizootic and since this epizootic is in its turn directly attributable to the 
decumanus epizootic, the epidemic is indirectly attributable to the latter epizootic.

While the last conclusion expresses the broad relations of the epidemic and the epizootics it must be added that:

(5) Infection is occasionally transferred directly from $M$. decumanus to man, i.e. without the intervention of $M$. rattus.

\section{THE SANITARY CIRCUMSTANCES IN BOMBAY CITY WHICH INFLUENCE THE SPREAD OF EPIDEMIC PLAGUE.}

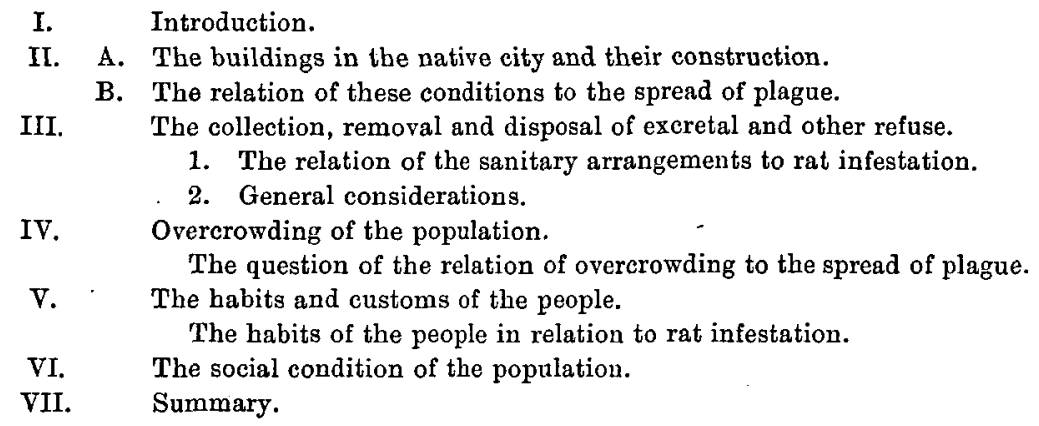

\section{INTRODUCTION.}

Having arrived at the conclusion that the epidemic is dependent upon the epizootics, we may proceed to inquire what the conditions are in Bombay which favour the spread of epidemic plague.

The inquiry resolves itself mainly into a consideration of the conditions in Bombay which favour the spread of epizootic plague and which facilitate the transference of infection from rats to man. While this is so, it is impossible to disregard the point of view of those who maintain that certain insanitary conditions (considered without reference to rat plague) play an important part in the spread of the epidemic. A brief description of the principal sanitary defects in the City will, therefore, be given, and discussion made as to their influence on plague. As a matter of fact several of these defects, in our view, have an important influence on human plague, for the sole reason, however, that they promote rat infestation and thus favour the spread of epizootic plague. Since frequent reference will be made in the following pages to the subjects of rat infestation and of rat plague, we would point out 


\section{Reports on Plague Investigations in India}

that it will conduce to a clear understanding of the issues involved in the whole problem, if the reader will distinguish between (1) the conditions which favour the spread of rat plague over the city (apart from its spread into buildings); (2) the conditions which favour the spread of rat plague into, and throughout, inhabited buildings; and (3) insanitary conditions (without reference to rats), which, as has been alleged, increase the liability to infection of man and at the same time aid in the spread of human plague.

We propose in the account that follows to describe, in the first place, the prevailing types of buildings in Bombay City, together with the conservancy arrangements in connection with such buildings. We shall, then, give a description of the conditions in which the people who occupy these buildings live, making special reference to the question of overcrowding, of the social conditions of the people and of their habits and customs. Lastly, the bearing of these points upon the spread of the epizootics and the epidemic will be discussed.

Before concluding these introductory remarks a word of explanation is necessary as to the nature of the evidence which we shall bring forward in support of our conclusions. This evidence is of two kinds. First, in the two years during which the Commission has been working in Bombay ample opportunity has been offered to its members for personal observation of the various conditions which prevail in the native city. Full advantage has been taken of these opportunities, so that from personal observation and experience we have been enabled to form definite opinions on the problems which presented themselves. Secondly, we have collected a large mass of statistical data in the manner already described. We are aware that these data are not altogether free from fallacies. Attention has already been drawn to certain sources of error, which in an oriental city like Bombay cannot fail to affect the accuracy of statistics relating to human plague.

\section{A. The Buildings in the Native City and their CONSTRUCTION.}

\section{General description.}

The typical inhabited building in the native city is a tenement building of considerable size; it is separated from adjoining buildings by gullies. The average size of the buildings is indicated in the statement that the average number of inhabitants per building for the whole island is about 30. Although the majority of the buildings shelter less 
than 20 persons, yet there are a considerable number with over 50, several with 200 and even a few with over 400 inhabitants.

The buildings are divided into houses or tenements, each holding being occupied as a rule by a single family. In some instances, however, we have found several families in one room, the number varying according to the size of the room. The majority of the buildings in Bombay are subdivided into ten or less holdings, but there is a considerable number containing 50 houses and over. In this connection it is worthy of note that $87.5 \%$ of the houses or holdings consist of one room only, and that $85 \%$ of the population live in such houses. This statement gives a good idea of the poverty of the inhabitants generally.

Attention may be drawn here to a type of building, known as a "chawl," which is common in sume sections in Bombay, and which may be described as a large tenement building occupied by the poorer class of natives. We may add that most of these chawls embody the worst structural features of buildings in Bombay. Plate XXIII shows good examples of this type of building.

One of the commonest, and at the same time one of the most important, characteristics of the buildings in Bombay is, that the ground-floors are often occupied with shops, godowns, or even stables. These shops, of course, vary greatly as to the nature of the articles exposed for sale, but most frequently, perhaps, they contain grain and other articles of food.

In Mandvi the ground-floors are very commonly occupied by godowns (Plate $\mathrm{XXV}$ ), at least $70 \%$ of the buildings in this section showing this peculiarity. The nature of these store-houses or godowns varies, but the commonest commodities stored in them are grain, spices and gunny-bags (empty grain sacks). Buildings with stables on the groundfloor are found everywhere.

\section{The construction of the buildings.}

The buildings in Bombay are for the most part of a flimsy construction. Proper foundations do not exist; the walls rest upon a plinth composed of rubble and earth with an outer facing of stone. The floors of the basement consist merely of the soil over which the building is constructed, rendered firm by a layer of rubble and earth and covered with a layer of beaten earth.

(a) The walls consist of a framework of stout wooden beams, which support the upper storeys, the spaces between the beams being filled up 


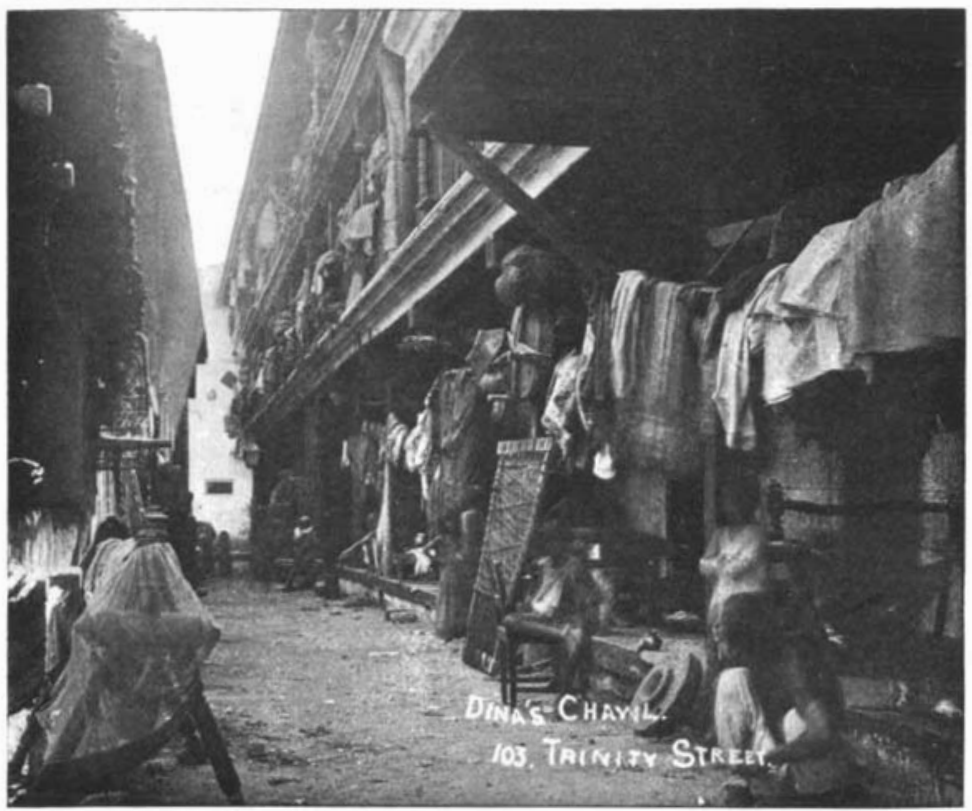

Bombay City: showing a typical chawl.

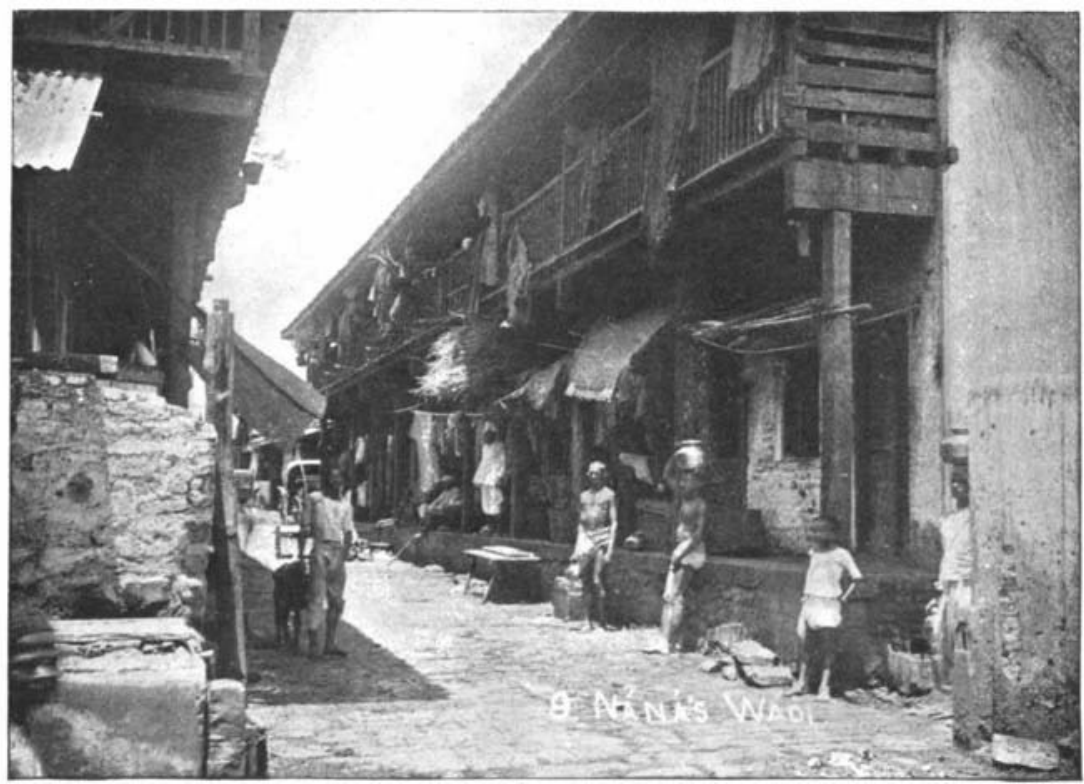

Bombay City: a typical chawl. 


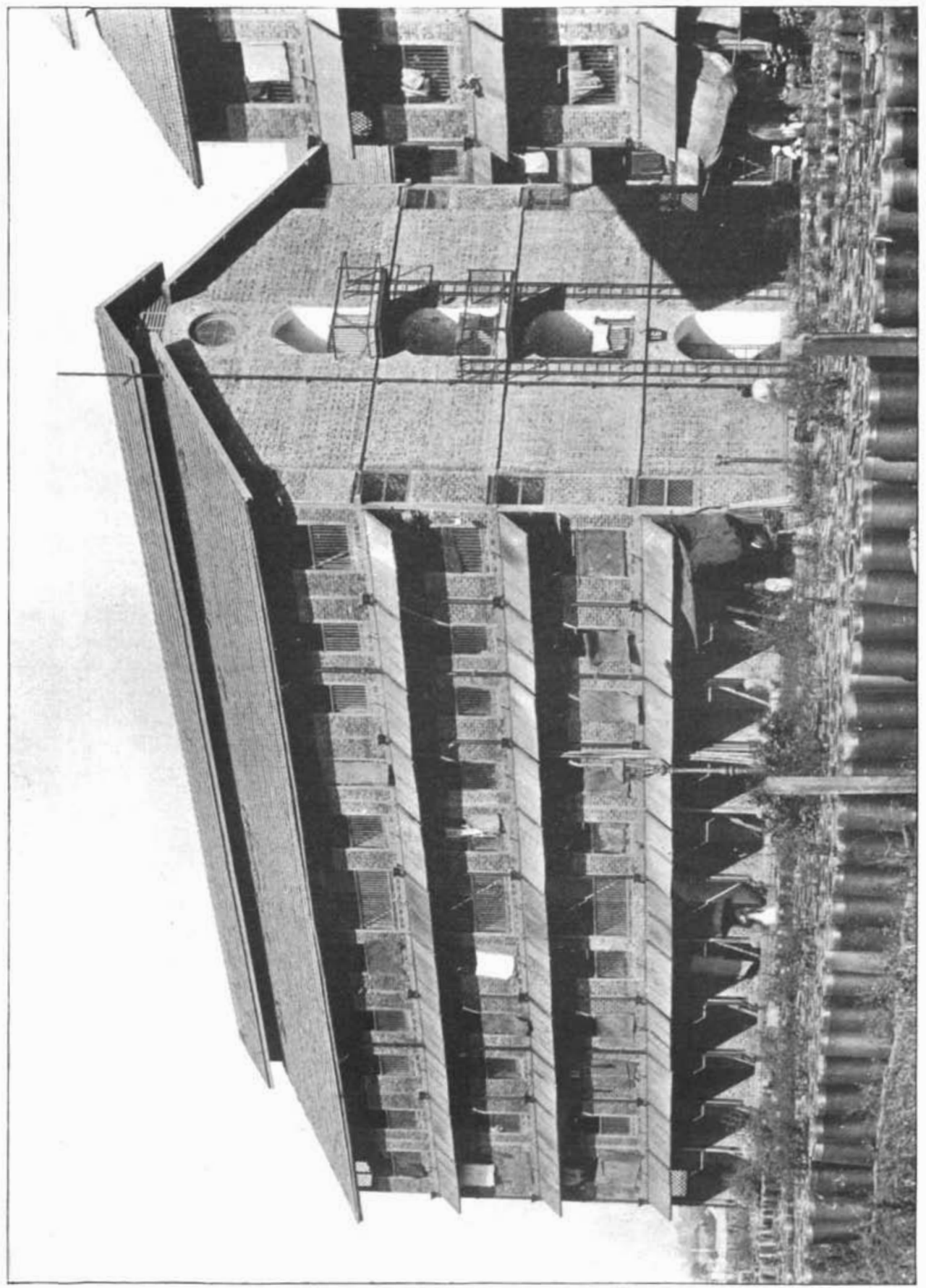




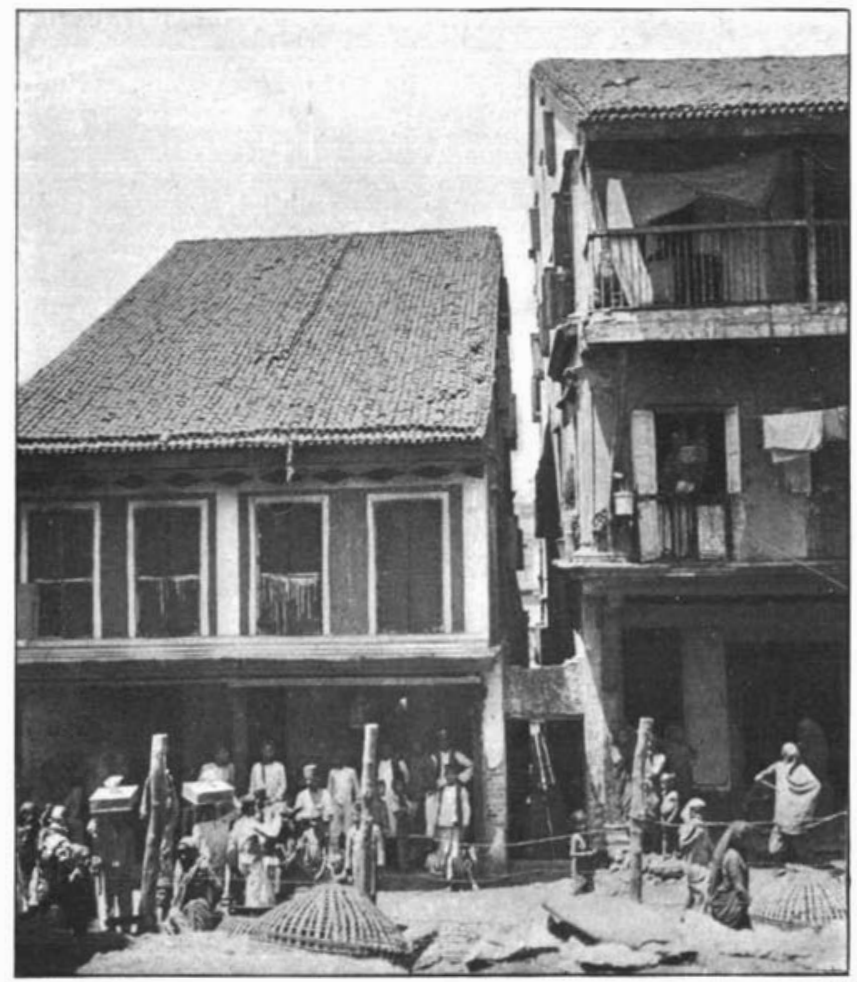

Bombay City: showing country tiles on roofs and a gully between the houses.

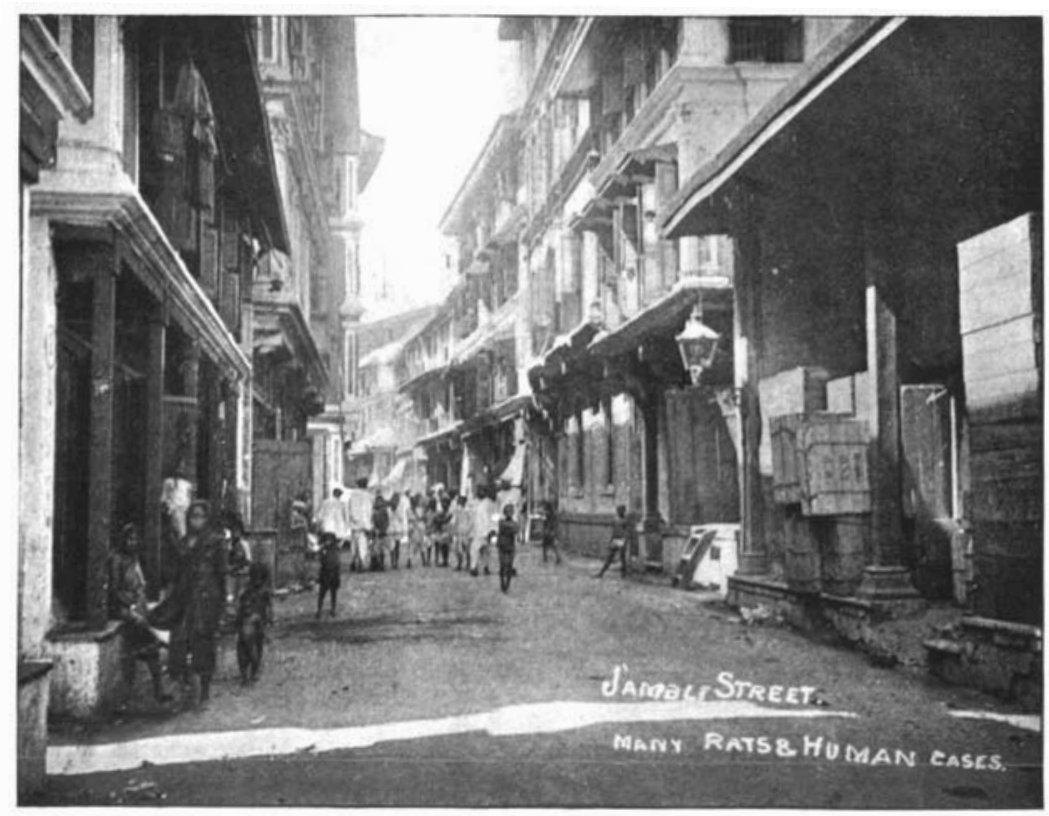

Bombay City: showing go downs on ground floor. 
with burnt bricks and mortar. The outer and inner surfaces of the walls are plastered over with a layer of "chunam"-a mixture of lime and sand-put on moist and allowed to set and then ornamented with some coloured wash.

(b) The floors are formed of boarding supported on joists. Such a simple wooden floor is, however, very rarely seen in Bombay. The planking is very frequently covered with a layer of beaten earth, on the surface of which cowdung is periodically applied. The earthen floor in a good many instances is overlaid with a layer of "chunam." On the ground-floor the boarding is, as a rule, dispensed with.

(c) The roofs consist of wooden joists, supporting a lattice of laths, on which are laid two to four layers of country tiles (Plate XXV). The great majority of buildings have this form of tiling, but in a certain number a single layer of flat Mangalore tiles is used (Plate XXIV). The tiled roofing generally serves the purpose of a ceiling in the case of rooms on the top storeys of buildings, that is to say, there is no proper ceiling in these rooms.

(d) Ventilation and lighting are provided for by means of the door, which invariably fits loosely, and by windows which, however, are sometimes absent. The windows consist of an upper and lower portion. The lower portion, in the majority of cases, is fitted with an iron grid and is capable of being closed by a wooden shutter. The upper half in the better class of houses is fitted with glass panes and is also provided with shutters. The windows sometimes look out upon dark and narrow gullies. From this description it might be imagined that the ventilation in the houses must be miserably deficient. It ought to be remembered, however, that the walls are flimsy, that the tiled roofs act as excellent ventilators, that the doors and the window-shutters fit very loosely and that, except in the colder nights of January and February, the windows are kept open.

In spite, therefore, of the overcrowding, which according to our British standard undoubtedly exists, we are of opinion that the ventilation in the great majority of the houses is adequate. We may note in support of this opinion, that the houses in Bombay rarely give the impression of closeness which is so common a feature in the houses of the poor at home.

The houses of the poorer class of natives are not infrequently badly lighted. It is not uncommon to observe the verandahs and windows covered up with screens of matting, pieces of cloth, etc. Some of the houses, from structural defects, are so dark that the occupants resort to 
lamplight during the day time. The corridors in chawls are also often very badly lighted.

\section{B. The Relation of 'ihese Conditions to the Spread of Plague.}

\section{The construction of the buildings.}

In an account of the epizootic we have already given details concerning the rat infestation of buildings.

It has been shown that Mus rattus is found in all parts of buildings, while Mus decumanus can be trapped only on the lower floors.

It is not difficult to connect these facts with the generally flimsy construction of the buildings as described above. We have, indeed, very frequently observed the floors and walls of houses riddled with the holes and burrows of Mus decumanus and of Mus rattus. In particular, we would point out that the inroads of Mus decumanus into buildings are greatly favoured by the defective plinths and by the lack of rat proof foundations. Rat holes may frequently be observed between the stones of the plinths and we have seen the material of which the foundations are made riddled in all directions with rat burrows.

We have not been able to obtain any statistical data bearing upon the relative incidence of plague on this class of buildings and on buildings of a substantial construction. In Bombay relatively few inhabited buildings conform to the latter description. We have, however, on several occasions found plague cases in such buildings. One instance may especially be referred to, in which a serious epidemic took place in a number of chawls, which have recently been built by the Improvement Trust (Plate XXIV). These chawls are of solid structure throughout and indeed in this respect leave nothing to be desired. While, therefore, it is impossible to determine the relative incidence of plague on ill-constructed buildings and on those which are substantially built, we can assert that the latter class of building is by no means exempt from severe plague outbreaks.

\section{The nature of the floors.}

It is obvious that the common type of floor in Bombay, i.e. the beaten earth floor, offers no obstacle to a burrowing animal like the rat. We have observed extensive burrows containing the nests of Mus decumanus in the floor (overlaid with "chunam") of a living-room in a chawl. In another instance we had the earthen floor (ground-floor) of a room 
opened up and found it undermined in every direction with the burrows of Mus rattus.

We have no data bearing upon the problem of the relative incidence of plague in rooms with different kinds of floors. We have, however, accumulated figures regarding the nature of the floors in the houses in which 9527 plague cases occurred in the course of the epidemic now under consideration. These figures are set forth in the accompanying table (XVI.), from which it is seen that $57.7 \%$ of the cases were found in houses provided with stone or cement (chunam) floors, $41.5 \%$ in houses with cowdung or earthen floors, and $0.7 \%$ in houses with uncovered wooden floors. While it is impossible to determine the relative frequency of these three types of floors in Bombay, the figures are not without their value, since they show that plague cases very commonly occur in houses with "pucca" floors.

\section{TABLE XVI.}

Showing percentage of plague cases in houses with different kinds of floors.

\begin{tabular}{|c|c|c|c|c|}
\hline & $\begin{array}{l}\text { Houses with } \\
\text { "pucca" floors }\end{array}$ & $\begin{array}{l}\text { Houses with } \\
\text { earth or } \\
\text { cowdung foors }\end{array}$ & $\begin{array}{l}\text { Houses with } \\
\text { wooden floors }\end{array}$ & Total \\
\hline Number of Cases & 5495 & 3960 & 72 & 9527 \\
\hline Percentage of total number & $57 \cdot 7$ & $41 \cdot 5$ & 0.7 & \\
\hline
\end{tabular}

"Pucca" floor includes floors of stone, cement and chunam (namely, a mixture of lime and sand).

\section{The nature of the ceilings and roofs.}

Country tiles offer a greater attraction for a climbing rat like Mus rattus than Mangalore tiles, simply on account of the shelter provided in the channels of the tiles in the former case. It has been our experience on removing such tiles to disturb many rats and to come across nests with young. The difference in this respect between the two kinds of tiles is well brought out in a table, already published, which shows the rat flea counts in the experimental godowns in the Parel Laboratory (vol. vI. p. 453). It is seen from this table that, summing up the results of several experiments, the number of fleas obtained from guineapigs placed in godowns with country tiled roofs is nearly four times the number obtained from guinea-pigs in the godowns with flat Mangalore tiles. Similar observations will be found in an additional paper on experiments in these godowns (vol. viI. p. 421). The explanation of the difference is, as we know from actual observation, that rats frequent the roofs of the godowns with country tiles much more than they do the roofs with Mangalore tiles.

Journ. of Hyg. vis 
No data are available, which might point to a greater incidence of plague on houses with any particular ceiling or on buildings which are roofed in any particular manner. In the two tables (XVII. and XVIII.) given herewith we see, however, that plague cases may occur under almost any kind of ceiling and in buildings which are roofed either with flat Mangalore tiles or with country tiles.

\section{TABLE XVII.}

Showing percentage of plague,cases in houses with different kinds of ceilings.

$\begin{array}{lccccc} & \begin{array}{c}\text { Houses with } \\ \text { wooden ceilings }\end{array} & \begin{array}{c}\text { Houses with } \\ \text { bamboo, or } \\ \text { lath ceilings }\end{array} & \begin{array}{c}\text { Houses with } \\ \text { matting ceilings }\end{array} & \begin{array}{c}\text { Houses with } \\ \text { corrugated } \\ \text { iron ceilings }\end{array} & \text { Total } \\ \text { Number of cases } & 5150 & 3412 & 438 & 81 & 9081 \\ \text { Percentage of total cases } & 56 \cdot 7 & \mathbf{3 7} 6 & 4.6 & 0.9 & \end{array}$

\section{TABLE XVIII.}

Showing percentage of plague cases in buildings with different kinds of tiles.

Number of cases

Percentage of total cases

$$
\begin{gathered}
\text { Buildings with } \\
\text { country tiles }
\end{gathered}
$$

7603

$86 \cdot 5$
Buildings with
Mangalore tiles

1185

$13 \cdot 5$
Total

8784

\section{TABLE XIX.}

Showing percentage of plague cases in houses which differed from one another as regards ventilation.

Number of plague cases Percentage of total cases

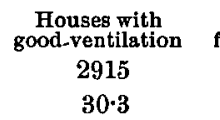

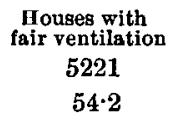

Houses with had ventilation Total $1491 \quad 9627$ $15 \cdot 5$

\section{The ventilation of the houses.}

We have already expressed our opinion that the ventilation of the houses in Bombay is not as defective as various writers on the subject have represented. We have not been able to collect statistical data for the purpose of determining whether plague incidence is greater on illventilated than on well-ventilated houses, because we do not know the relative proportions of such houses in the whole of Bombay. Nevertheless, our experience has been, that, while we no doubt came across plague cases in badly ventilated houses, we have likewise seen many cases in houses in which the ventilation left nothing to be desired.

In addition, we can bring forward data obtained from an analysis of the plague case cards, on which the opinion of the inspecting medical 
officer regarding the ventilation of plague houses was recorded. The results of this analysis are presented in Table XIX. It is seen that out of 9627 cases the ventilation is classified as good in $30.3 \%$, as fair in $54.2 \%$ and as bad in $15.5 \%$ of the houses.

\section{Defective lighting of houses.}

The influence of light and darkness on rat infestation is well illustrated in the godown experiments to which we have just alluded. The flea counts, recorded in the same table, which were made in a countrytile roofed godown with a small roof light, and in a Mangalore-tiled godown, also with a roof light, have been compared with the flea counts obtained in two godowns, similar to the first two but with no roof light. The result is that three times the number of fleas were obtained in the dark godowns as in the godowns with a roof light.

With regard to the relation of the lighting of houses to plague incidence data similar to those obtained for ventilation were recorded on the plague case cards. The result of the analysis of these data is given in the accompanying table (XX.), from which it is seen that the lighting was classified as good in $31.1 \%$, as fair in $53.4 \%$, and as bad in $15.5 \%$ of the houses. Moreover, our personal experience of two extensive epidemics in Bombay has been that we have come across many plague cases in houses which were well lighted.

\section{TABLE XX.}

Showing percentage of plague cases in houses which differed from one another as regards lighting.

Number of plague cases

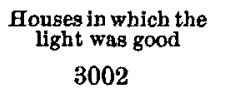

3002

Percentage of total cases

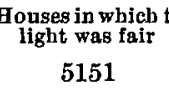

$53 \cdot 4$
Housegin which the
light was bad ight was bad Total

1493

$15 \cdot 5$
9646

\section{Shops, godowns and stables in inhabited buildings.}

In an account of rat infestation in Bombay, as evidenced by extensive trapping operations in different situations, it has been shown (Table I.) that relatively to the proportions of the total rats (Mus rattus and Mus decumanus) caught in all the places where traps were set, more Mus decumanus were caught in foodshops than Mus rattus, a circumstance which we referred to the proximity of these shops to gullies. On the other hand, food godowns appear especially to attract Mus rattus and non-food godowns Mus decumanus. Stables have a special attraction for Mus decumanus. It must be borne in mind that both species of rats 
are found together in all these places. When it is remembered that, as we have shown, the rattus epizootic, on which the epidemic directly depends, is in its turn attributable to the decumanus epizootic, the significance of the close association of the two species in these common haunts will be at once apparent.

\section{The Collection, Removal and Disposal of Excretal AND OTHER REFUSE.}

One of the first things which would attract the attention of a sanitarian on visiting the native city of Bombay is that separating adjoining buildings there is a narrow passage or gully (Plates XXV, $\mathrm{XXVI}$ ), and that this gully evidently plays an important part in the sanitary arrangements of the buildings.

A gully consists of an open half-pipe channel on each side and an elevated portion in the middle with a small gutter running along its centre. The side channels receive the waste water from the bathing stands in the building. The water passes through an iron screen and trap, which keep back the grosser solid material, into an inspection chamber and then on into the sewers under the street. The central portion of the gully is intended to carry off the storm water in the rainy season. This water, when in full stream, passes over a jump trap at the mouth of the gully and then into a system of storm water drains, which are quite distinct from the sewers. If 'the stream is a small one, the water falls into the jump trap and thence through the inspection chamber into the sewers.

The gullies also play an important part in the conservancy arrangements of the buildings. In this connection it must be explained that very few buildings in the native town of Bombay are provided with a water-carriage system. When this is present, as it is in the modern buildings, the house-drain is efficiently trapped before opening into the sewer. In the great majority of instances, however, the night soil is removed by hand. In each building there are privies-as a rule on every floor. The privies open into a shoot, which leads down to a chamber on the ground-floor; access to this chamber is obtained from the gully by means of a small door. In the chamber a basket is placed, which receives both the solid and liquid material which comes down the shoot. The liquid material percolates through the sides of the basket into the half-pipe channel at the side of the gully and then flows down this channel along with the sullage water into the sewers. The solid 
JOURNAL OF HYGIENE (PLAGUE NO.), VOL. VII. NO. 6.

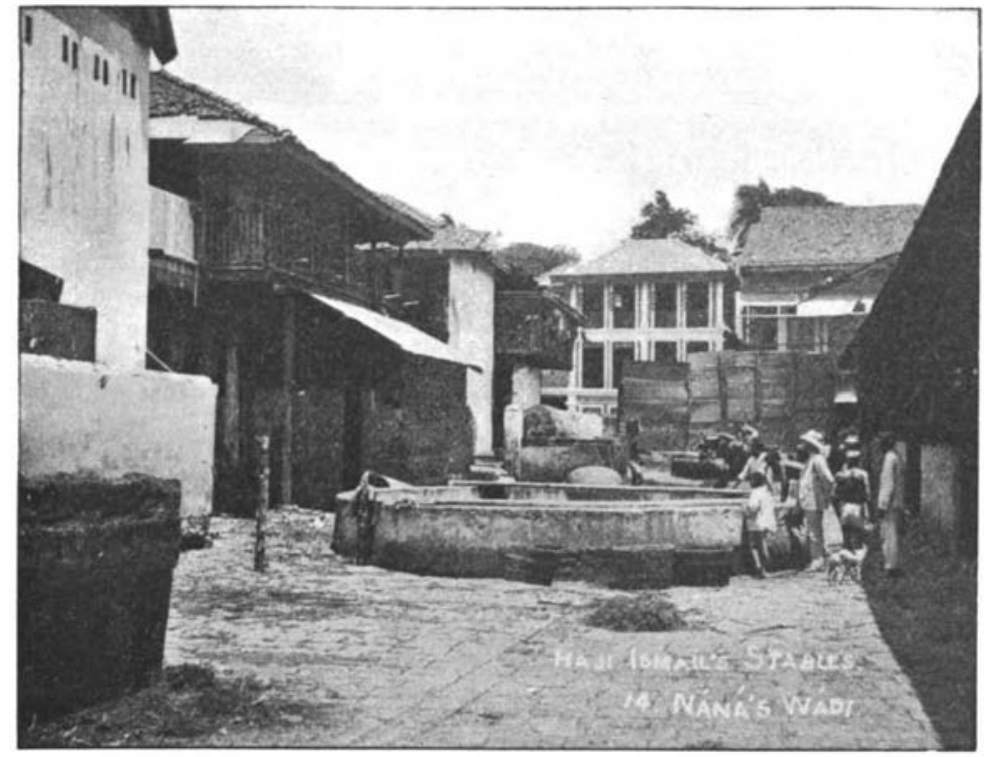

Bombay City: showing Courtyard with stables.

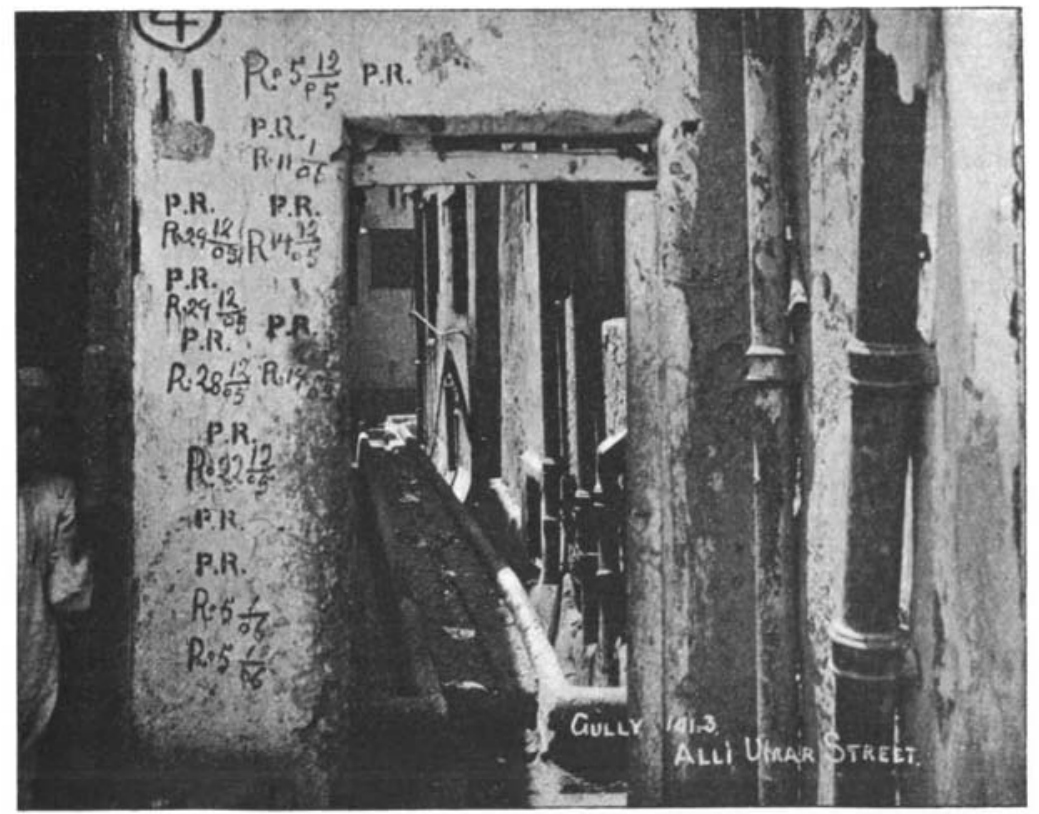

Bombay City: showing a gully, note the marks indicating the occurrence here of plague-infected rats. 
material intercepted in the basket is removed by men called "halalkores" to the nearest central dépôt, where it is emptied into the sewers.

It has been already mentioned that the storm water system of drains is quite distinct from the sewers. The former open into the sea at several points on the shores of the island. They come into complete function only in the rainy season; during the rest of the year they are practically dry.

The proper use of the gullies has already been described. It remains to be added, that the people use them as depositories for all the refuse of the house. From the windows above the sweepings of the rooms, scraps of food and other débris, are freely thrown out into the gully below and to a lesser extent into the streets and lanes. It is the duty of a special corps of municipal servants, known as "sweepers," to keep the streets and gullies clean, but even with their best endeavour this is an almost impossible task.

\section{The relation of the sanitary arrangements to rat infestation.}

The reader will have gathered from the foregoing description that a gully is nothing else than an open drain. Every building in the native city is bounded on at least one side by a gully in communication with the general sewage system and with the storm water drainage system. It is not difficult to understand from this statement that the gully in Bombay is one of the principal haunts of Mus decumanus, as well as of Mus rattus. The close proximity of gullies to inhabited buildings and the association of the two rats in this situation favour the spread of infection from Mus decumanus to the colonies of rats in buildings. Plague-infected Mus decumanus are very frequently found in gullies, and we may note that while investigating the infectivity of plague houses plague-infected rats were frequently found a short time before in the adjoining gully.

The food thrown out of the houses into the gullies by the people acts as a continual attraction for rats of both species. The drain pipes opening into the gullies afford an easy path for entrance into and exit from the upper storeys of buildings in the case of Mus rattus and also of Mus decumanus. The drainage and sewage systems afford shelter to Mus decumanus. 


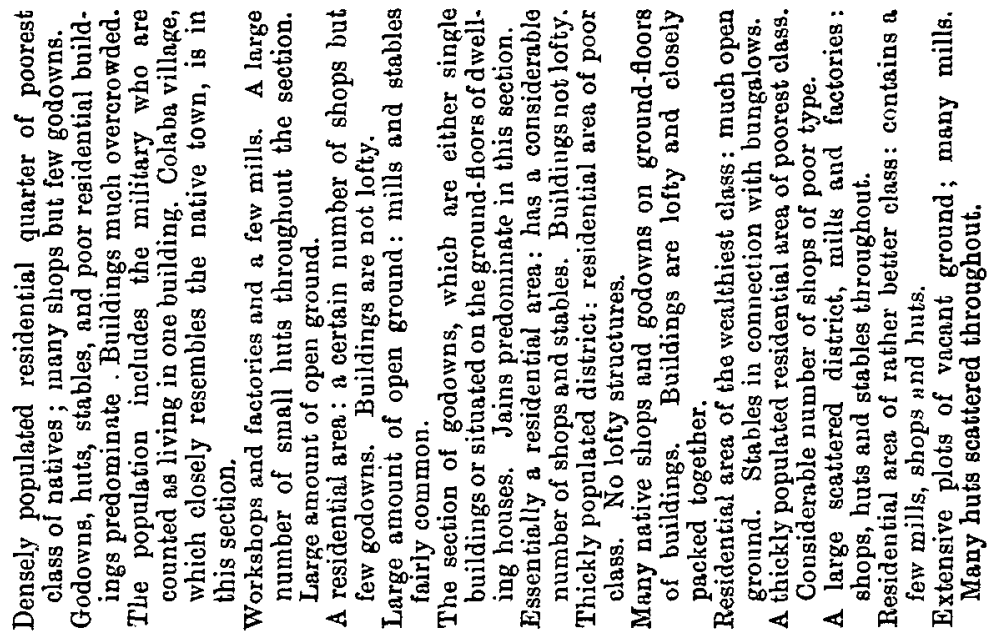

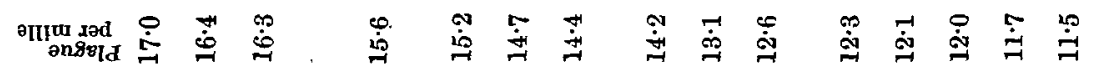

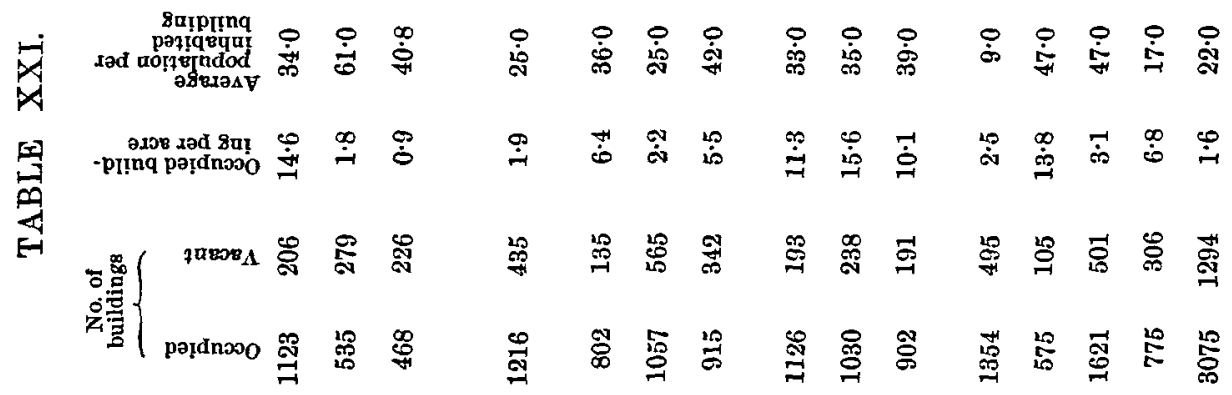

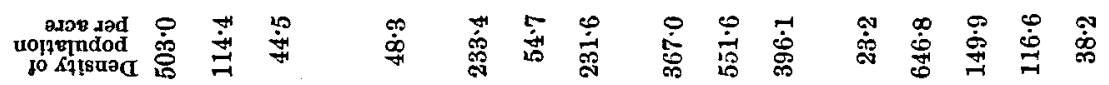

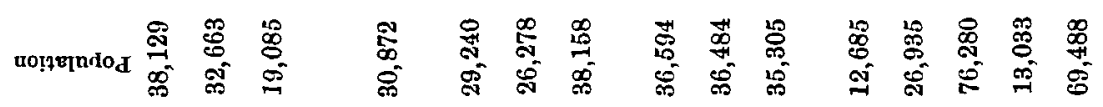

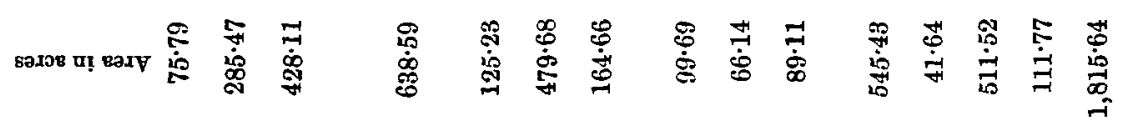

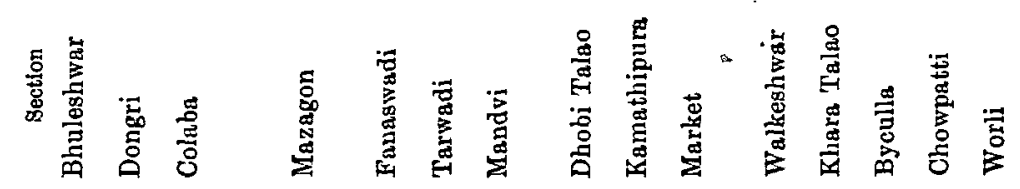



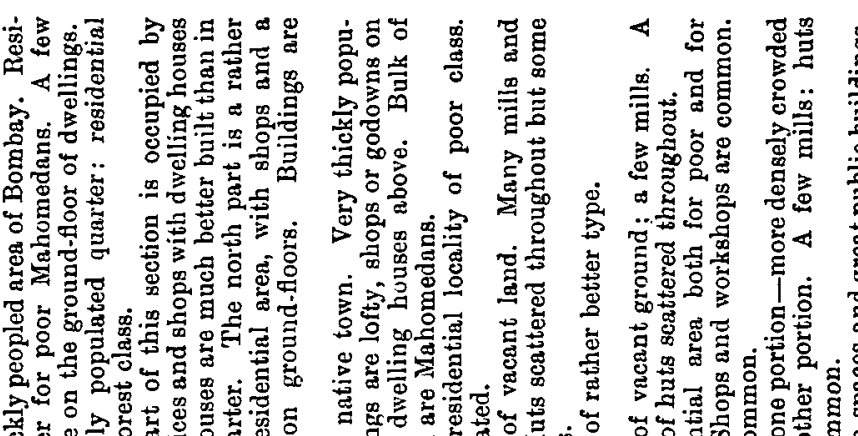

离 离总

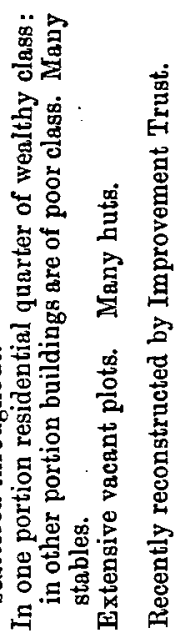

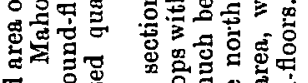

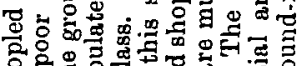

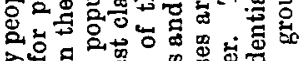

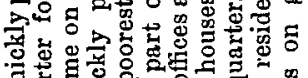

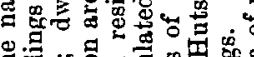

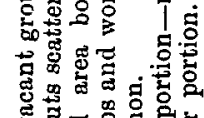

它家

总部

要,

要要

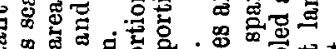

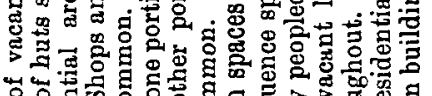

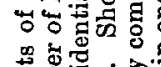

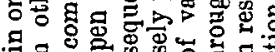

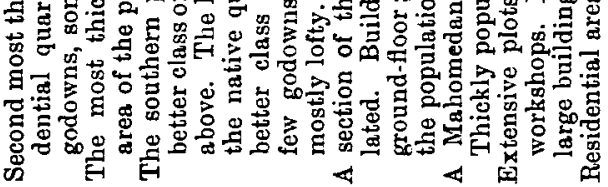

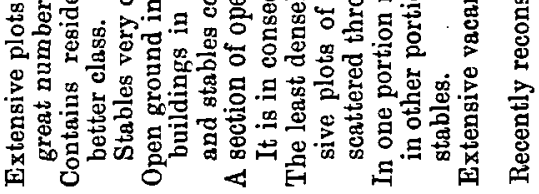

$\stackrel{\leftrightarrow}{\vec{H}} \stackrel{\circ}{\vec{G}}$

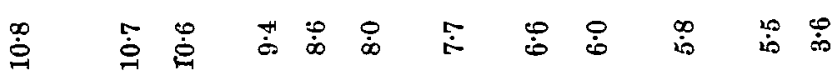

过官审

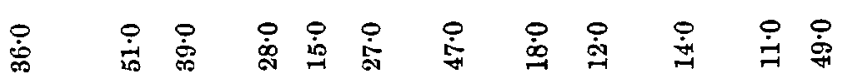

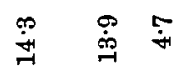

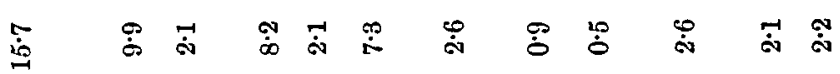

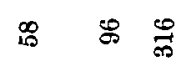

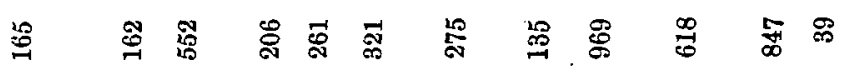

蛋 思

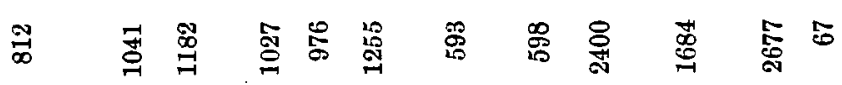

电害突

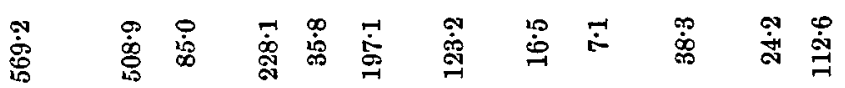

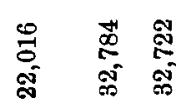

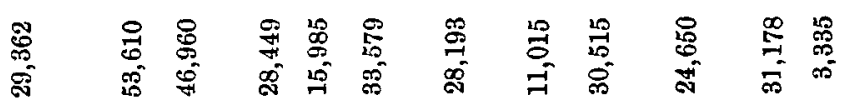

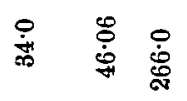

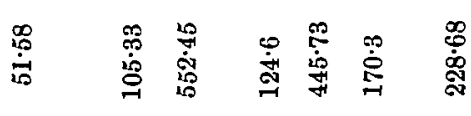

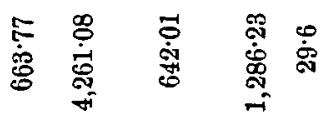

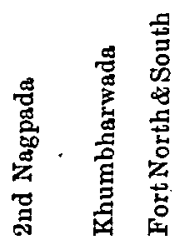

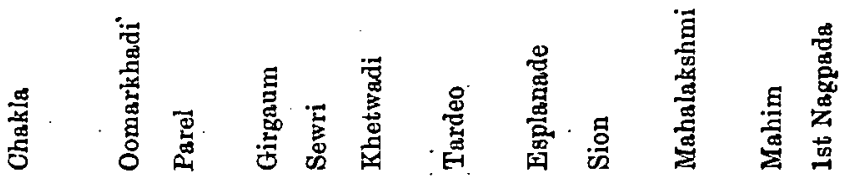




\section{General considerations.}

It cannot be doubted that, when judged according to European standards of sanitation, gullies must be regarded as being highly insanitary structures. Nevertheless, excluding the epizootics from consideration, we have not been able to discover any definite relation connecting this state of affairs with the spread of epidemic plague.

We may, for example, contrast the city of Bombay with the villages in the northern portion of the island, namely, Worli, Wadhala and Sion, in which there are no attempts at a conservancy system, the inhabitants using for the purposes of nature the fields beyond the limits of the village. It is a well recognised fact that, when plague has been epidemic in these villages, the proportion of the population affected has been as great, if not greater, than in the case of Bombay City. Again, in the city we have found plague cases in buildings provided with an efficient drainage system. Mention has already been made of a severe epidemic which took place in 1906 in a number of new chawls in Morland Road. These chawls are provided with a modern water carriage system. The privies are outside the houses and are flushed by means of an ample supply of water, the drains being efficiently trapped.

\section{Overcrowding of the Population.}

It is certain that in some districts of Bombay there is dense overcrowding. Not only are the buildings densely packed together, but in many buildings the cubic space available in the several rooms is small in proportion to the number of inhabitants.

The question of the relation of overcrowding to the spread of plague.

Using the same method as that employed by Mr Hankin and cited by the Indian Plague Commission, we have compared the incidence of plague in the different sections with the density of population of each section. The criteria which we have used as an indication of density of population are :

(a) The number of inhabitants per acre ;

(b) The number of inhabited buildings per acre; and

(c) The average number of inhabitants per occupied building.

As pointed out by the Indian Plague Commission none of these criteria, taken separately, can be considered as an accurate measure of 
overcrowding. We need not repeat the obvious objections which were raised in their report to these methods of estimating the density of the population, but shall content ourselves with drawing attention to the data obtained, since we are able to give the assurance, based upon an intimate knowledge of Bombay, that the statistics presented do, as a matter of fact, provide a rough indication of the density of the population in the different sections.

We have constructed a table (XXI.) showing the plague mortality per mille in the different sections during the year September 1905October 1906, and showing, at the same time, the figures relating to the three criteria of density mentioned above. This shows at once that there is no relation between the severity of plague in these sections and any of the factors which contribute to overcrowding of the population.

Additional evidence on the question at issue has been obtained by an analysis of over 4000 plague case cards, on which was recorded the number of square feet per head in the house in which the plague case occurred. The data thus obtained are set forth in the accompanying table (XXII.), from which it is seen that while no doubt there was dense overcrowding in very many instances, still there was a very considerable percentage of houses in which overcrowding could not be said to exist.

Viewing the evidence as a whole we are of opinion that there is no relation between overcrowding and plague incidence.

\section{TABLE XXII.}

Showing percentage of plague cases in different houses classified according to their condition as regards overcrowding.

\begin{tabular}{|c|c|c|c|c|}
\hline & $\begin{array}{c}\text { Houses in } \\
\text { which the } \\
\text { area per head } \\
\text { was } 10 \mathrm{sq} . \\
\text { feet or less }\end{array}$ & $\begin{array}{c}\text { Houses in } \\
\text { which the area } \\
\text { per head was } \\
\text { between } 11 \text { and } \\
25 \text { sq. feet }\end{array}$ & $\begin{array}{c}\text { Houses in } \\
\text { which the area } \\
\text { per head was } \\
\text { between } 26 \text { to } \\
50 \text { sq. feet }\end{array}$ & $\begin{array}{l}\text { Houses in } \\
\text { which the } \\
\text { area per head } \\
\text { was more than } \\
50 \text { sq. feet }\end{array}$ \\
\hline umber of plague cases & 430 & 1648 & 1433 & 700 \\
\hline Percentage of total cases & $10 \cdot 2$ & $39 \cdot 1$ & $34 \cdot 1$ & $16 \cdot 6$ \\
\hline
\end{tabular}

\section{The Habits and Customs of the People.}

Closely bound up with the social condition of the people are their habits, which we now pass on to consider.

As we have already pointed out the great majority of the inhabitants of Bombay are poor and live in houses consisting of one room only. In this room the food is cooked and eaten. The people take their meals on plantain leaves or brass platters, placed on the floor, no tables nor chairs being used. 
The supplies of raw material-grain, seeds used in the preparation of curry powder, etc.-are stored in wooden chests. The room is also used as a sleeping room, the floor, either bare or with a grass mat, often serving as a bed. Furniture, properly so called, is scanty or may be even absent, but one will often observe in the rooms wooden boxes containing grain, heaps of frewood or of cowdung cakes, used as fuel, brass and earthenware pots, in addition to articles which appear to the European to be useless accumulations of rubbish, but on which the native of India sets considerable store (Plate XXVII). In order to provide storage room for these articles a small loft is often improvised with planks or bamboos either inside the room or on the verandah (Plate XXIII). On this loft is stored.all kinds of rubbish and odds and ends, such as earthenware and brass jars, pieces of matting, firewood, old clothes, etc. While the floor of the room is often swept and kept clean, being covered at short intervals with a fresh layer of cowdung, this miscellaneous property is seldom disturbed.

While the living rooms of the people are kept fairly clean this cannot be said of the environs of the buildings. We have already referred to the use the people make of the gullies as depositories for the house refuse. Another native custom, which increases the difficulty of keeping the surroundings of buildings clean, is that of tethering cattle, sheep and goats in the courts and lanes and even in the entrances of buildings.

This description of the habits of the people applies only to the poorer classes. One observes that, as they rise in the social scale, the mode of living becomes more like that of Europeans. The compounds of the houses are kept clean and the household rubbish which accumulates is relegated to outhouses.

\section{The habits of the people in relation to rat infestation.}

We have already pointed out the relation of the common structural defects in the houses occupied by the poorer classes to the infestation of buildings by rats. Important as these facts are in this connection the habits of the people thernselves do much to promote rat infestation of their houses, and may alone constitute a source of grave danger, even. when the people occupy well-constructed buildings.

In the first place, the natives manifest a universal indifference to the presence of rats (Mus rattus, especially) in their houses, and in some instances, as we have already said, go so far as to protect them 
JOURNAL OF HYGIENE (PLAGUE NO.), VOL. VII. NO. 6

PLATE XXVII

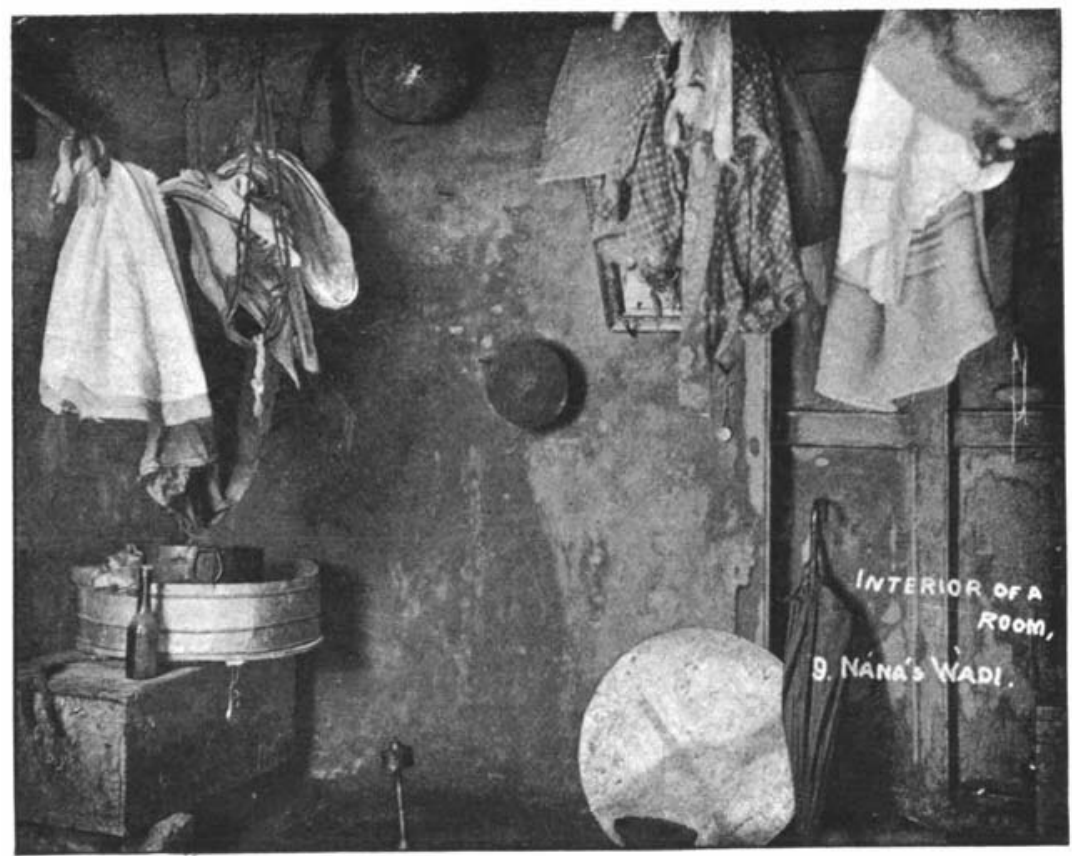

Bombay City: interior of a room in a chawl. 
from molestation. In the second place, a plentiful supply of food is provided for them both outside and inside the buildings. The refuse thrown into the gullies and streets, the remains of food supplied to the animals tethered in or near the buildings, the grain and other eatable materials stored inside the living rooms, all these things attract and are able to support a very large rat population.

Again, the conditions inside the houses, the boxes left undisturbed for long periods, the accumulations of rubbish and the improvised lofts, offer excellent shelter for Mus rattus. It has been with us a common experience when searching the houses and moving the furnishings about for this purpose to come across rats of this species and to find nests of young rats.

As an illustration of the influence of the habits of the people and the conditions resulting therefrom on the spread of plague, we may cite with advantage the case of the chawls in Morland Road, to which passing reference has twice before been made.

These chawls, 16 in number, were built recently by the City Improvement Trust and, in fact, some of them had only just been occupied before the plague epidemic of 1906 began. The walls are solidly built of brick and are supported on a high masonry plinth (Plate XXIV). The floors are of concrete or of patent stone and the roofs of Mangalore tiles. The verandahs and corridors are also paved with concrete and are wide and airy, the lighting and ventilation of the whole building leaving nothing to be desired. There are no gullies, most excellent water-closets being provided.

The buildings in themselves offer no shelter to rats. In spite of this Mus rattus is common in the houses. It is certain that the rat infestation of these buildings is due entirely to the habits of the people in the matter of the disposal of their household belongings as described above. Unfortunately for the inhabitants of these chawls this state of things, for which they themselves were largely responsible, had disastrous consequences, for in the epidemic of 1906 the chawls were so badly infected, that the people had to vacate them and live in huts made of bamboos and matting built on an adjoining piece of vacant ground.

These chawls have a population of about 4000 and no fewer than 57 cases of plague occurred amongst the inhabitants. At the time of the epidemic there was a considerable mortality amongst the rats in the chawls and several were proved on examination by us to be plague infected. In some of the rooms in which dead rats had been found and plague cases had occurred a very large number of rat fleas were obtained, 


\section{$784 \quad$ Sanitary Circumstances of Bombay}

in one instance 263 in a room, on guinea-pigs used as traps and placed in the rooms only after they had been "disinfected." (Vide these Reports Vol. vr. Table II. p. 482.) In two instances guinea-pigs used for this purpose died of plague.

\section{The Social Condition of the Population.}

The general experience of plague workers in Bombay has been that the incidence of the disease is not so great amongst the well-to-do classes as amongst the poorer population. Our own experience bears this out, and, moreover, we have collected certain statistical data which are in harmony with it.

It was considered that the social condition of the people might be indicated by classifying them according to the number of rooms in the house which they occupied. As a matter of fact, we are convinced from personal observation that for statistical purposes this criterion of social condition can be accepted as being approximately exact for Bombay. We have accordingly worked out the relative incidence of plague during the epidemic of 1906 on people who lived in houses of one room, two rooms, three rooms etc. In the accompanying table (XXIII.) are set forth the figures for the whole of Bombay. The figures referring to the population are taken from the census of 1901, the last available. A study of this table shows conclusively that the incidence of plague is greatest on the people inhabiting the smaller houses-one-roomed houses especially - and that the incidence becomes less as the number of rooms in the house becomes greater. We obtained confirmatory evidence of this from similar tables relating separately to 21 of the sections of the City.

It would appear then that the incidence of plague is greater on the poorer than on the well-to-do classes. When it is remembered that the poorer classes constitute the mass of the population-8.5\% of the total population living in one-roomed houses-it becomes necessary to consider why this should be so. Everything that has been written in this account applies to the poorer class of the population, namely, the buildings in which they live, their manner of living and, most important of all, the danger to which they are exposed from rats. It seems to us, then, that the explanation is to be found in the conditions in which they live and in their habits. 


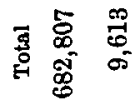

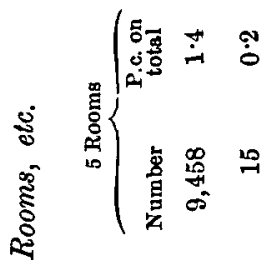

$$
\begin{aligned}
& \text { 象 }
\end{aligned}
$$

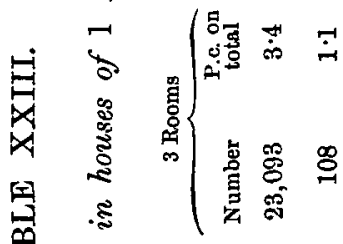

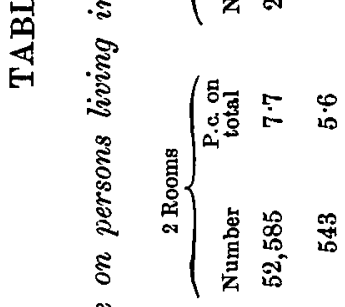

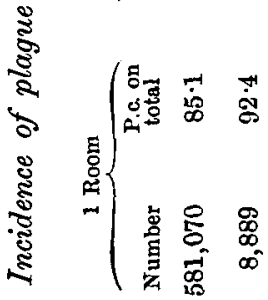

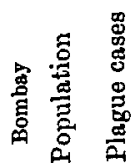




\section{Summary.}

From the considerations stated above we feel justified in coming to the conclusion that the insanitary conditions which exist in Bombay have no influence-at least none which acts directly-on the spread of epidemic plague.

While this is so, certain almost universal sanitary defects, notably the gully system and the construction of buildings, undoubtedly facilitate the diffusion of epizootic plague throughout the City, and thus indirectly influence the spread of the epidemic.

Even when the people live in well-constructed buildings free from sanitary defects and offering in themselves no shelter to rats, they still remain exposed to danger from rats in their houses. Mus rattus is attracted into such houses by the shelter afforded by the little disturbed property of the people, who themselves are quite indifferent to the presence of rats in their houses. 
The southern part of the section Fort North and South is occupied by better class offices and shops with dwelling houses above. The houses are much better built than in the northern quarter, which is a native residential area, with shops and a few godowns on the groundfloors. Buildings are mostly lofty. 


\section{MAP 2 \\ BOMBAY CITY \\ FORT NORTH AND SOUTH \\ October, I905}




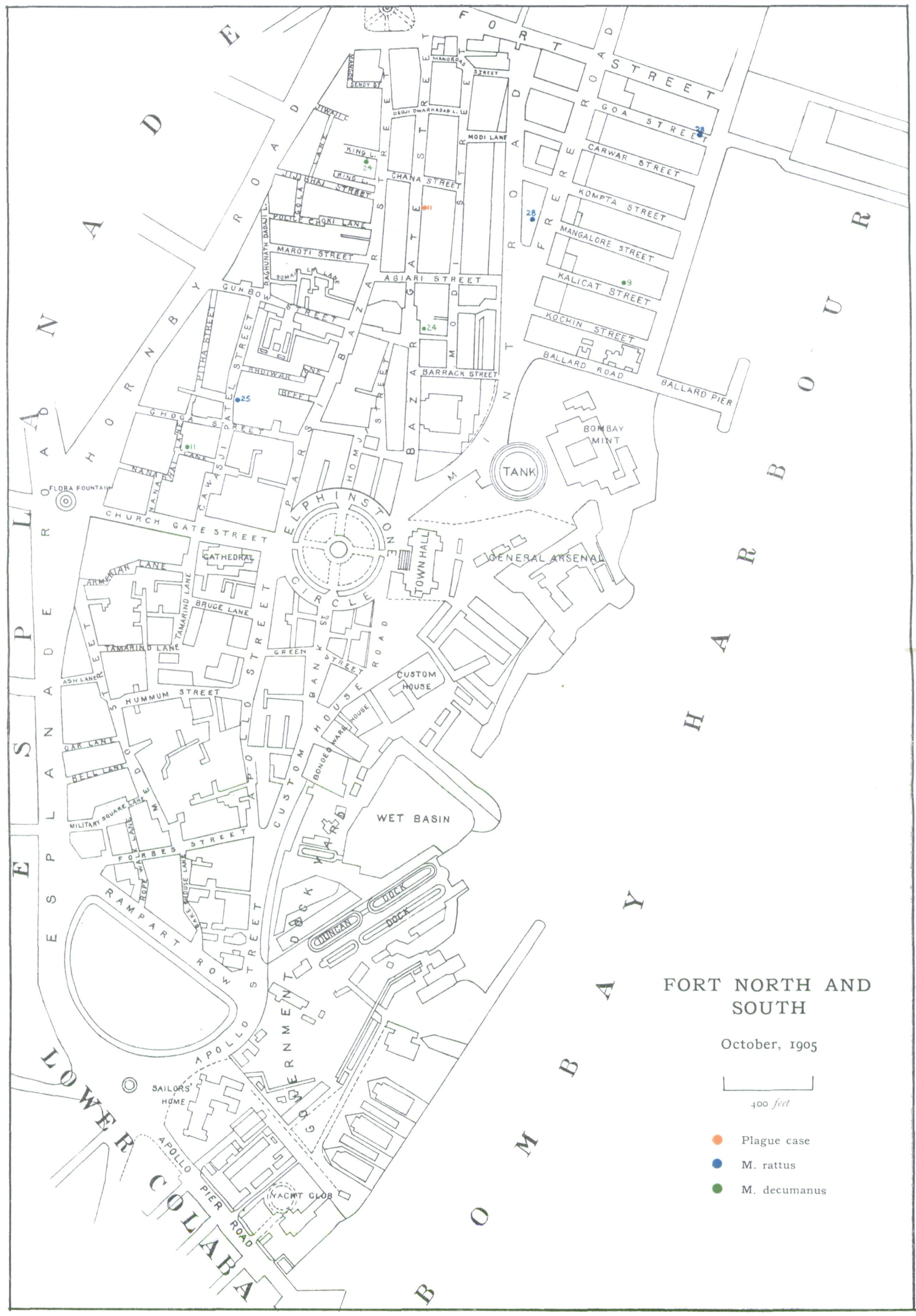




\section{MAP 3 \\ BOMBAY CITY \\ FORT NORTH AND SOUTH}

November, 1905 


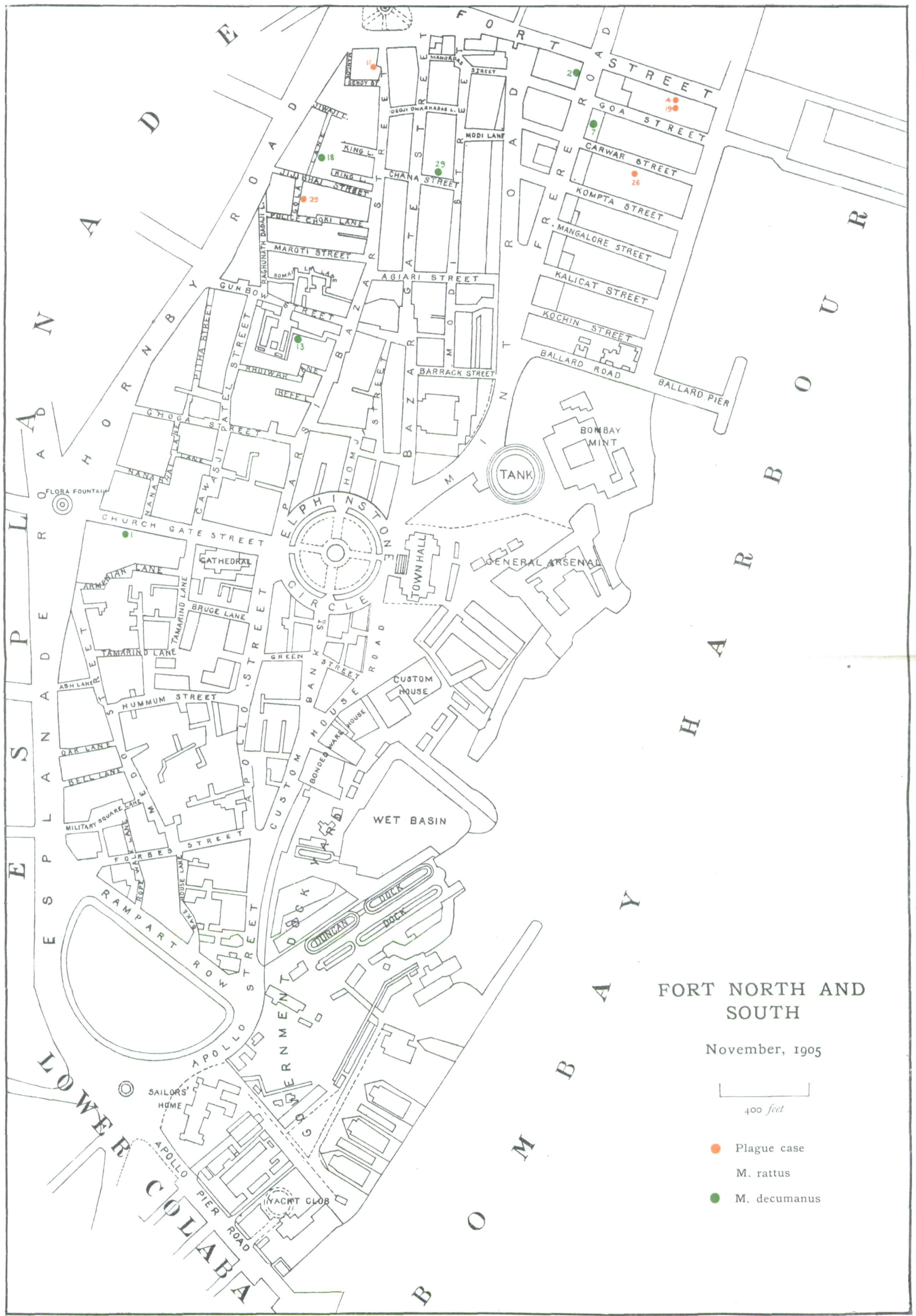




\author{
MAP 4 \\ BOMBAY CITY \\ FORT NORTH AND SOUTH
}

December, rgo5 


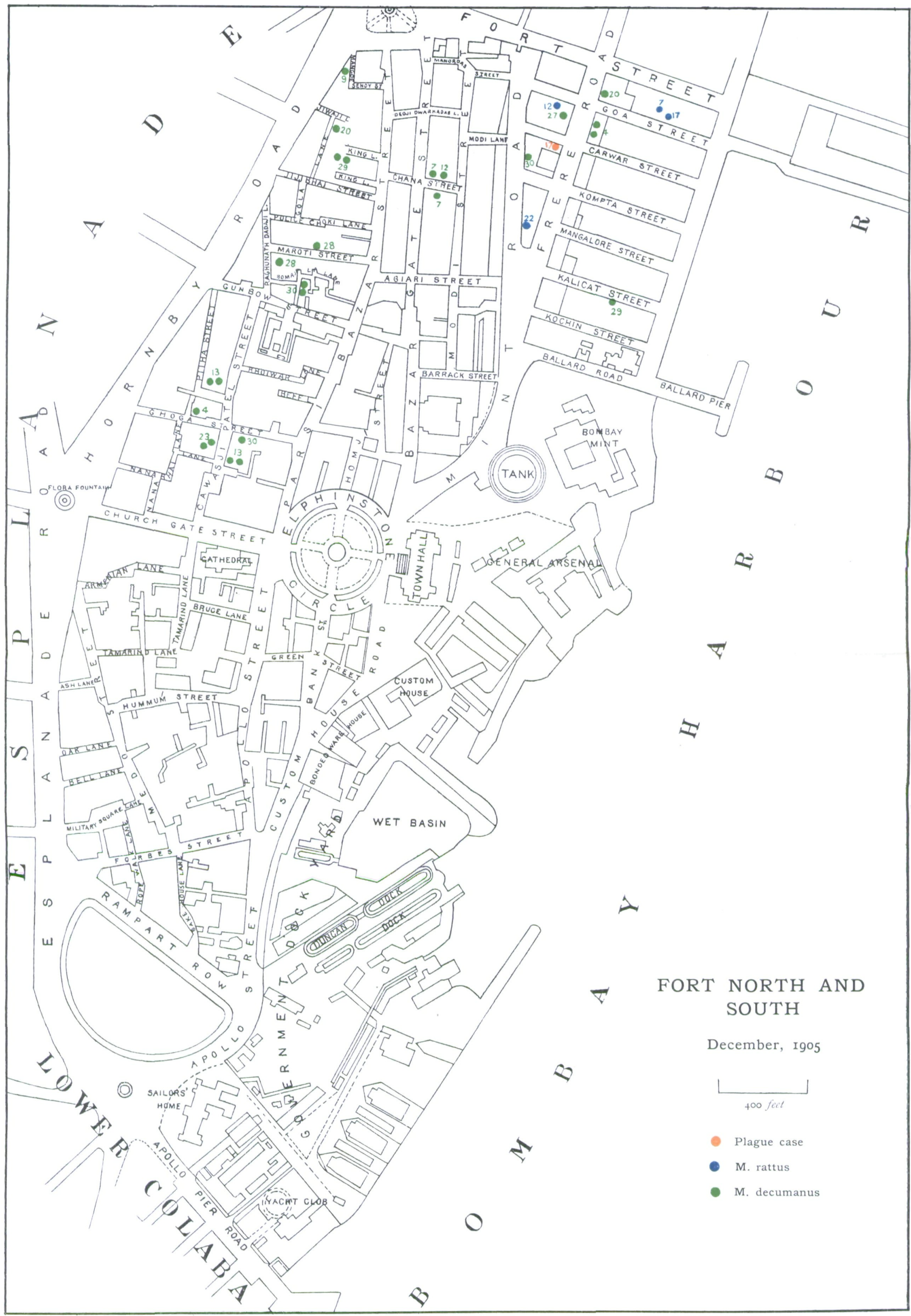




\author{
MAP 5 \\ BOMBAY CITY \\ FORT NORTH AND SOUTH \\ January, 1906
}




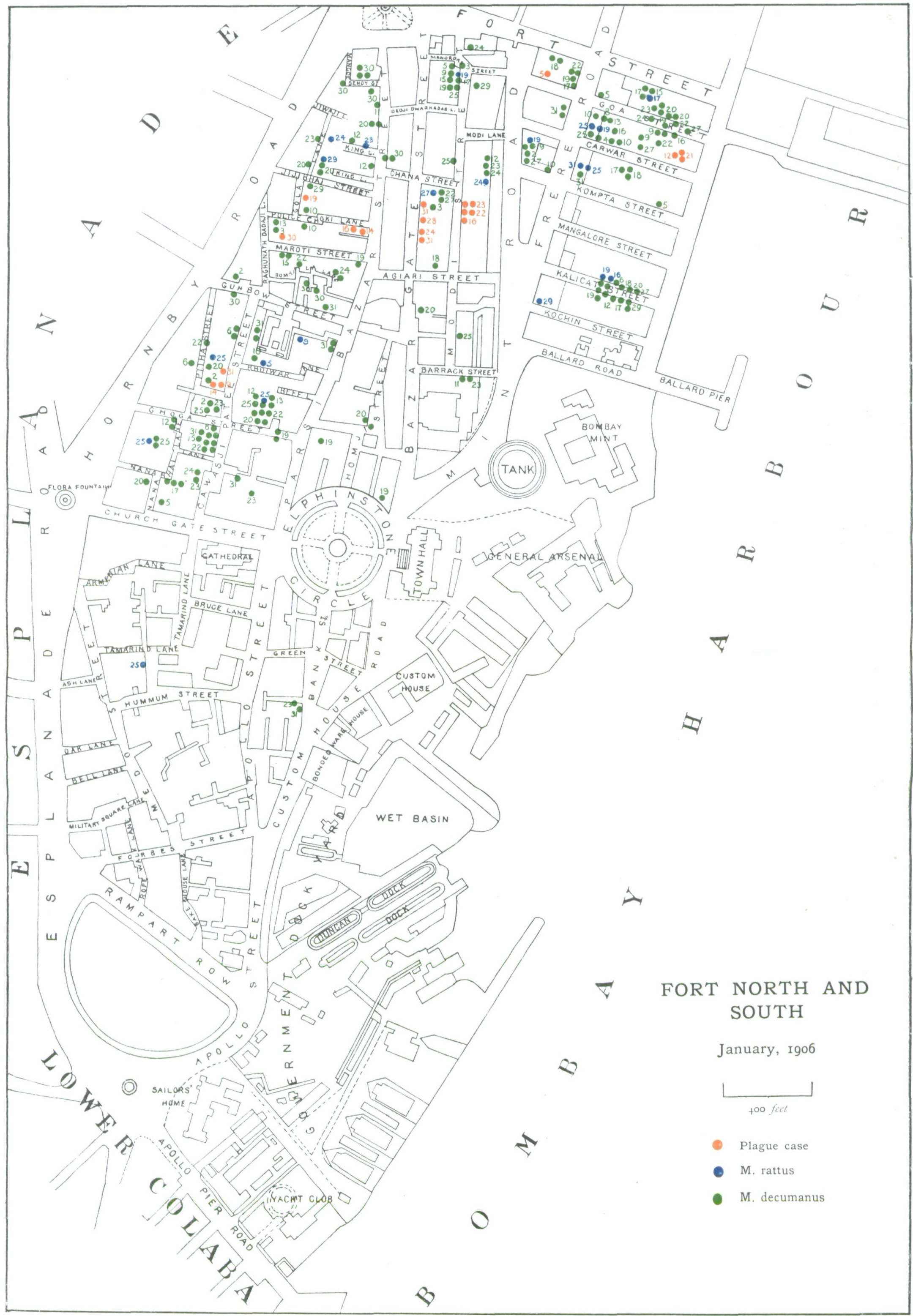


MAP 6

BOMBAY CITY

FORT NORTH AND SOUTH

February, I906 


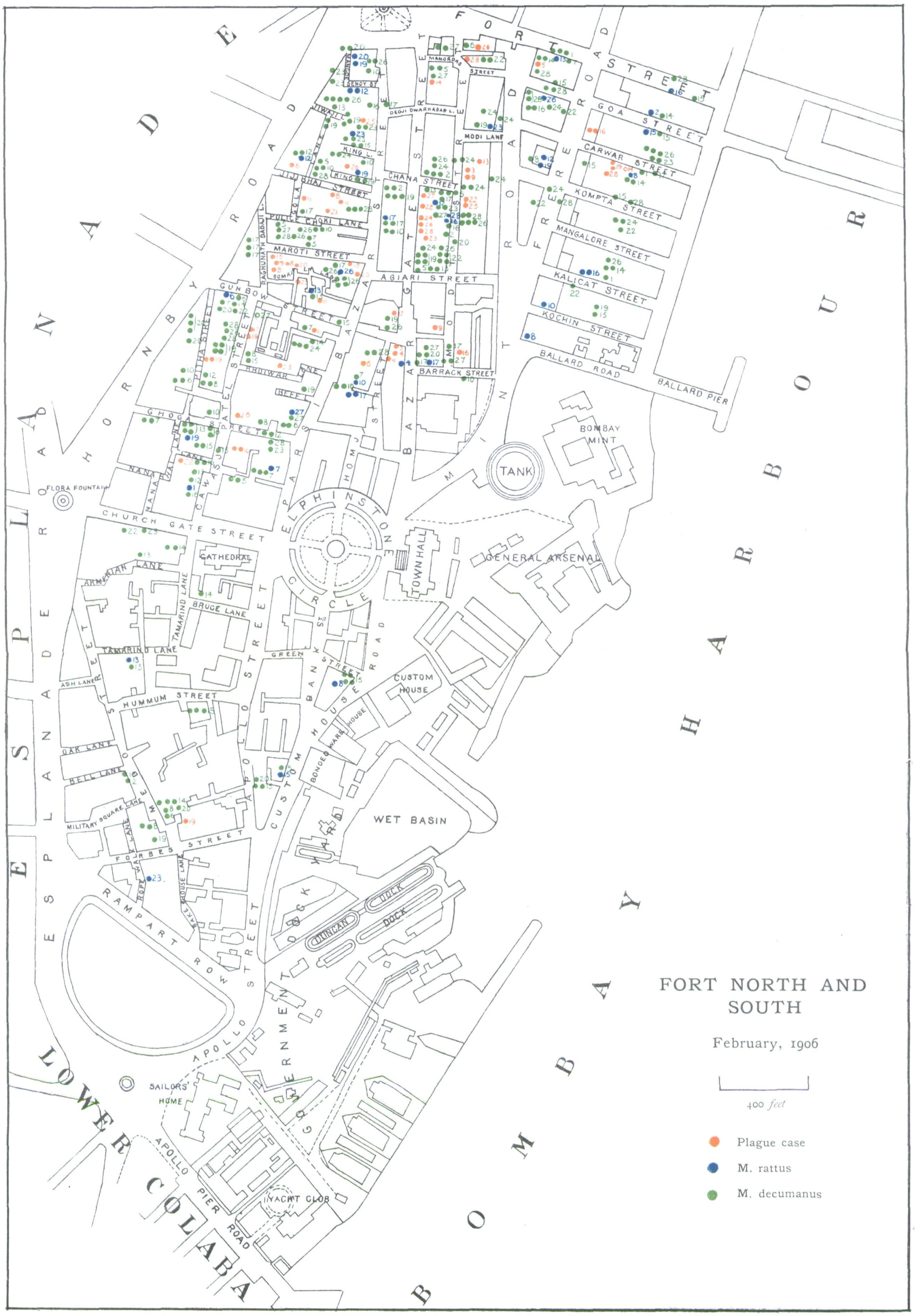




\section{MAP 7 \\ BOMBAY CITY \\ FORT NORTH AND SOUTH \\ March, I906}




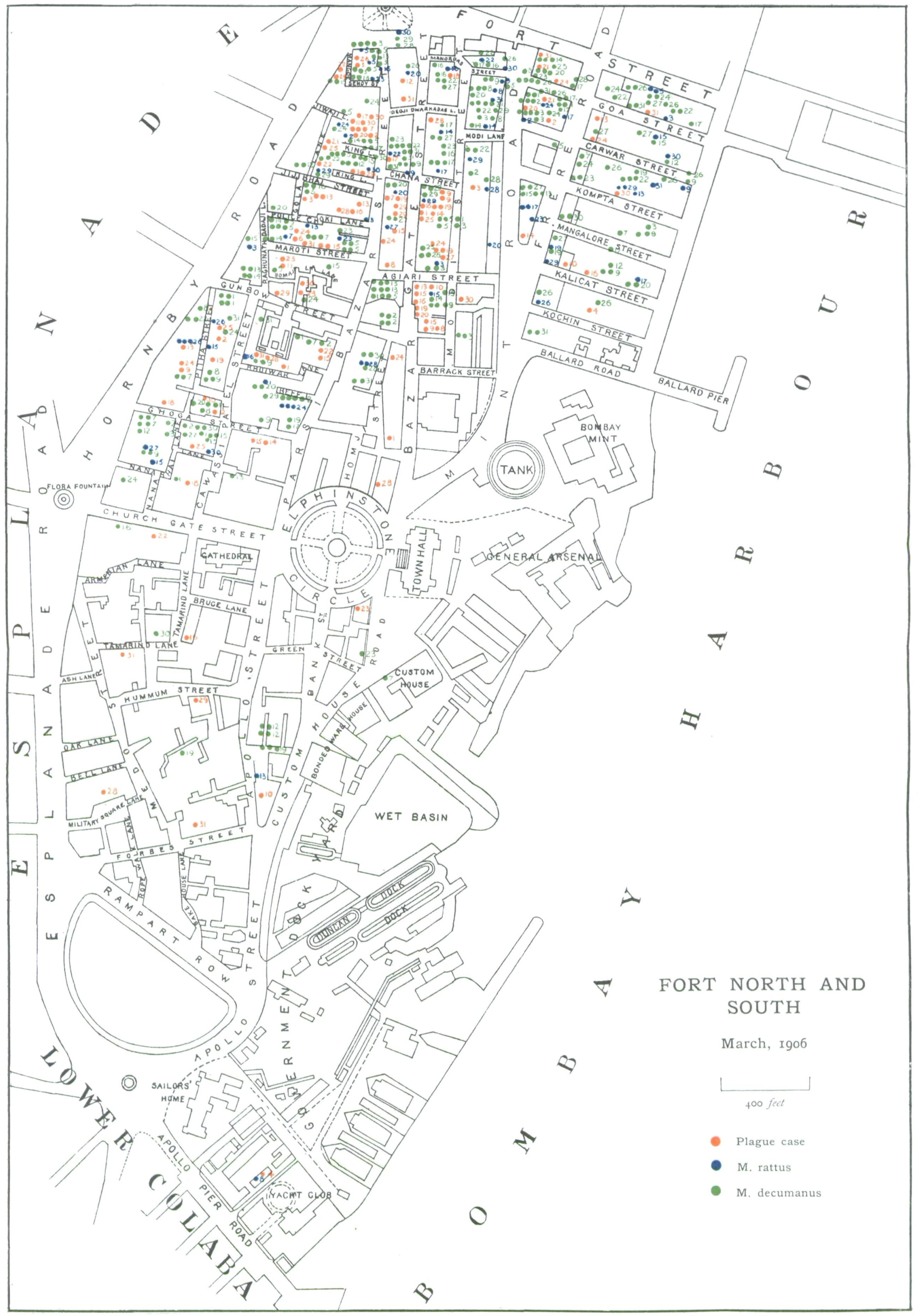




\section{MAP 8 \\ BOMBAY CITY \\ FORT NORTH AND SOUTH \\ April, 1906}


MAP 8

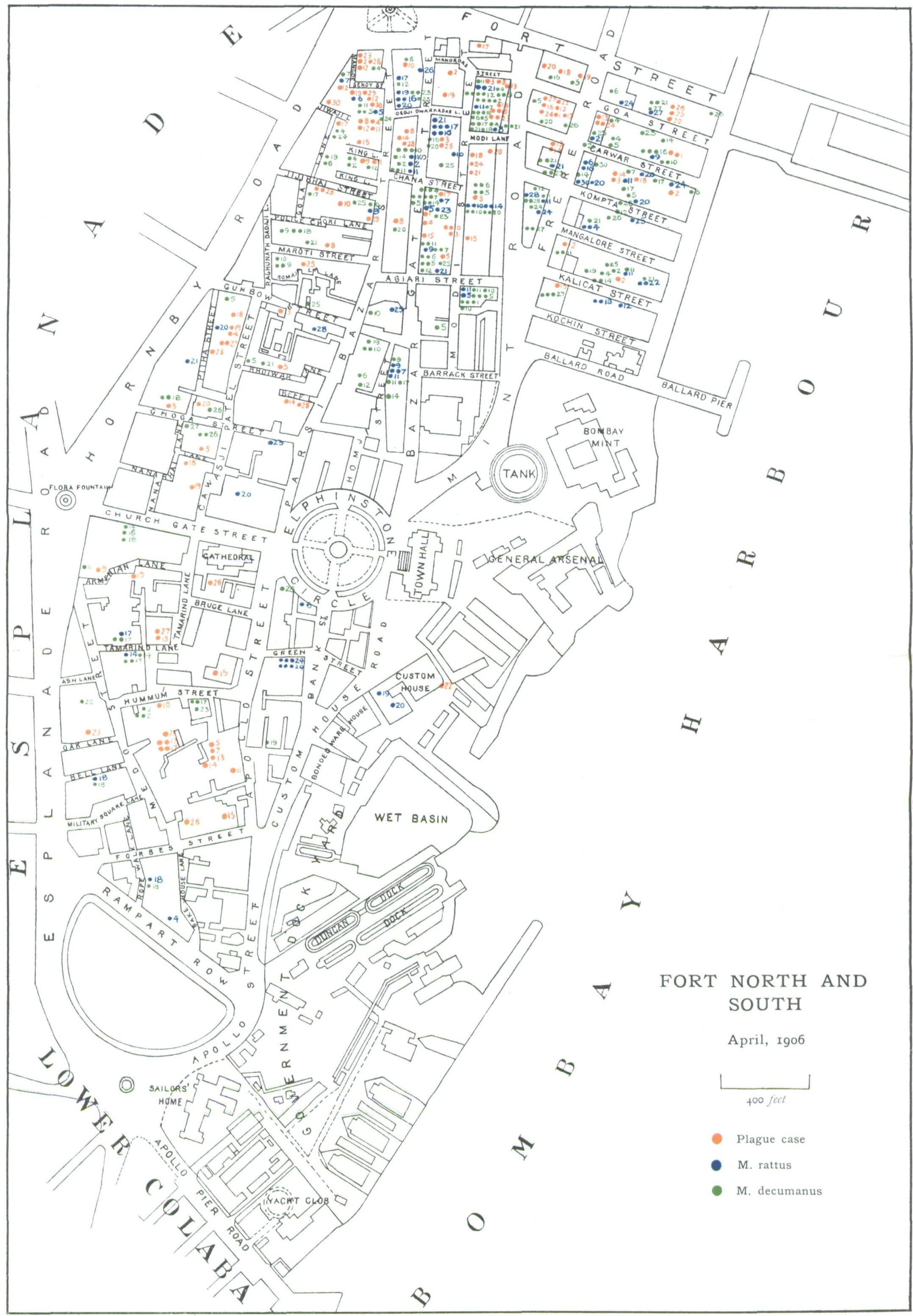


MAP 9

\section{BOMBAY CITY}

FORT NORTH AND SOUTH

May, 1906 


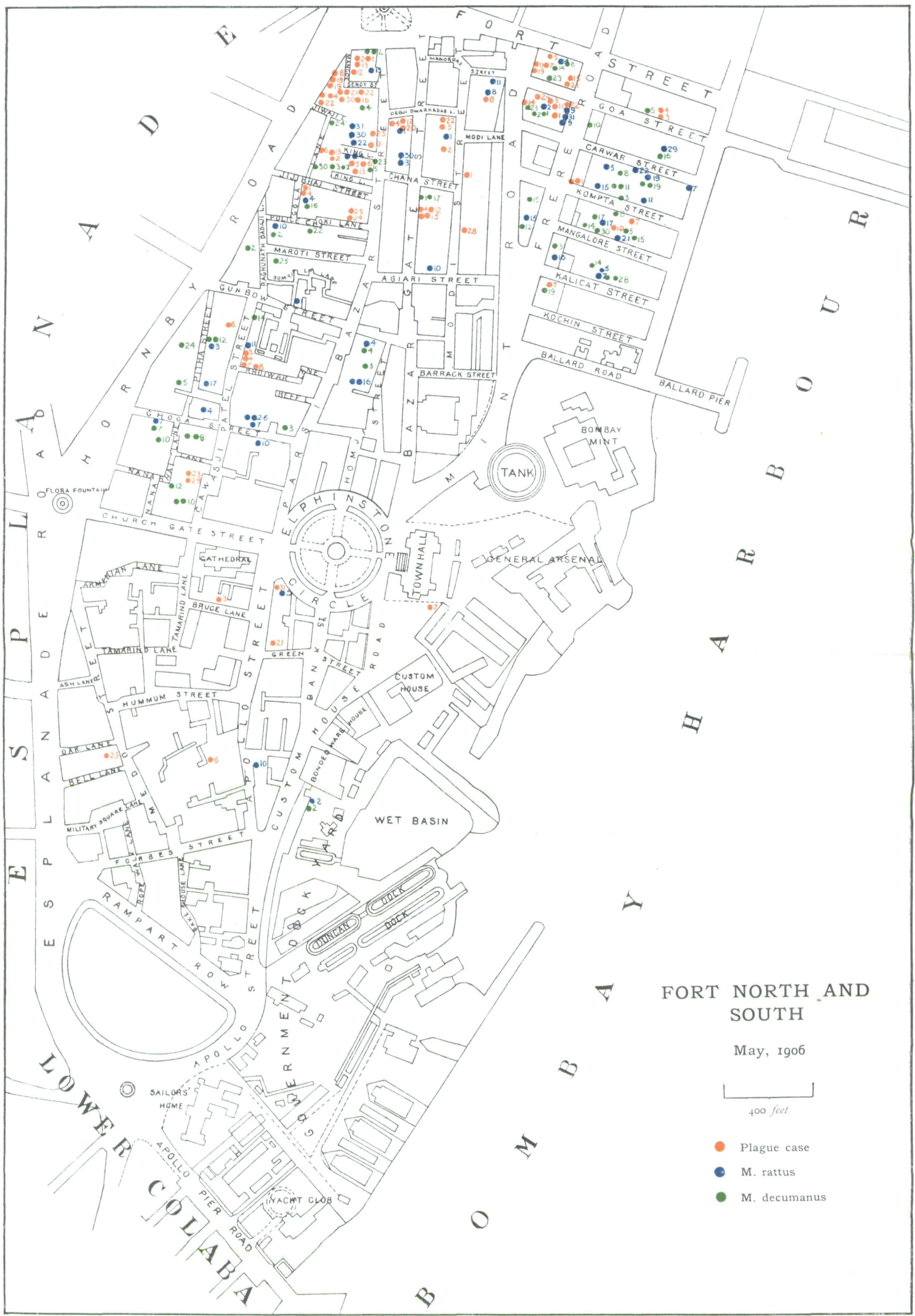




\section{MAP 10 \\ BOMBAY CITY \\ FORT NORTH AND SOUTH}

June, I9o6 


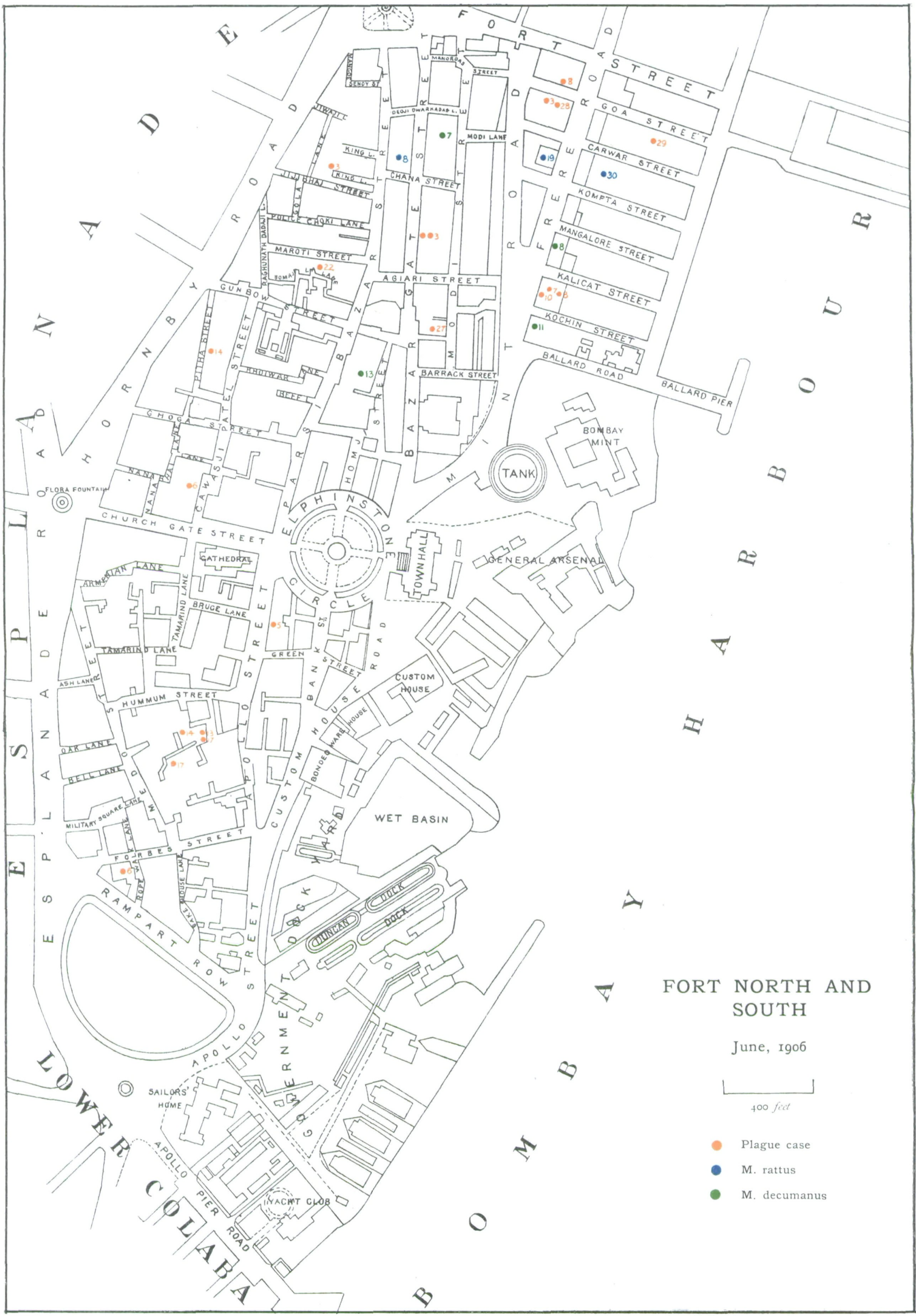


MAP 11

BOMBAY CITY

FORT NORTH AND SOUTH

July, 1906 


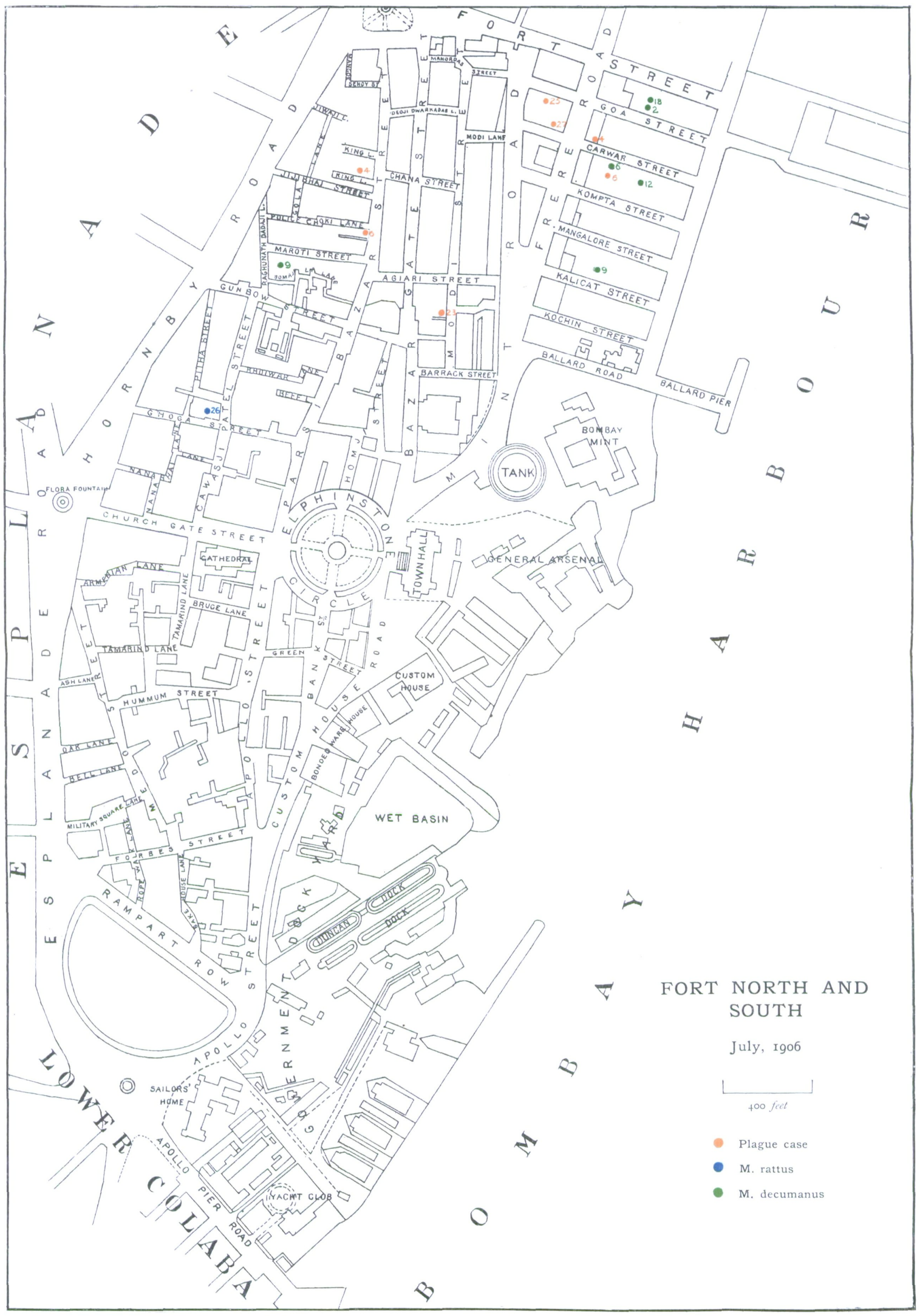




\section{MAP 12 \\ BOMBAY CITY \\ FORT NORTH AND SOUTH}

August, I906 


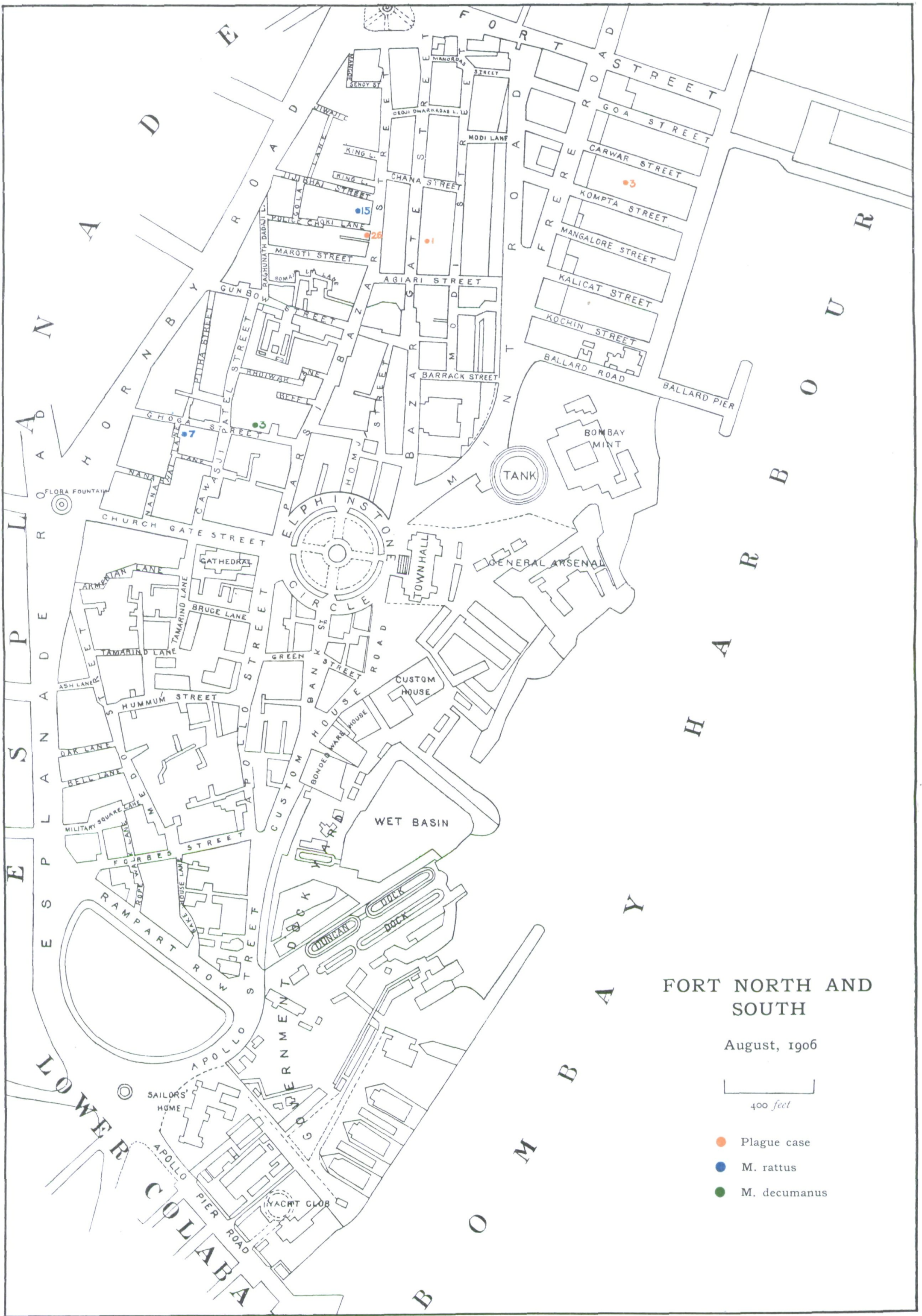


MAP 13

\section{BOMBAY CITY \\ FORT NORTH AND SOUTH}

September, Igo6 


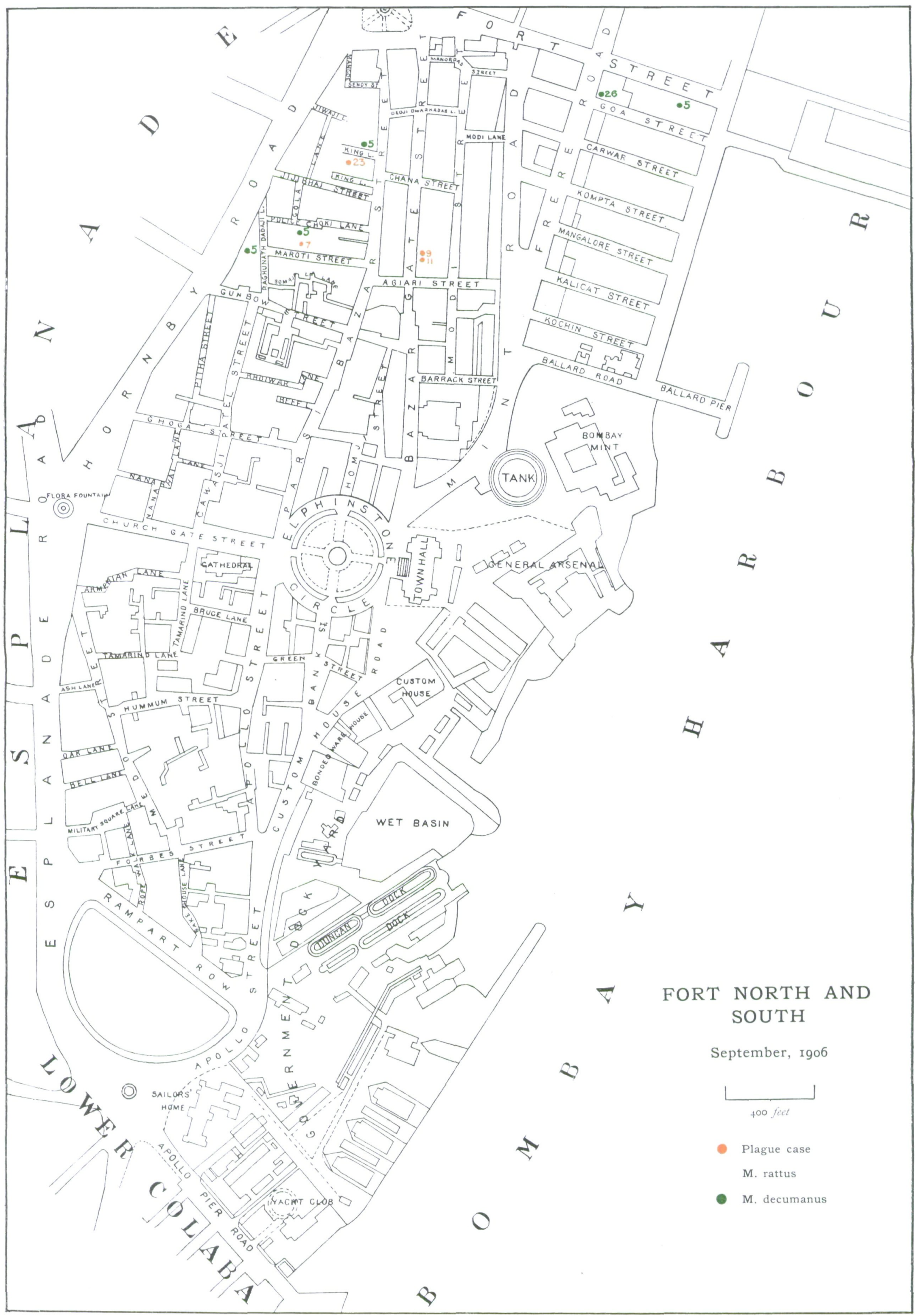




\section{APPENDIX I.}

Fort North and South.

Fortnightly periods

1 st to 14 th October

15 th to 28 th ",

29 th to 11 th November

12th to 25th

26 th to 9 th December

10th to 23 rd

24th to 6th January

7 th to 20 th ,"

21st to 3rd February

4th to 17 th

18th to 3rd March

4 th to 17 th,

18th to 31st ,,

1st to 14th April

15 th to 28 th ,,

29th to 12th May

13th to 26th ,,

27th to 9th June

10th to 23rd,

24th to 7 th July

8th to 21st ,,

22nd to 4th August

5th to 18th

19 th to 1st September

2nd to 15th

16 th to 29 th

1st to 14th October

15 th to 28 th "

29th to 11th November

12th to 25th

26th to 9th December

10th to 23rd

24 th to 6 th January

7 th to 20 th ",

21st to 3rd February

4 th to 17 th

\begin{tabular}{c} 
Plague \\
mortality \\
3 \\
0 \\
3 \\
1 \\
1 \\
7 \\
1 \\
2 \\
4 \\
6 \\
19 \\
38 \\
31 \\
44 \\
43 \\
59 \\
42 \\
19 \\
10 \\
8 \\
5 \\
1 \\
5 \\
0 \\
0 \\
2 \\
0 \\
\hline 13
\end{tabular}

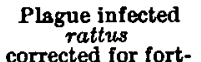

rattus
corrected for fortnight of 14 days

\section{0}

$2 \cdot 3$

0

0

0

$3 \cdot 5$

$4 \cdot 2$

$9 \cdot 4$

$17 \cdot 3$

$28 \cdot 2$

$25 \cdot 0$

$32 \cdot 7$

$51 \cdot 6$

$46 \cdot 2$

$57 \cdot 2$

$39 \cdot 7$

$17 \cdot 5$

$6 \cdot 8$

$1 \cdot 2$

$1 \cdot 4$

0

$1 \cdot 2$

4.2

0

0

$\frac{0}{13 \cdot 0}$

Mandvi.

\section{3}

3

2

2

8

3

3

5

11

15
Plague infected

decumanus

corrected for fort-
night of 14 days

$2 \cdot 3$

$2 \cdot 3$

$3 \cdot 7$

$2 \cdot 3$

$8 \cdot 2$

$11 \cdot 7$

$29 \cdot 4$

$93 \cdot 3$

$113 \cdot 2$

$164 \cdot 5$

$229 \cdot 8$

$198 \cdot 3$

$158 \cdot 9$

$156 \cdot 8$

$101 \cdot 5$

$43 \cdot 2$

$22 \cdot 2$

$10 \cdot 7$

$2 \cdot 3$

$2 \cdot 3$

$4 \cdot 7$

$1 \cdot 4$

0

0

$5 \cdot 8$

$\frac{1 \cdot 4}{52 \cdot 0}$ 
Fortnightly periods

18th to 3rd March

4 th to 17 th

18th to 31st,

1st to 14th April

15th to 28 th

29th to 12th May

13th to 26th ,,

27 th to 9 th June

10th to 23rd,

24th to 7th July

8 th to 21st ,"

22nd to 4th August

5 th to 18 th

19th to 1st September

2nd to 15th "

16 th to 29 th ,

1st to 14th October

15 th to 28th

29 th to 11 th November

12th to 25 th

26th to 9th December

10th to 23rd ",

24th to 6th January

7 th to 20 th

21st to 3rd February

4 th to 17th

18th to 3rd March

4 th to 17th ,"

18th to 31st,,

1st to 14th April

15th to 28th ",

29th to 12th May

13th to 26th ,

27th to 9th June

10th to 23rd ,"

24th to 7 th July

8 th to 21st ,

22nd to 4th August

5 th to 18 th

19th to 1st September

2 nd to 15 th

16 th to 29 th

\begin{tabular}{|c|}
\hline $\begin{array}{l}\text { Plague } \\
\text { mortality }\end{array}$ \\
\hline 30 \\
\hline 67 \\
\hline 61 \\
\hline 79 \\
\hline 118 \\
\hline 57 \\
\hline 26 \\
\hline 6 \\
\hline 9 \\
\hline 8 \\
\hline 0 \\
\hline 6 \\
\hline 6 \\
\hline 7 \\
\hline 8 \\
\hline 8 \\
\hline 21 \\
\hline
\end{tabular}

\section{Plague infected}

corrected for fort-

night of 14 days

$132 \cdot 1$

$205 \cdot 9$

$116 \cdot 7$

$100 \cdot 8$

$166 \cdot 9$

$105 \cdot 0$

$54 \cdot 8$

$30 \cdot 1$

$12 \cdot 8$

$16 \cdot 8$

$11 \cdot 7$

$7 \cdot 9$

$11 \cdot 2$

$31 \cdot 3$

$31 \cdot 5$

$\frac{30 \cdot 8}{52 \cdot 0}$

Plague infected

corrected for fort-

night of 14 days

$271 \cdot 8$

$209 \cdot 4$

$188 \cdot 5$

$133 \cdot 0$

$171 \cdot 5$

90.6

$50 \cdot 2$

$32 \cdot 4$

$30 \cdot 3$

$16 \cdot 6$

$7 \cdot 0$

$13 \cdot 3$

$36 \cdot 4$

$29 \cdot 9$

$45 \cdot 5$

$49 \cdot 0$

$88 \cdot 0$

\section{Chakla.}

\begin{tabular}{rcr}
3 & $1 \cdot 2$ & $3 \cdot 5$ \\
2 & $2 \cdot 3$ & $5 \cdot 8$ \\
1 & 0 & $2 \cdot 3$ \\
1 & 0 & $3 \cdot 5$ \\
0 & $2 \cdot 4$ & $11 \cdot 7$ \\
1 & $1 \cdot 2$ & $12 \cdot 8$ \\
0 & $1 \cdot 4$ & $22 \cdot 4$ \\
1 & $15 \cdot 1$ & $81 \cdot 7$ \\
10 & $19 \cdot 6$ & $168 \cdot 7$ \\
4 & $52 \cdot 5$ & $161 \cdot 7$ \\
4 & $46 \cdot 9$ & $231 \cdot 2$ \\
18 & $70 \cdot 5$ & $228 \cdot 7$ \\
59 & $80 \cdot 5$ & $205 \cdot 8$ \\
55 & $70 \cdot 0$ & $126 \cdot 0$ \\
82 & $58 \cdot 0$ & $101 \cdot 1$ \\
46 & $17 \cdot 5$ & $26 \cdot 8$ \\
15 & $8 \cdot 1$ & $15 \cdot 1$ \\
6 & $2 \cdot 8$ & $2 \cdot 8$ \\
4 & $1 \cdot 2$ & $7 \cdot 0$ \\
1 & $1 \cdot 2$ & $2 \cdot 3$ \\
2 & 0 & $4 \cdot 7$ \\
0 & $1 \cdot 4$ & $6 \cdot 1$ \\
0 & 0 & $7 \cdot 5$ \\
1 & $3 \cdot 5$ & $4 \cdot 9$ \\
1 & $1 \cdot 2$ & $1 \cdot 7$ \\
1 & $1 \cdot 4$ & $2 \cdot 8$ \\
\hline 12 & $17 \cdot 0$ & $55 \cdot 0$
\end{tabular}


Fortnightly periods

1st to 14th Oetober

15th to 28th ,"

29 th to 11 th November

12 th to 25 th

26th to 9th December

10th to 23rd,

24 th to 6 th January

7 th to 20 th ",

21st to 3rd February

4 th to 17 th ",

18th to 3rd March

4 th to 17 th ,"

18th to 31st ,

1st to 14th April

15th to 28 th ",

29th to 12th May

13th to 26th ",

27 th to 9 th June

10th to 23rd,,

24th to 7th July

8th to 21st.

22nd to 4th August

5th to 18th

19th to 1st September

2nd to 15th

\section{Market.}

\section{Plague
mortality}

4

0

0

0

0

0

2

3

2

6

6

12

26

75

71

98

75

35

11

4

2

1

2

1

1

16 th to 29 th ,

1st to 14th October

15th to 28th ,,

29th to 11th November

12 th to 25th

26 th to 9 th December

10th to 23rd ",

24th to 6th January

7 th to 20 th ,"

21st to 3rd February

4 th to 17 th

18th to 3rd March

4th to 17th,

18th to 31st,,

1st to 14th April

15th to 28th,

29th to 12th May

13th to 26th ,

Journ. of Hyg. vit

\begin{tabular}{|c|c|}
\hline $\begin{array}{l}\text { Plague infected } \\
\text { rattus } \\
\text { corrected for fort- } \\
\text { night of } 14 \text { days }\end{array}$ & $\begin{array}{l}\text { Plague infected } \\
\text { decumanus } \\
\text { corrected for fort- } \\
\text { night of } 14 \text { days }\end{array}$ \\
\hline 0 & $1 \cdot 2$ \\
\hline $1 \cdot 2$ & $2 \cdot 3$ \\
\hline $1 \cdot 2$ & 0 \\
\hline $1 \cdot 2$ & $3 \cdot 5$ \\
\hline $1 \cdot 2$ & $1 \cdot 2$ \\
\hline $1 \cdot 2$ & $7 \cdot 0$ \\
\hline 0 & $14 \cdot 0$ \\
\hline $1 \cdot 2$ & $25 \cdot 7$ \\
\hline $1 \cdot 4$ & $25 \cdot 2$ \\
\hline $8 \cdot 4$ & $55 \cdot 4$ \\
\hline $25 \cdot 7$ & $195 \cdot 1$ \\
\hline $43 \cdot 2$ & $244 \cdot 4$ \\
\hline $99 \cdot 6$ & $276 \cdot 5$ \\
\hline $93 \cdot 8$ & $163 \cdot 8$ \\
\hline $51 \cdot 3$ & $85 \cdot 2$ \\
\hline $15 \cdot 2$ & $15 \cdot 2$ \\
\hline $4 \cdot 7$ & $4 \cdot 7$ \\
\hline $1 \cdot 2$ & $2 \cdot 8$ \\
\hline 0 & $1 \cdot 2$ \\
\hline $1 \cdot 4$ & 0 \\
\hline 0 & $\mathbf{0}$ \\
\hline 0 & 0 \\
\hline $1 \cdot 2$ & 0 \\
\hline 0 & 0 \\
\hline 0 & 0 \\
\hline 0 & 0 \\
\hline $13 \cdot 0$ & $43 \cdot 0$ \\
\hline
\end{tabular}

Oomarkhadi.

$\begin{array}{rlr}3 & 2 \cdot 3 & 3 \cdot 5 \\ 1 & 1 \cdot 2 & 3 \cdot 5 \\ 1 & 0 & 3 \cdot 5 \\ 1 & 0 & 11 \cdot 6 \\ 0 & 0 & 9 \cdot 3 \\ 0 & 2 \cdot 3 & 14 \cdot 0 \\ 5 & 4 \cdot 2 & 72 \cdot 8 \\ 2 & 14 \cdot 0 & 122 \cdot 5 \\ 6 & 45 \cdot 0 & 308 \cdot 0 \\ 33 & 83 \cdot 1 & 319 \cdot 7 \\ 65 & 71 \cdot 9 & 297 \cdot 5 \\ 75 & 61 \cdot 2 & 279 \cdot 4 \\ 108 & 60 \cdot 4 & 129 \cdot 7 \\ 71 & 32 \cdot 2 & 54 \cdot 6 \\ 87 & 44 \cdot 4 & 57 \cdot 2 . \\ 65 & 10 \cdot 5 & 26 \cdot 9 \\ 18 & 8 \cdot 2 & 11 \cdot 7 \\ & & \end{array}$




Fortnightly periods
27th to 9th June
10th to 23rd ,"
24th to 7th July
8th to 21st ",
22nd to 4th August
5th to 18th
19th to 1st September
2nd to 15th ",
16th to 29th ,

1st to 14th October 15th to 28 th ," 29th to 11th November 12th to 25th 26th to 9th December 10th to 23 rd 24th to 6th January 7 th to 20 th 21st to 3rd February 4th to 17th 18th to 3rd March 4 th to 17 th , 18th to 31st 1st to 14th April 15th to 28th ,, 29 th to 12 th May 13th to 26th , 27th to 9th June 10th to 23rd ," 24th to 7 th July 8th to 21st ,, 22nd to 4th August 5 th to 18 th ,, 19th to 1st September 2nd to 15 th 16 th to 29 th ",

1st to 14th October 15 th to 28 th ," 29th to 11th November 12 th to 25 th 26th to 9th December 10th to 23rd 24th to 6th January 7 th to 20 th

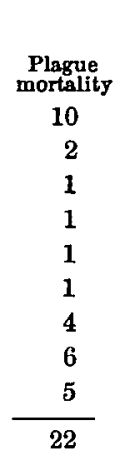

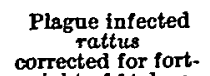
night of 14 days $7 \cdot 7$

$2 \cdot 4$

$6 \cdot 3$

$3 \cdot 5$

$2 \cdot 6$

$6 \cdot 1$

$8 \cdot 6$

$4 \cdot 7$

$\frac{2 \cdot 8}{18 \cdot 0}$

Dongri.

2

1

3

0

1

0

2

2

12

20

29

48

99

75

78

67

38

16

13

1

12

3

7

2

3

$\frac{2}{20}$

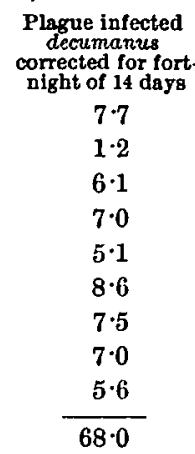

$3 \cdot 5$

$8 \cdot 2$

$1 \cdot 2$

$3 \cdot 5$

$4 \cdot 6$

3.5

$16 \cdot 8$

$29 \cdot 2$

$43 \cdot 6$

$159 \cdot 4$

$173 \cdot 6$

$160 \cdot 4$

$109 \cdot 4$

$49 \cdot 0$

$28 \cdot 0$

$19 \cdot 8$

$16 \cdot 6$

$6 \cdot 3$

$12 \cdot 8$

$1 \cdot 2$

$4 \cdot 6$

$10 \cdot 0$

$7 \cdot 7$

$7 \cdot 5$

$11 \cdot 7$

$\frac{9 \cdot 8}{34 \cdot 0}$

Dhobi Talao.

0

$2 \cdot 4$

$4 \cdot 6$

4.6

$25 \cdot 0$

$73 \cdot 5$ 


\section{Reports on Plague Investigations in India 791}

\begin{tabular}{|c|c|c|c|}
\hline Fortnightly periods & $\begin{array}{c}\text { Plague } \\
\text { mortality }\end{array}$ & $\begin{array}{l}\text { Plague infected } \\
\text { rattus } \\
\text { corrected for fort- } \\
\text { night of } 14 \text { days }\end{array}$ & $\begin{array}{l}\text { Plague infected } \\
\text { decumanus } \\
\text { corrected for fort- } \\
\text { night of } 14 \text { days }\end{array}$ \\
\hline 21st to 3rd February. & 7 & $11 \cdot 4$ & $142 \cdot 6$ \\
\hline 4th to 17 th $\quad "$ & 20 & $7 \cdot 5$ & $259 \cdot 0$ \\
\hline 18th to 3rd March & 34 & $37 \cdot 2$ & $225 \cdot 2$ \\
\hline 4th to 17 th & 63 & $45 \cdot \tilde{5}$ & $228 \cdot 0$ \\
\hline 18th to 31st $"$ & 96 & $39 \cdot 9$ & $227 \cdot 5$ \\
\hline 1st to 14th April & 70 & $37 \cdot 4$ & $131 \cdot 6$ \\
\hline 15th to 28 th, & 96 & $26 \cdot 8$ & $95 \cdot 6$ \\
\hline 29th to 12th May & 62 & $10 \cdot 5$ & $29 \cdot 2$ \\
\hline 13th to 26th , & 36 & 10.5 & $9 \cdot 4$ \\
\hline 27th to 9th June & 10 & $2 \cdot 8$ & $8 \cdot 6$ \\
\hline 10th to $23 \mathrm{rd}$ & 3 & 0 & $1 \cdot 2$ \\
\hline 24th to 7 th July & 1 & 0 & $4 \cdot 9$ \\
\hline 8th to 21st , & 2 & 0 & 0 \\
\hline 22nd to 4th August & 3 & 0 & 0 \\
\hline 5th to 18 th $\quad "$ & 0 & 0 & $1 \cdot 2$ \\
\hline 19th to 1st September & 3 & 0 & 0 \\
\hline 2nd to 15th & 1 & 0 & $1 \cdot 7$ \\
\hline 16th to 29 th & 3 & 0 & 0 \\
\hline & 20 & $9 \cdot 0$ & $56 \cdot 0$ \\
\hline \multicolumn{4}{|c|}{ Bhuleshwar. } \\
\hline 1st to 14th October & 4 & 0 & $4 \cdot 6$ \\
\hline 15th to 28 th & 2 & $1 \cdot 2$ & $1 \cdot 2$ \\
\hline 29th to 11th November & 0 & $2 \cdot 3$ & $2 \cdot 3$ \\
\hline 12th to 25 th & 1 & 0 & $11 \cdot 7$ \\
\hline 26th to 9th December & 0 & 0 & $19 \cdot 8$ \\
\hline 10th to $23 r d$ & 1 & $2 \cdot 3$ & $28 \cdot 0$ \\
\hline 24th to 6th January & 2 & $7 \cdot 0$ & $51 \cdot 8$ \\
\hline 7 th to 20 th & 2 & $15 \cdot 2$ & $86 \cdot 3$ \\
\hline 21st to 3rd February & 9 & $20 \cdot 8$ & $127 \cdot 9$ \\
\hline 4th to 17 th $"$ & 11 & $48 \cdot 1$ & $256 \cdot 0$ \\
\hline 18th to 3rd March & 34 & $73 \cdot 4$ & 350.5 \\
\hline 4th to 17 th & 85 & $112 \cdot 5$ & $365 \cdot 2$ \\
\hline 18th to 31st ", & 133 & $92 \cdot 4$ & $258 \cdot 8$ \\
\hline 1st to 14th April & 104 & $49 \cdot 0$ & $114 \cdot 8$ \\
\hline 15th to 28 th & 104 & $54 \cdot 8$ & $66 \cdot 5$ \\
\hline 29th to 12th May & 73 & $24 \cdot 5$ & $25 \cdot 7$ \\
\hline 13th to 26th & 44 & $12 \cdot 9$ & $9 \cdot 3$ \\
\hline 27th to 9th June & 20 & $2 \cdot 8$ & $1 \cdot 4$ \\
\hline 10 th to $23 \mathrm{rd} n$ & 4 & $1 \cdot 2$ & $2 \cdot 3$ \\
\hline 24 th to 7 th July & 4 & 0 & $1 \cdot 2$ \\
\hline 8th to 21st & 1 & $2 \cdot 4$ & $4 \cdot 7$ \\
\hline 22nd to 4th August & 1 & $1 \cdot 4$ & $4 \cdot 7$ \\
\hline 5th to 18th ", & 1 & $4 \cdot 0$ & $4 \cdot 0$ \\
\hline 19th to 1st September & 2 & $1 \cdot 2$ & $2 \cdot 3$ \\
\hline 2nd to 15 th & 2 & $1 \cdot 2$ & 0 \\
\hline \multirow[t]{2}{*}{ 16th to 29 th } & 5 & 1.4 & $2 \cdot 8$ \\
\hline & 24 & $20 \cdot 0$ & $69 \cdot 0$ \\
\hline
\end{tabular}


Fortnightly periods

1st to 14th October

15th to 28th ,"

29 th to 11 th November

12 th to 25 th

26th to 9th December

10th to 23rd ",

24 th to 6th January

7 th to 20 th "

21st to 3rd February

4th to 17th

18th to 3rd March

4 th to 17th ,,

18th to 31st ,,

1st to 14th April

15 th to 28 th ,"

29th to 12th May

13th to 26th

27th to 9th June

10th to 23rd

24th to 7th July

8th to 21st ,

22nd to 4th August

5 th to 18 th

19th to 1st September

2nd to 15th

16 th to 29 th

1st to 14th October

15 th to 28 th

29 th to 11 th November

12 th to 25 th

26th to 9th December

10th to 23rd ",

24th to 6th January

7 th to 20 th

,

21st to 3rd February

4 th to 17 th

18 th to 3rd March

4 th to 17th, ,

18th to 31st,

1st to 14th April

15 th to 28 th ,"
Fanaswadi.

\begin{tabular}{|c|c|c|}
\hline$\underset{\text { mortality }}{\text { Plague }}$ & $\begin{array}{l}\text { Plague infected } \\
\text { rattus } \\
\text { corrected for fort- } \\
\text { night of } 14 \text { days }\end{array}$ & $\begin{array}{l}\text { Plague infected } \\
\text { decumanus } \\
\text { corrected for fort. } \\
\text { night of } 14 \text { days }\end{array}$ \\
\hline 2 & o & $2 \cdot 3$ \\
\hline 1 & $\mathbf{0}$ & 0 \\
\hline 0 & o & 0 \\
\hline 1 & 0 & $1 \cdot 2$ \\
\hline 0 & 0 & 0 \\
\hline 0 & 0 & 0 \\
\hline 0 & 0 & $4 \cdot 2$ \\
\hline 1 & $1 \cdot 2$ & $8 \cdot 1$ \\
\hline 6 & $1 \cdot 2$ & $40 \cdot 7$ \\
\hline 19 & $11 \cdot 9$ & $40 \cdot 7$ \\
\hline 18 & $14 \cdot 7$ & $35 \cdot 6$ \\
\hline 37 & $19 \cdot 2$ & $45 \cdot 5$ \\
\hline 61 & $14 \cdot 9$ & $61 \cdot 8$ \\
\hline 64 & $7 \cdot 0$ & $57 \cdot 4$ \\
\hline 93 & $15 \cdot 2$ & $30 \cdot 3$ \\
\hline 79 & $4 \cdot 7$ & $14 \cdot 0$ \\
\hline 29 & $2 \cdot 4$ & $8 \cdot 2$ \\
\hline 13 & $2 \cdot 6$ & $1 \cdot 4$ \\
\hline 8 & 0 & 0 \\
\hline 1 & 0 & 0 \\
\hline 5 & $\mathbf{0}$ & $1 \cdot 2$ \\
\hline 2 & 0 & 1.2 \\
\hline 2 & 0 & 0 \\
\hline $\mathbf{1}$ & 0 & $1 \cdot 2$ \\
\hline 0 & 0 & 0 \\
\hline 2 & 0 & 0 \\
\hline 17 & $\overline{3 \cdot 0}$ & $13 \cdot 0$ \\
\hline
\end{tabular}

Khara Talao.

$\begin{array}{rlr}0 & 2 \cdot 4 & 4 \cdot 7 \\ 0 & 0 & 0 \\ 0 & 0 & 6 \cdot 8 \\ 1 & 2 \cdot 3 & 16 \cdot 4 \\ 0 & 2 \cdot 3 & 9 \cdot 3 \\ 0 & 1 \cdot 2 & 22 \cdot 1 \\ 0 & 8 \cdot 4 & 46 \cdot 2 \\ 1 & 12 \cdot 9 & 74 \cdot 6 \\ 3 & 16 \cdot 8 & 165 \cdot 7 \\ 6 & 36 \cdot 9 & 216 \cdot 5 \\ 28 & 43 \cdot 4 & 190 \cdot 2 \\ 25 & 39 \cdot 7 & 123 \cdot 7 \\ 59 & 29 \cdot 9 & 78 \cdot 4 \\ 53 & 15 \cdot 4 & 51 \cdot 8 \\ 60 & 12 \cdot 9 & 37 \cdot 3\end{array}$


nightly periods

29th to 12th May

13th to 26th ,"

27th to 9th June

10 th to $23 r d$,

24th to 7 th July

8 th to 21st,

22nd to 4th August

5 th to $18 \mathrm{th}$

19 th to 1 st September

2nd to 15th

Plague infected

Plague
mortality

rattus

corrected for fort-
night of 14 days

Plague infected

decumanus

corrected for fort.

35

$8 \cdot 2$

night of 14 days

16 th to 29 th

",

26

$5 \cdot 9$

$17 \cdot 5$

9

$\mathbf{9} \cdot \mathbf{3}$

$6 \cdot 1$

$11 \cdot 0$

$2 \cdot 4$

$5 \cdot 8$

$12 \cdot 1$

$2 \cdot 3$

$4 \cdot 7$

$2 \cdot 3$

$9 \cdot 1$

4. 0

$4 \cdot 0$

$10 \cdot 3$

$\begin{array}{r}1 \\ 3 \\ 5 \\ \hline 12\end{array}$

\begin{tabular}{c}
$1 \cdot 2$ \\
0 \\
0 \\
\hline $10 \cdot 0$
\end{tabular}

$7 \cdot 0$

$\frac{1 \cdot 4}{43 \cdot 0}$

Khumbharwada.

1st to 14th October

15 th to 28th ,"

29 th to 11th November

\begin{tabular}{rlc}
3 & 0 & $2 \cdot 4$ \\
0 & 0 & 0 \\
1 & 0 & $2 \cdot 3$ \\
0 & 0 & $2 \cdot 4$ \\
1 & 0 & $8 \cdot 2$ \\
1 & $1 \cdot 2$ & $9 \cdot 4$ \\
2 & $1 \cdot 4$ & $15 \cdot 4$ \\
1 & $2 \cdot 3$ & $28 \cdot 0$ \\
1 & $7 \cdot 0$ & $45 \cdot 5$ \\
2 & $12 \cdot 4$ & $111 \cdot 1$ \\
20 & $29 \cdot 4$ & $180 \cdot 1$ \\
30 & $30 \cdot 3$ & $197 \cdot 2$ \\
64 & $49 \cdot 2$ & $156 \cdot 3$ \\
75 & $43 \cdot 4$ & $130 \cdot 2$ \\
74 & $43 \cdot 2$ & $91 \cdot 0$ \\
54 & $17 \cdot 5$ & $26 \cdot 9$ \\
26 & $4 \cdot 7$ & $8 \cdot 2$ \\
5 & $1 \cdot 4$ & $2 \cdot 8$ \\
1 & $1 \cdot 2$ & 0 \\
0 & 0 & $9 \cdot 3$ \\
0 & 0 & $1 \cdot 2$ \\
1 & 0 & 0 \\
0 & $1 \cdot 2$ & $2 \cdot 3$ \\
0 & $1 \cdot 4$ & $1 \cdot 4$ \\
0 & $1 \cdot 7$ & 0 \\
1 & 0 & $1 \cdot 4$ \\
\hline 14 & $9 \cdot 0$ & $39 \cdot 0$
\end{tabular}


Fortnightly periods

1st to 14th October

15 th to 28 th ,"

29th to 11th November

12 th to 25 th ,"

26th to 9th December

10th to 23rd ,

24th to 6th January

7 th to 20th ",

21st to 3rd February

4th to 17 th

18th to 3rd March

4 th to 17 th ,"

18th to 31st ,,

1st to 14th April

15 th to 28 th ,"

29th to 12th May

13th to 26 th ,"

27 th to 9 th June

10th to 23rd,

24 th to 7 th July

8 th to 21st ,,

22nd to 4th August

5 th to 18 th ",

19 th to 1 st September

2nd to 15 th ",

16 th to 29 th "
Khetwadi.

\begin{tabular}{ccc}
$\begin{array}{c}\text { Plague } \\
\text { mortality }\end{array}$ & $\begin{array}{c}\text { Plague infected } \\
\text { rattus } \\
\text { corrected for fort- } \\
\text { night of 14 days }\end{array}$ & $\begin{array}{c}\text { Plague infected } \\
\text { decumanus } \\
\text { corrected for fort } \\
\text { night of 14 days }\end{array}$ \\
0 & 0 & 0 \\
0 & 0 & 0 \\
0 & $1 \cdot 4$ & 0 \\
0 & 0 & 0 \\
1 & 0 & 0 \\
0 & 0 & 0 \\
0 & 0 & 0 \\
0 & 0 & $4 \cdot 7$ \\
1 & $2 \cdot 6$ & $5 \cdot 1$ \\
2 & $1 \cdot 2$ & $11 \cdot 4$ \\
10 & $3 \cdot 7$ & $23 \cdot 1$ \\
14 & $1 \cdot 2$ & $25 \cdot 7$ \\
53 & $9 \cdot 1$ & $56 \cdot 9$ \\
55 & $11 \cdot 2$ & $51 \cdot 8$ \\
58 & $15 \cdot 2$ & $22 \cdot 1$ \\
39 & $5 \cdot 9$ & $14 \cdot 0$ \\
19 & $3 \cdot 5$ & $1 \cdot 2$ \\
3 & 0 & $1 \cdot 4$ \\
4 & 0 & 0 \\
2 & 0 & 0 \\
3 & 0 & 0 \\
0 & 0 & 0 \\
1 & 0 & 0 \\
1 & 0 & 0 \\
1 & 0 & 0 \\
2 & 0 & 0 \\
\hline 10 & $2 \cdot 0$ & $8 \cdot 0$ \\
& 0 &
\end{tabular}

\section{APPENDIX II.}

\section{REPORT ON 'CERTAIN PLAGUE STATISTICS.}

BY M. GREENWOOD, JR., M.R.C.S., L.R.C.P.

(London Hospital Medical School.)

For the purposes of this investigation I was supplied with the following data: (1) return of all cases of human plague in Bombay for 68 periods of one week: (2) return of total numbers of $M$. rattus brought in and number affected with plague during the same period: (3) the same for $M$. decumanus ${ }^{1}$.

I was requested to determine : (1) what statistical relationship exists between plague in rats and plague in man : (2) whether, supposing such relationship to exist,

1 The crude figures shọn in Table XXIV were used, except that short weeks were corrected to six days. 


\section{BOMBAY IV}

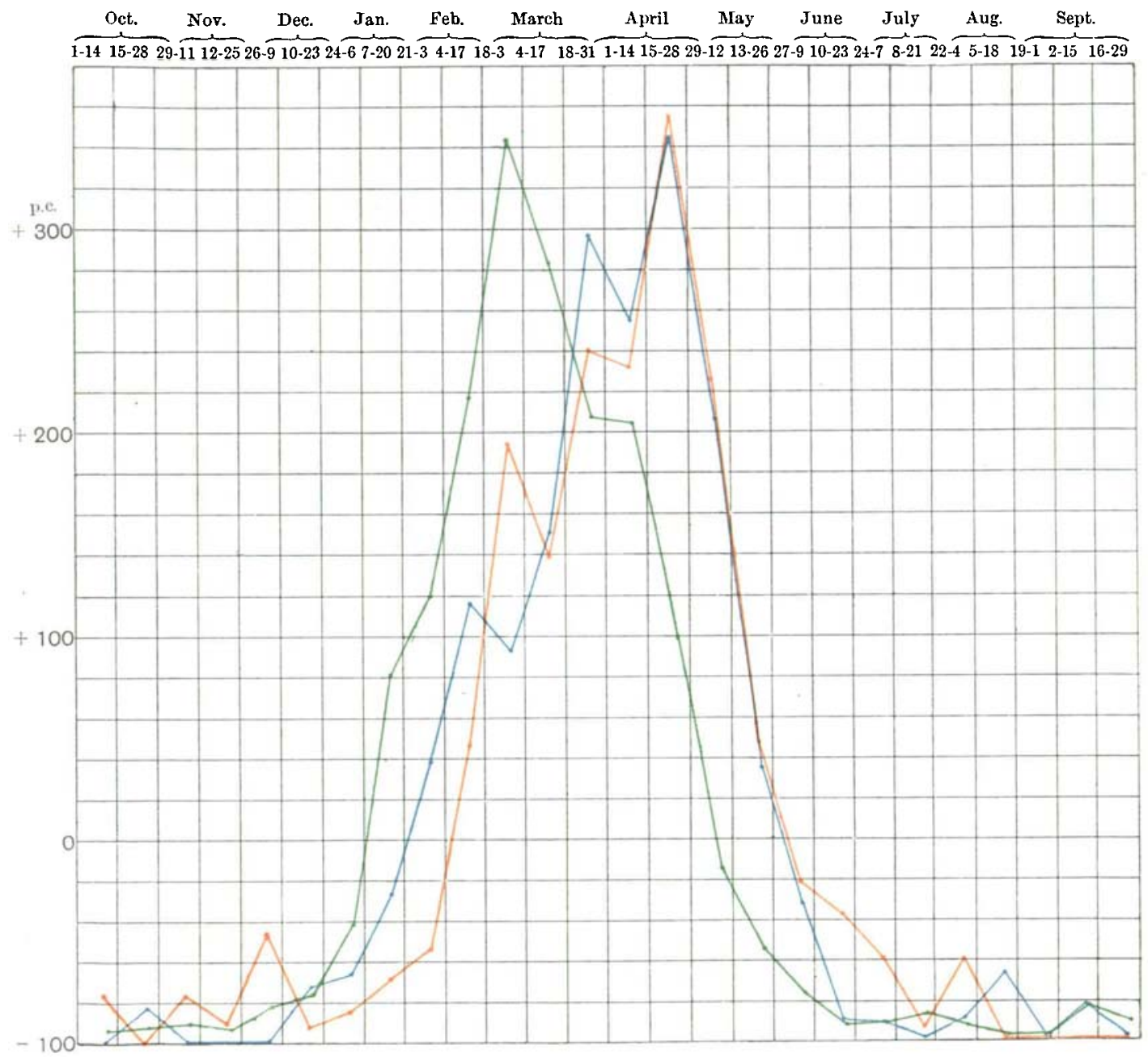

FORT NORTH AND SOUTH

October, I905 to September, Ig06

\footnotetext{
Plague infected decumanus

Plague infected rattus

Human plague deaths
} 


\section{BOMBAY V}

Oct. Nov. Dec. Jan. Feb. March April May June July Aug. Sept.

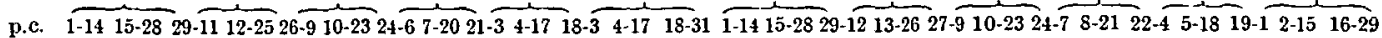
$+500$

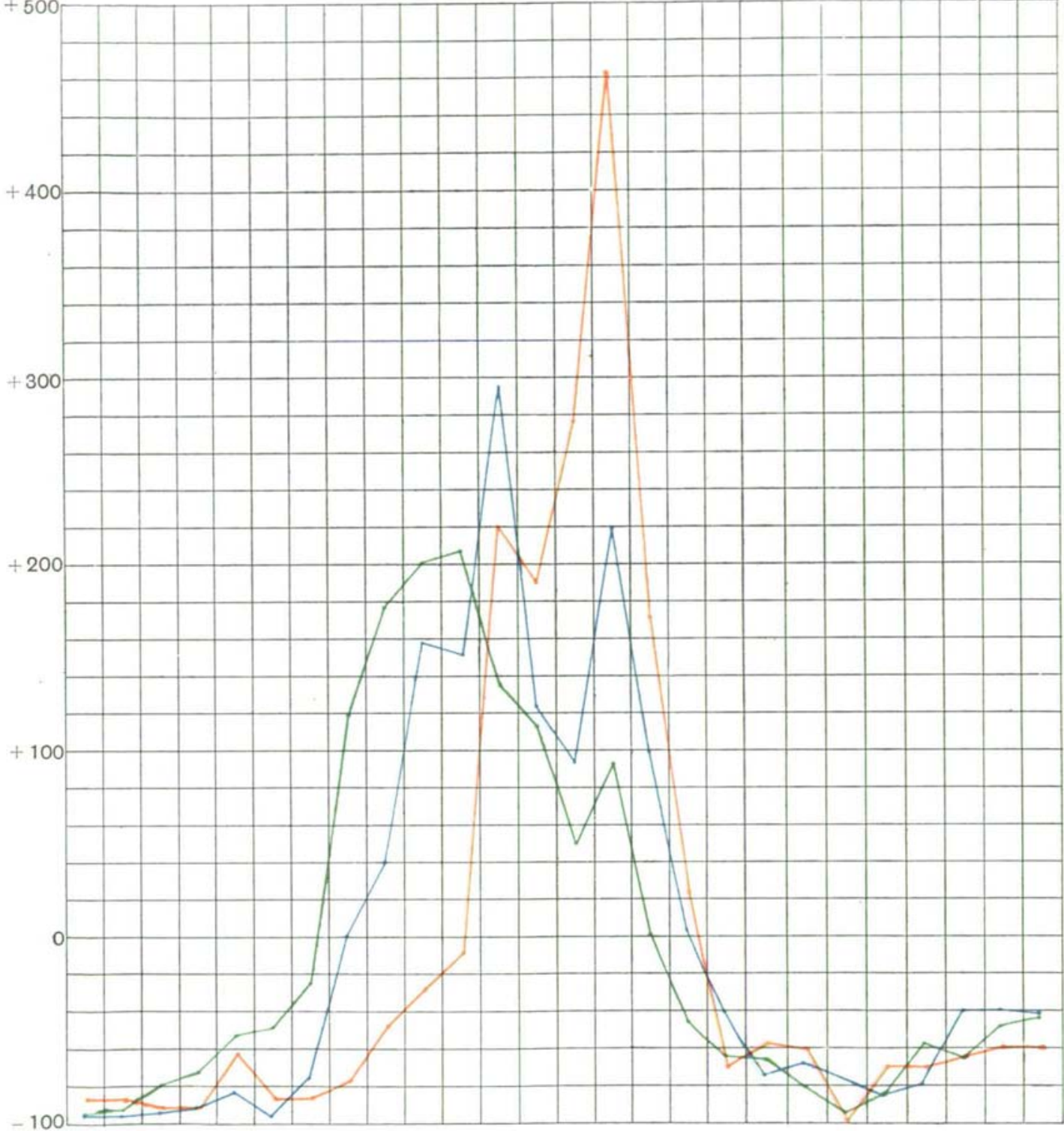

\section{MANDVI}

October, 1905 to September, 1906

\footnotetext{
Plague infected decumanus

- Plague infected rattus

-.- Human plague deaths
} 
Oct. Nov. Dec. Jan. Feb. Marci April May June July Aug. Sept.

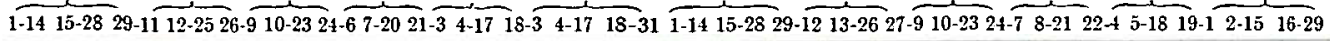

o
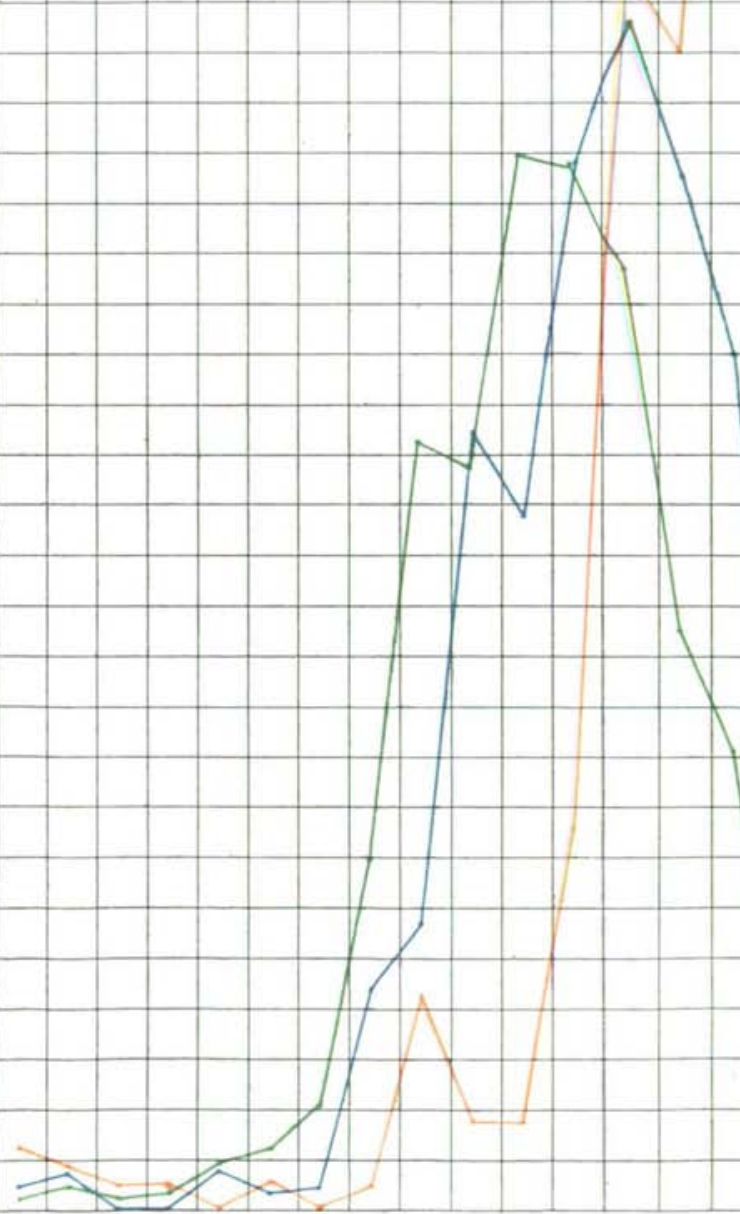

$\sqrt{ }$

CHAKLA

October, Ig05 to September, Ig06

- Plague infected decumanus

- Plague infected rattus

https://doi.org/10.1017/50022172400033684 Published online by Cambrandgevne divaths 


\section{BOMBAY VII}

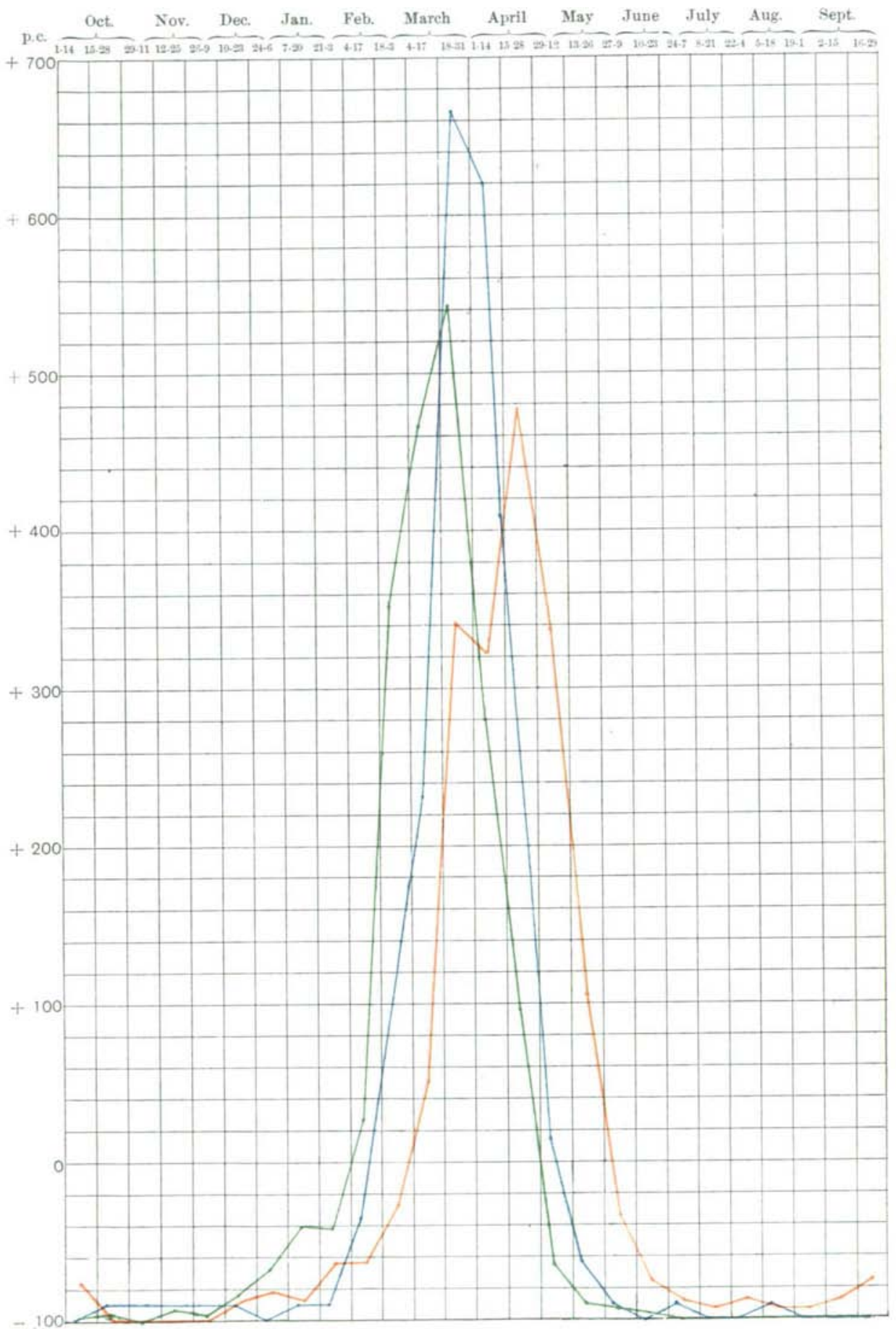

MARKE'T

October, 1905 to September, I906

- Plague infected decumanus

Plague infected rattus 


\section{BOMBAY VIII}

Oct. Nov. Dec. Jan. Feb. March April May June July Aug. Sept.

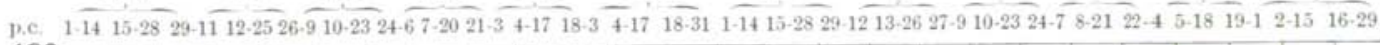

$+200$
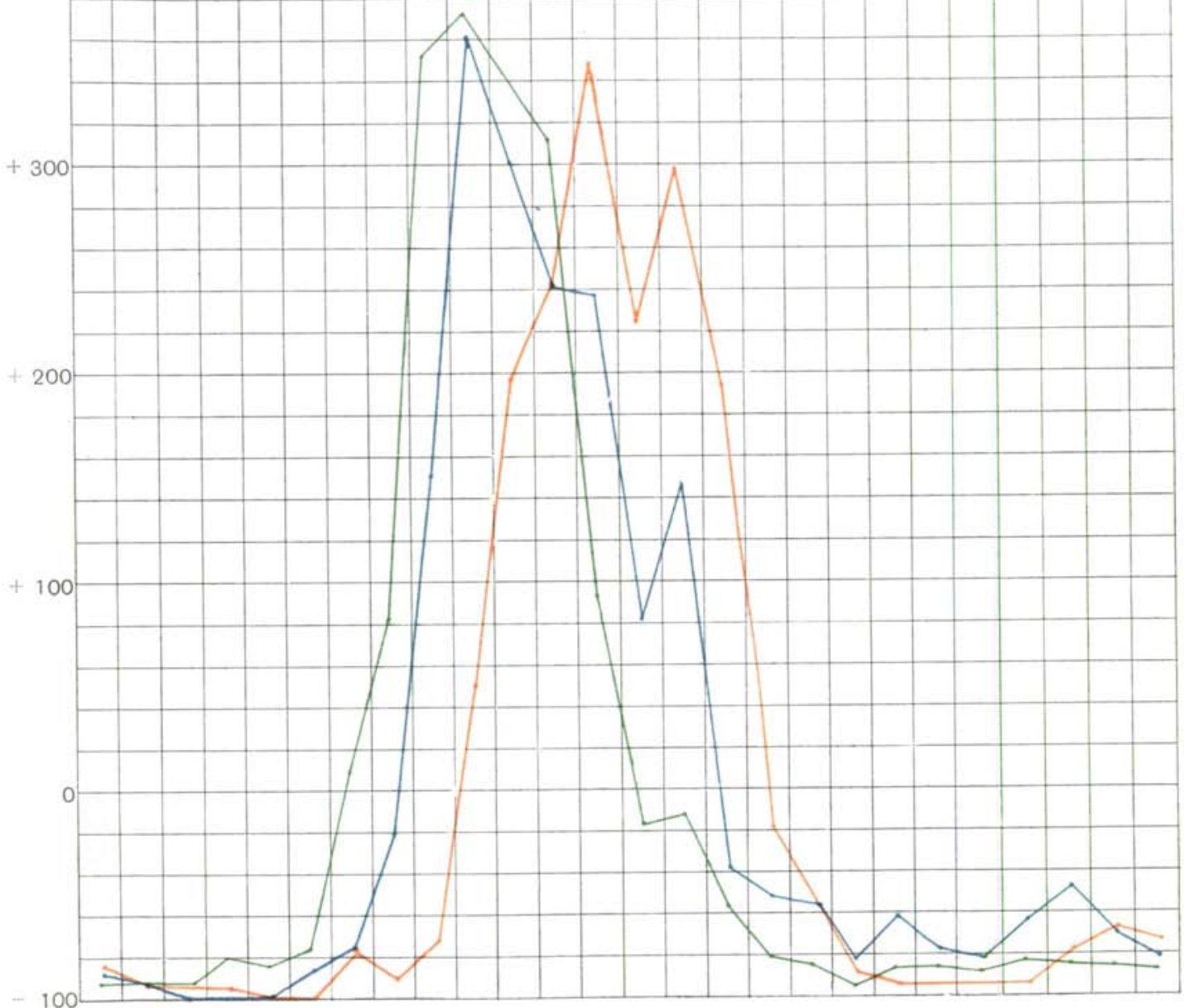

UMARKHADI

October, I905 to September, I906

- Plague infected decumanus

- Plague infected rattus

- Human plague deaths 


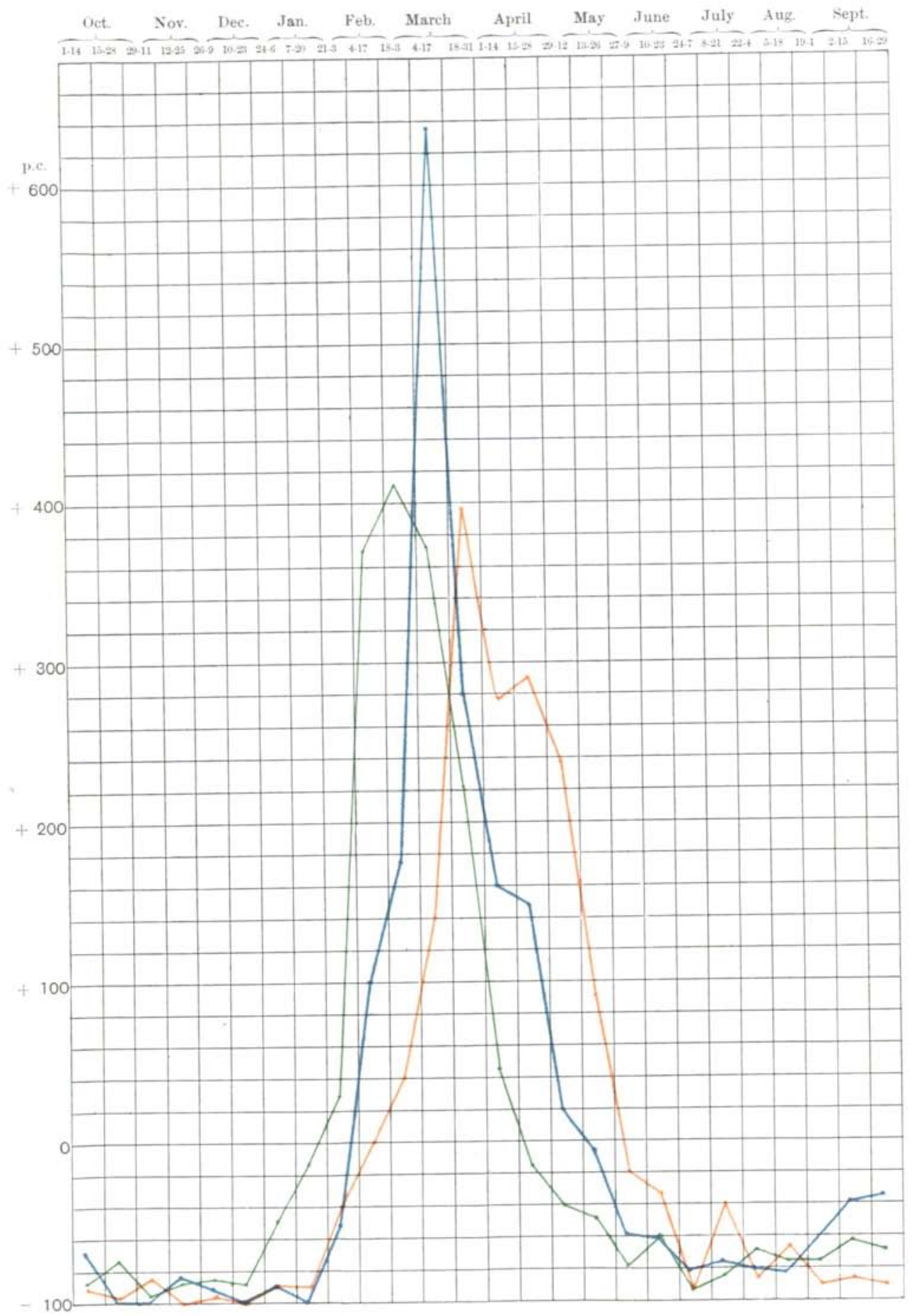

DONGRI

October, I905 to September, Ig06

- Plague infected decumanus

- Plague infected rattus 


\section{BOMBAY X}

Oet. Nov. Dec. Jan. Feb. March April May June July Aug. Sept.

1-14 15-28 29-11 12-25 26-9 10-23 24-6 7-20 21-34+17 18-3 4-17 18-31 1-14 15-28 29-12 13-26 27-9 10-2324-7 8-21 22-4 5-18 19-1 2-15 16-29

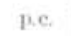

$+400$

$+300$

$+200$
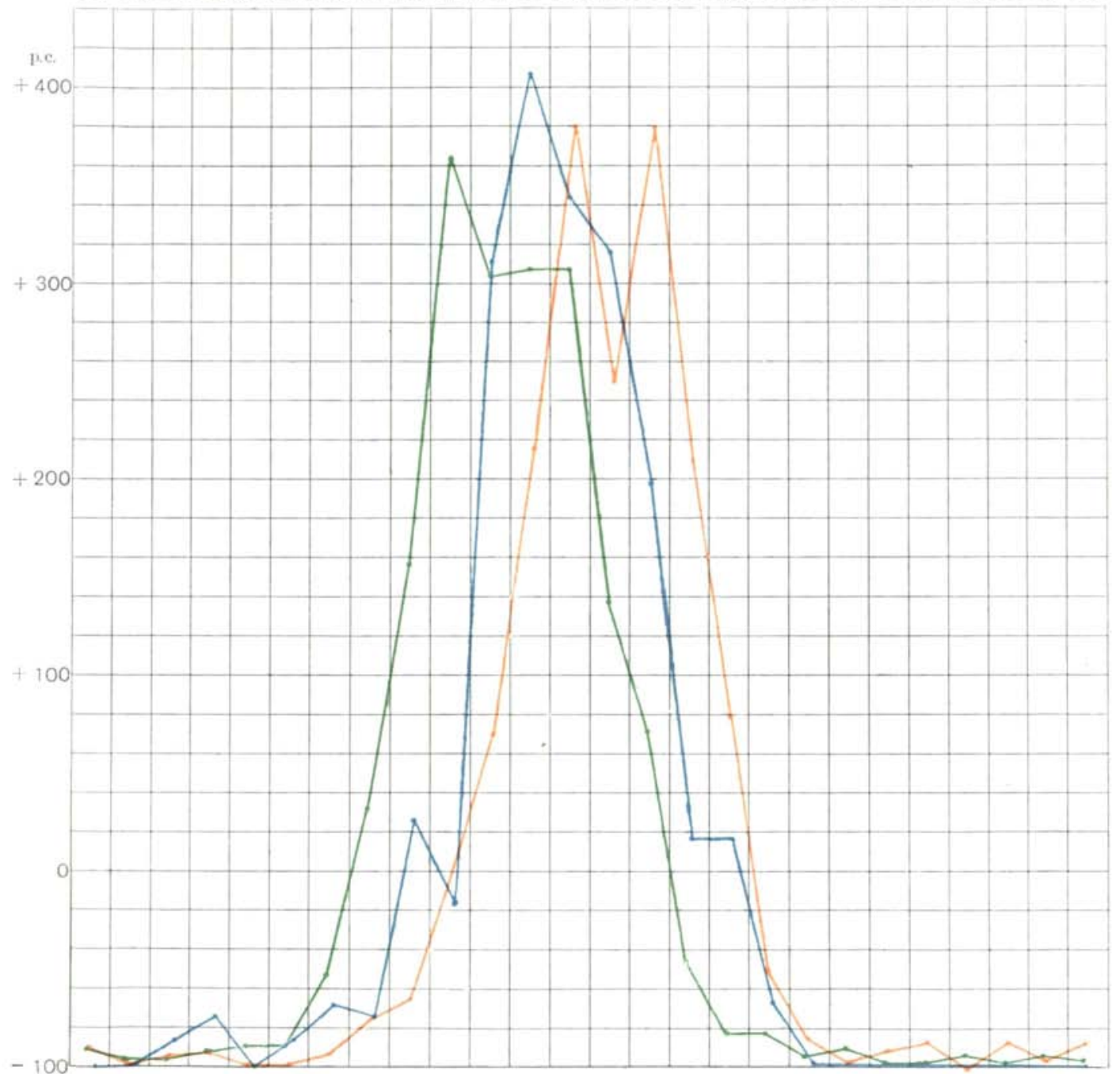

\section{DHOBI TALAO}

October, 1905 to September, rgo6

- Plague infected decumanus

- Plague infected rattus

- Human plague deaths 
Oet. Nov. Dec. Jan. Feb. Mareh April May June July Aug. Sejt.

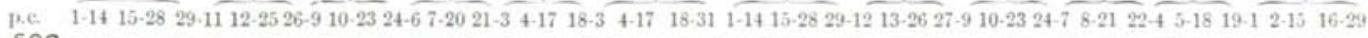

\begin{tabular}{|l|l|l|l|l|l|l|l|l|l|l|l|}
\hline & & & & & & & & & & & \\
\hline & & & & & & & & & & & \\
\hline
\end{tabular}

$+300$

$+200$

$+100$

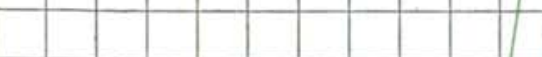

$-$
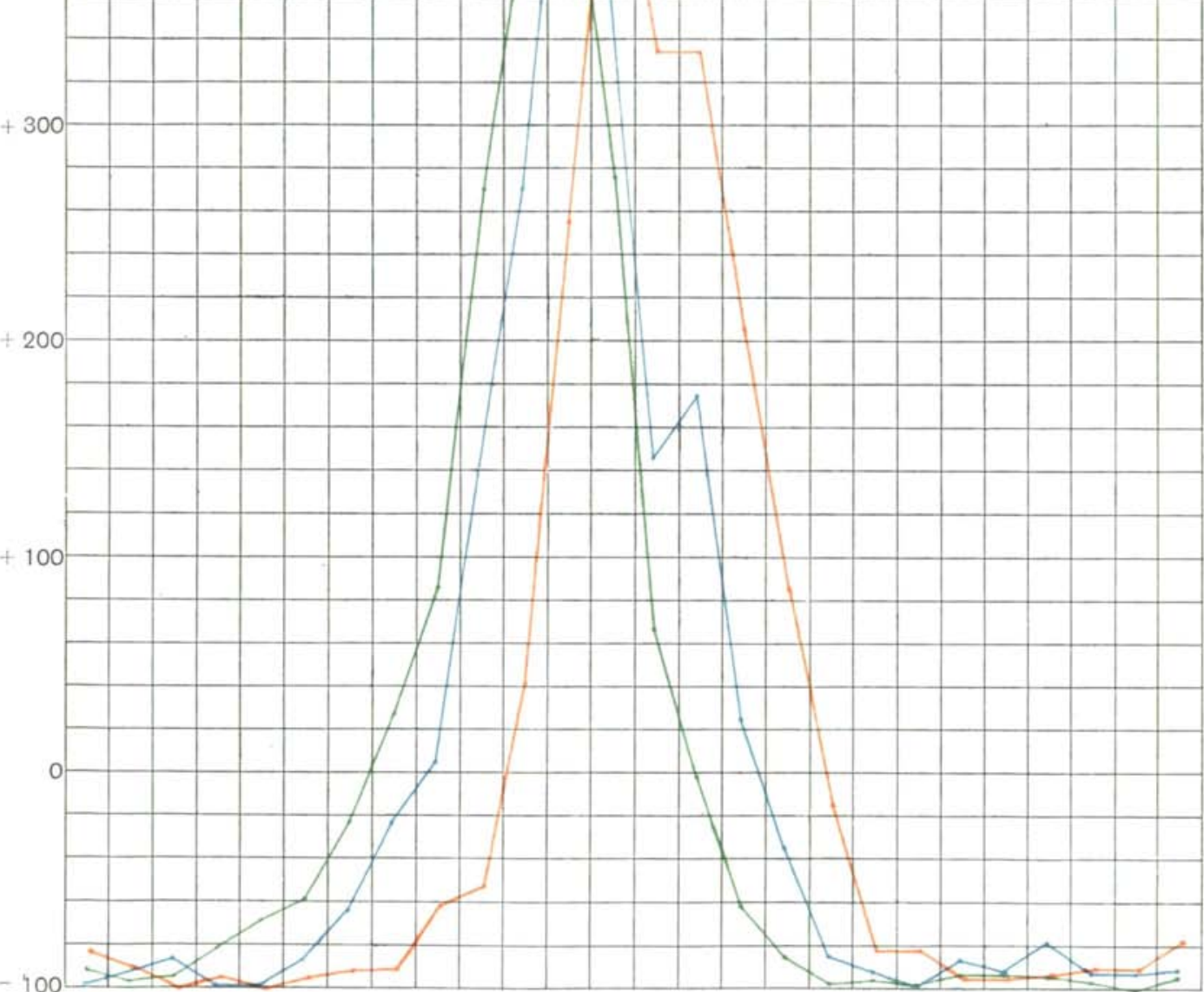

BULESHWAR

October, I905 to September, I906

- Plague infected decumanus

- Plague infected rattus

- Human plague deaths 
Oct. Nov Dee. Jan Feb. Mareh Alril May June July Aug. Sept.

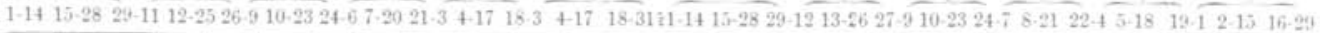

0

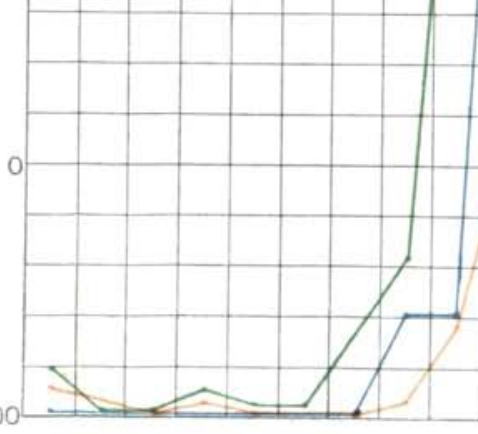

FANASWADI

October, I905 to September, I906

- Plague infected decumanus

- Plague infected rattus 
Oct. Nov. Dec. Jan. Feb. March April May June July Aug. Sept.

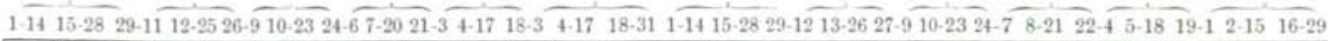

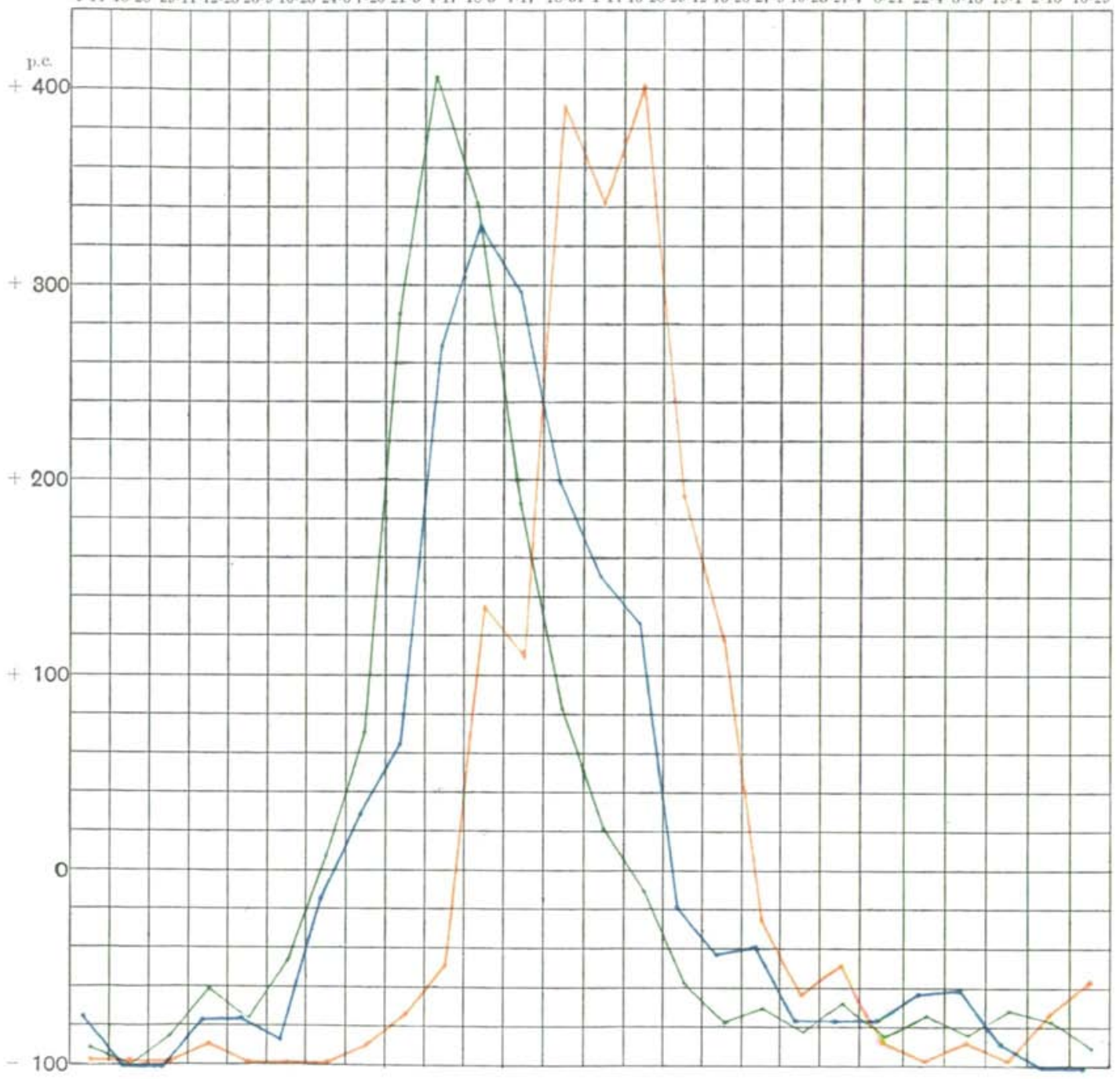

KARA TALAO

October, 1905 to September, Igo6

- Plague infected decumanus

- Plague infected rattus

- Human plague deaths 


\section{BOMBAY XIV}

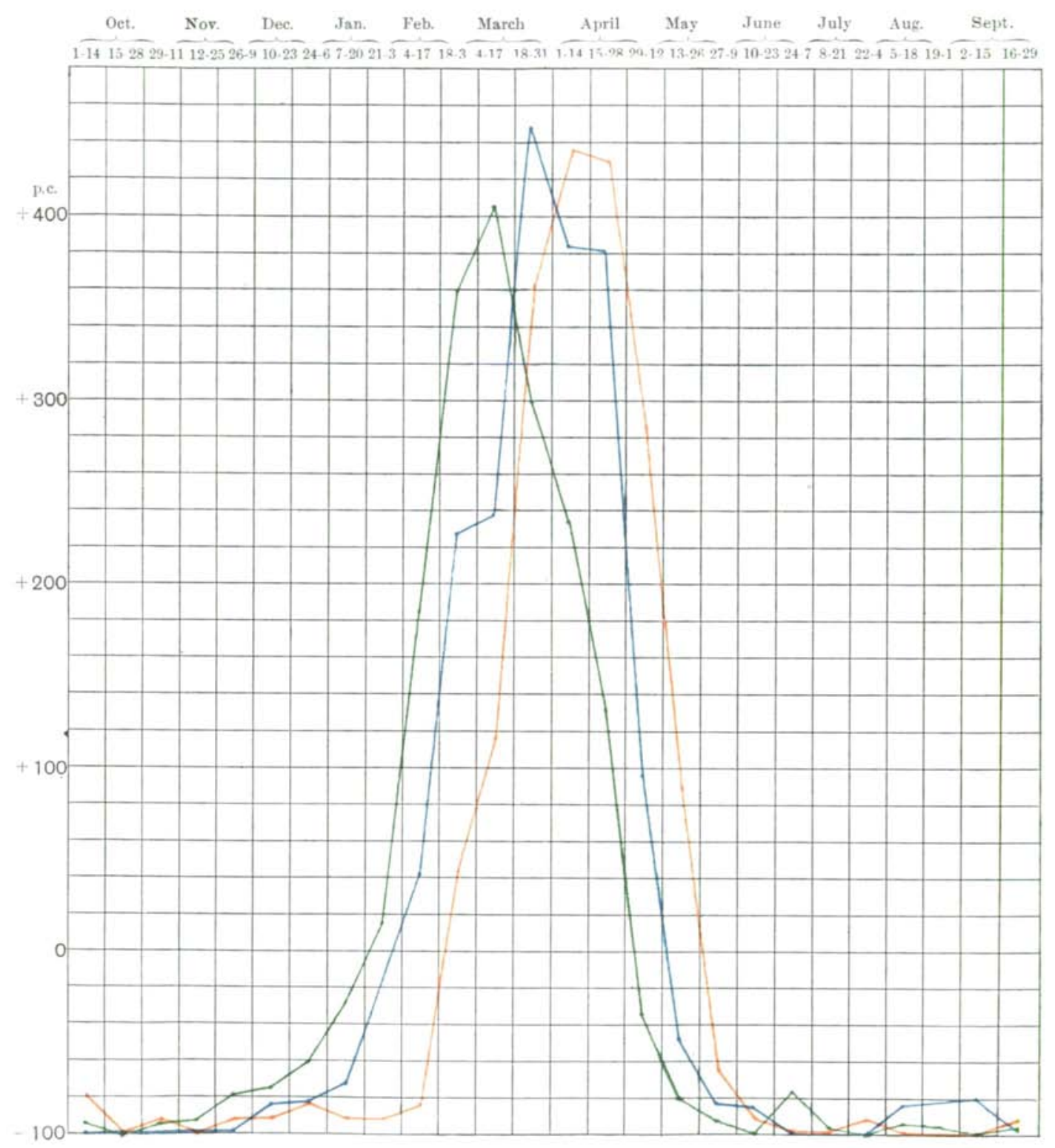

KUMBARWADA

October, rgo5 to September, I906

- Plague infected decumanus

- Plague infected rattus

- Human plague deaths 


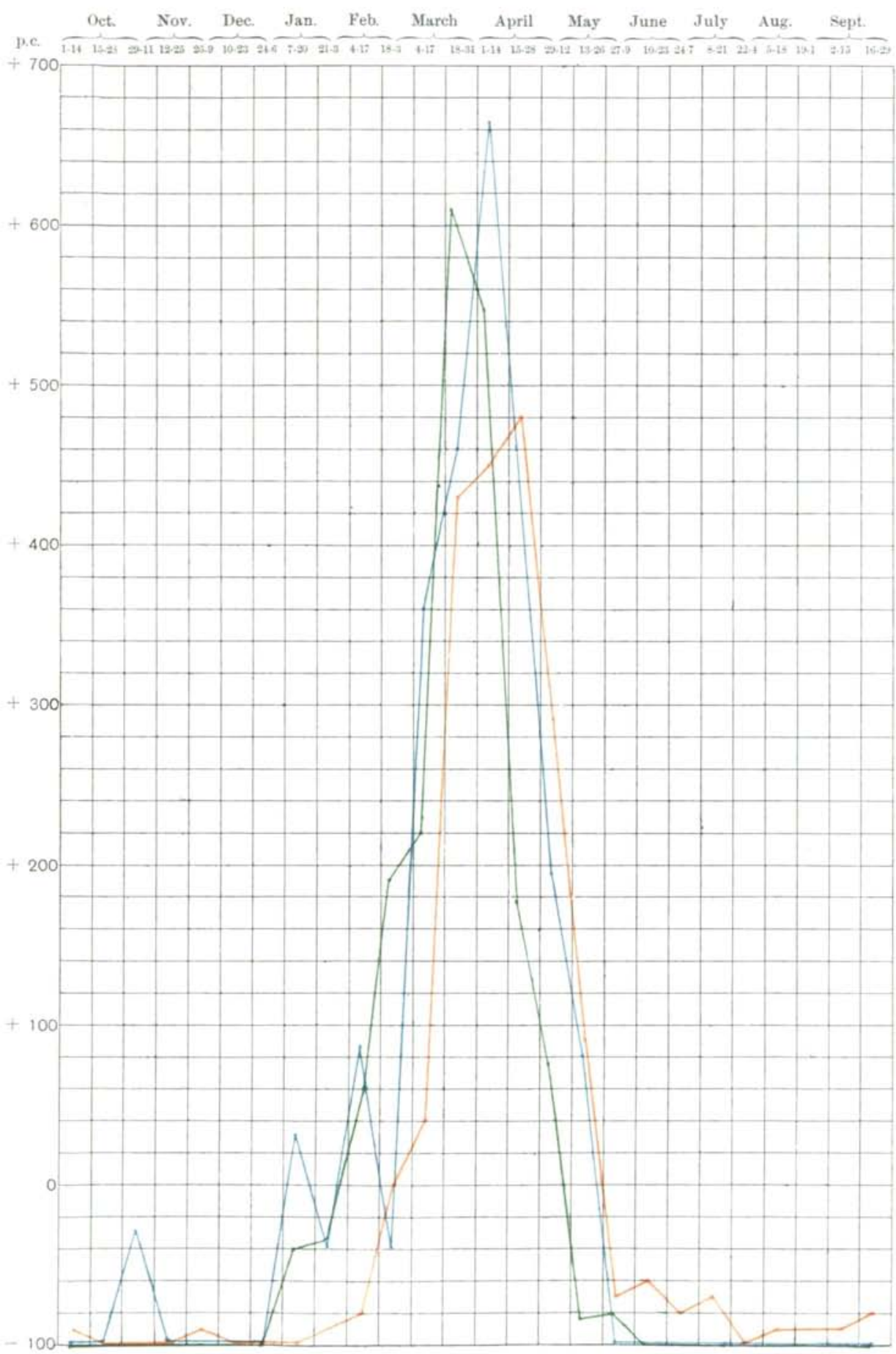

\section{KHETWADI}

October, rgo5 to September, I906

- Plague infected decumanus

- Plague infected rattus

- Human plague deaths 


\section{Reports on Plague Investigations in India}

the connection is closer between human plague returns for one week and the incidence of rat plague in some earlier week than between the figures for the same period in both cases.

In attempting to answer these questions, two assumptions are necessary: (1) that the diagnosis is certain : (2) that rats are collected uniformly, there being no special activity in bringing them in when plague is rife among human beings. Obviously if the second assumption is unsound, the figures are useless.

I have measured the relationship between human and rat plague as follows.

The coefficients of correlation $(r)$ between human plague returns (absolute figures) and rat plague returns (percentages) have been obtained by the usual process. To avoid "grouping errors," each observation was referred separately to the axis. Sheppard's moment corrections were not used, the contact at the ends of the range not being very high.

Taking the figures for the same week, I find the correlation between human plague and plague in $M$. rattus to be $8801 \pm 0184^{1}$; between plague in man and plague in $M$. decumanus, $7481 \pm 036$.

At first sight, this appears to suggest almost as close a relationship between decumanus and human plague as between the latter and plague in rattus. I believe this to be apparent, not real, correlation, for the following reasons.

The correlation between plague in rattus and plague in decumanus is very high, $\cdot 945 \pm 00875$, that is, the three variables are related. It is known that, if we have three related variables, the correlation between any two of them for a constant value of the third (the so-called "Partial Correlation Coefficient") is equal to :

$$
\frac{r_{12}-r_{13} \cdot r_{23}}{\sqrt{1-r_{13}^{2}} \times \sqrt{1-r_{23}^{2}}}
$$

where $r_{12}$ is the correlation between the first and second variables, $r_{23}$ between the second and third, $r_{13}$ between the first and third.

In the above case, the partial correlation between human plague and plague in decumanus is actually negative (-538). If, on the other hand, we calculate the partial correlation between human plague and rattus plague for a constant value of decumanus plague, we obtain $\cdot 7976$, which is still very large. 'In other words, all the correlation between plague in decumanus and plague in man is accounted for by the high correlation between plague in rattus and plague in decumanus; there is no evidence of an independent (positive) connection between human and decumanus plague incidence.

If $\mathrm{I}$ am right in thinking that rattus is more closely associated than decumanus with human dwellings, this result is quite intelligible and an argument in favour of the method adopted. For these reasons, I have not further considered the decumanus returns.

So far, we have found that the correlation between human and rattus returns for the same week is very high; we must next ascertain the values of $r$ on correlating human plague figures of one week with those of rattus for an earlier week.

1 The non-statistician is reminded that $r$ must lie between 0 and $\pm 1, \pm 1$ marking (under "normal" conditions) a complete causal relationship.

A negative value simply means that as one variable increases the other decreases, while they both increase together if $r$ is positive.

Any value of $r$ greater than 75 is very large. 
Showing the crude results of the rat examination.

M. DECUNIANUS

\begin{tabular}{|c|c|c|c|c|c|c|c|c|c|c|c|c|}
\hline \multirow[b]{2}{*}{$\begin{array}{r}\text { Week } \\
\text { ending }\end{array}$} & \multirow[b]{2}{*}{$\begin{array}{l}\text { Total rats } \\
\text { examined }\end{array}$} & \multirow[b]{2}{*}{$\begin{array}{c}\text { Total } \\
\text { examined }\end{array}$} & \multirow[b]{2}{*}{ Alive } & \multirow[b]{2}{*}{ Dead } & \multicolumn{5}{|c|}{ Plague infected } & \multirow[b]{2}{*}{$\begin{array}{c}\text { Per } \\
\text { cent. }\end{array}$} & \multirow{2}{*}{ 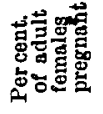 } & 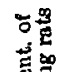 \\
\hline & & & & & Total & $\begin{array}{l}\text { Per } \\
\text { cent. }\end{array}$ & Alive & $\begin{array}{l}\text { Per } \\
\text { cent. }\end{array}$ & Dead & & & 总苛 \\
\hline July 8, 1905 & 1412 & 868 & 385 & 483 & 8 & 0.9 & 1 & $0 \cdot 3$ & 7 & $1 \cdot 4$ & $16 \cdot 0$ & - \\
\hline $\begin{array}{l}15 \\
22\end{array}$ & 1176 & 692 & 298 & 394 & 9 & $1 \cdot 3$ & 1 & $0 \cdot 3$ & 8 & $2 \cdot 0$ & $13 \cdot 8$ & - \\
\hline $\begin{array}{r}22 \\
-\quad 27\end{array}$ & 1137 & 640 & 239 & 401 & 4 & 0.6 & 0 & & 4 & $1 \cdot 0$ & $12 \cdot 2$ & $13 \cdot 4$ \\
\hline & 1330 & 797 & 284 & 513 & 4 & 0.5 & 0 & & 4 & 0.8 & 13.7 & $17 \cdot 6$ \\
\hline $\begin{array}{r}\text { Aug. } \overline{5} \\
12\end{array}$ & 1342 & 740 & 245 & 495 & 5 & 0.7 & 0 & & 5 & $1 \cdot 0$ & $11 \cdot 4$ & $17 \cdot 3$ \\
\hline $\begin{array}{l}12 \\
19\end{array}$ & 1287 & 752 & 255 & 497 & 9 & $1 \cdot 2$ & 0 & & 9 & $1 \cdot 8$ & $9 \cdot 7$ & $16 \cdot 0$ \\
\hline 19 & 1172 & 674 & 219 & 455 & 6 & 0.9 & 0 & & 6 & $1 \cdot 3$ & $12 \cdot 0$ & $16 \cdot 0$ \\
\hline 26 & 1229 & 648 & 236 & 412 & 9 & 1.4 & 0 & & 9 & $2 \cdot 2$ & $11 \cdot 7$ & $18 \cdot \overline{5}$ \\
\hline Sept. 2 & 1454 & 805 & 324 & 481 & 8 & $1 \cdot 0$ & 1 & 0.3 & 7 & $1 \cdot \tilde{z}$ & $16 \cdot 6$ & $18 \cdot 8$ \\
\hline 9 & 1381 & 730 & 252 & 478 & 9 & $1 \cdot 2$ & 1 & 0.4 & 8 & $1 \cdot 7$ & $14 \cdot 2$ & $16 \cdot 1$ \\
\hline 16 & 1808 & 935 & 341 & 594 & 12 & $1 \cdot 3$ & 0 & $0 \cdot 0$ & 12 & $2 \cdot 0$ & $12 \cdot 9$ & $22 \cdot 6$ \\
\hline 23 & 1950 & 954 & 334 & 620 & 19 & $2 \cdot 0$ & 2 & $0 \cdot 6$ & 17 & $2 \cdot 7$ & $14 \cdot 7$ & $21 \cdot 6$ \\
\hline 30 & 1628 & 851 & 386 & 465 & 15 & $1 \cdot 8$ & 0 & 0.0 & 15 & $3 \cdot 2$ & $14 \cdot 3$ & $29 \cdot 9$. \\
\hline Oct. 7 & 1611 & 856 & 418 & 438 & 13 & $1 \cdot 5$ & 1 & $0 \cdot 2$ & 12 & $2 \cdot 7$ & $18 \cdot 4$ & $29 \cdot 3$ \\
\hline 14 & 1654 & 950 & 444 & 506 & 18 & 1.9 & I & 0.2 & 17 & $3 \cdot 4$ & $18 \cdot 4$ & $27 \cdot 9$ \\
\hline 21 & 1797 & 1003 & 413 & 590 & 20 & $2 \cdot 0$ & 0 & & 20 & $3 \cdot 4$ & $14 \cdot 6$ & $27 \cdot 0$ \\
\hline 28 & 1662 & 920 & 336 & 584 & 16 & $1 \cdot 7$ & 0 & & 16 & $2 \cdot 7$ & $16 \cdot 2$ & $28 \cdot 3$ \\
\hline Nov. 4 & 1378 & 902 & 325 & 577 & 23 & $2 \cdot 6$ & 0 & & 23 & $4 \cdot 0$ & $16 \cdot 3$ & $28 \cdot 6$ \\
\hline 11 & 1148 & 712 & 294 & 418 & 15 & $2 \cdot 1$ & 1 & 0.3 & 14 & $3 \cdot 3$ & $13 \cdot 5$ & $24 \cdot 9$ \\
\hline 18 & 1353 & 827 & 276 & 551 & 36 & $4 \cdot 35$ & 0 & & 36 & $6 \cdot 5$ & $14 \cdot 1$ & $25 \cdot 6$ \\
\hline 25 & 1661 & 789 & 242 & 547 & 37 & $4 \cdot 7$ & 0 & & 37 & $6 \cdot 7$ & $17 \cdot 3$ & $27 \cdot 6$ \\
\hline Dec. 2 & 2012 & 1088 & 378 & 710 & 54 & $5 \cdot 0$ & 1 & & 53 & $7 \cdot 6$ & 16.4 & $22 \cdot 3$ \\
\hline 9 & 2393 & 1284 & 414 & 870 & 52 & $4 \cdot 0$ & 1 & 0.2 & 51 & $5 \cdot 9$ & $13 \cdot 3$ & $22 \cdot 9$ \\
\hline 16 & 2587 & 1359 & 471 & 888 & 66 & $4 \cdot 9$ & 0 & 0.0 & 66 & $7 \cdot 4$ & $16 \cdot 1$ & $18 \cdot 1$ \\
\hline 23 & 2345 & 1136 & 403 & 733 & 83 & 73 & 3 & 0.7 & 80 & 10.9 & $13 \cdot 9$ & $21 \cdot 3$ \\
\hline 30 & 2235 & 1160 & 406 & 754 & 118 & $10 \cdot 2$ & 3 & 0.7 & 115 & $15 \cdot 2$ & $16 \cdot 8$ & $21 \cdot 0$ \\
\hline Jan. 6, 1906 & 2474 & 1416 & 449 & 967 & 169 & $11 \cdot 9$ & 4 & $0 \cdot 9$ & 165 & $17 \cdot 0$ & $11 \cdot 1$ & $16 \cdot 8$ \\
\hline 13 & $\mathbf{3 3 6 9}$ & 2106 & 395 & 1711 & 282 & $13 \cdot 4$ & 8 & $2 \cdot 0$ & 274 & $16 \cdot 0$ & $11 \cdot 8$ & $17 \cdot 7$ \\
\hline 20 & 4320 & 2891 & 369 & 2522 & 476 & 16.5 & 1 & 0.3 & 475 & $18 \cdot 8$ & $8 \cdot 9$ & $17 \cdot 2$ \\
\hline 27 & 5510 & 4131 & 320 & 3811 & 576 & $13 \cdot 9$ & 2 & 0.6 & 574 & $15 \cdot 0$ & $8 \cdot 5$ & $14 \cdot 8$ \\
\hline Feb. $\mathbf{3}$ & 5324 & 4030 & 251 & 3779 & 610 & $15 \cdot 1$ & 2 & $0 \cdot 8$ & 608 & $16 \cdot 0$ & $9 \cdot 7$ & $15 \cdot 3$ \\
\hline 10 & 4443 & 3197 & 128 & 3069 & 715 & $22 \cdot 4$ & 3 & $2 \cdot 2$ & 712 & $23 \cdot 2$ & $12 \cdot 0$ & $13 \cdot 8$ \\
\hline 17 & 5734 & 4096 & 264 & 3832 & 1014 & $24 \cdot 8$ & 6 & $2 \cdot 3$ & 1008 & $26 \cdot 3$ & $11 \cdot 5$ & $15 \cdot 0$ \\
\hline 24 & 4182 & 2981 & 119 & 2862 & 944 & $31 \cdot 7$ & 5 & $4 \cdot 2$ & 939 & $32 \cdot 8$ & $15 \cdot 5$ & $12 \cdot 7$ \\
\hline March 3 & 4705 & 3295 & 170 & 3125 & 1136 & $34 \cdot 5$ & 3 & $1 \cdot 8$ & 1133 & $36 \cdot 3$ & $18 \cdot 2$ & $16 \cdot 1$ \\
\hline . 10 & 2606 & 1812 & 126 & 1686 & 725 & $40 \cdot 0$ & 8 & $6 \cdot 3$ & 717 & $42 \cdot 5$ & $17 \cdot 5$ & $14 \cdot 0$ \\
\hline 17 & 3782 & 2666 & 105 & 2561 & 1129 & $42 \cdot 3$ & 5 & $4 \cdot 8$ & 1124 & $43 \cdot 9$ & $20 \cdot 3$ & $16 \cdot 7$ \\
\hline 24 & 3216 & 2106 & 89 & 2017 & 838 & $39 \cdot 8$ & 5 & $5 \cdot 6$ & 833 & $41 \cdot 3$ & $23 \cdot 7$ & $17 \cdot 6$ \\
\hline 31 & 3416 & 2205 & 116 & 2089 & 891 & $40 \cdot 4$ & 3 & $2 \cdot 6$ & 888 & $42 \cdot 5$ & $18 \cdot 8$ & $17 \cdot 0$ \\
\hline April 7 & 2596 & 1600 & 120 & 1480 & 512 & $32 \cdot 0$ & 3 & $2 \cdot 5$ & 509 & $34 \cdot 4$ & $17 \cdot 7$ & $18 \cdot 6$ \\
\hline 14 & 2688 & 1671 & 132 & 1539 & 560 & $33 \cdot 5$ & 3 & $2 \cdot 5$ & 557 & $36 \cdot 2$ & $16 \cdot 3$ & $20 \cdot 5$ \\
\hline 21 & 3284 & 1869 & 139 & 1730 & 616 & $33 \cdot 0$ & $\mathbf{5}$ & $3 \cdot 6$ & 611 & $35 \cdot 3$ & $17 \cdot 3$ & $19 \cdot 7$ \\
\hline 28 & 2350 & 1391 & 134 & 1257 & 380 & $27 \cdot 3$ & 1 & 0.7 & 379 & $30 \cdot 1$ & 20.5 & $21 \cdot 9$ \\
\hline May 5 & 1990 & 1131 & 101 & 1030 & 214 & $18 \cdot 9$ & 2 & $2 \cdot 0$ & 212 & $20 \cdot 6$ & $19 \cdot 0$ & $20 \cdot 2$ \\
\hline 12 & 1821 & 1046 & 110 & 936 & 150 & $14 \cdot 3$ & 1 & 0.9 & 149 & 15.9 & $16 \cdot 8$ & $20 \cdot 3$ \\
\hline 19 & 1616 & 932 & 114 & 818 & 111 & 11.9 & 1 & 0.9 & 110 & $13 \cdot 4$ & $15 \cdot 2$ & $20 \cdot 3$ \\
\hline 26 & 1171 & 693 & 121 & 572 & 84 & $12 \cdot 1$ & 3 & $2 \cdot 5$ & 81 & $14 \cdot 2$ & $17 \cdot 6$ & $15 \cdot 4$ \\
\hline June 2 & 993 & 557 & 76 & 481 & 54 & $9 \cdot 7$ & 2 & $2 \cdot 6$ & 52 & $10 \cdot 8$ & $16 \cdot 0$ & $17 \cdot 4$ \\
\hline 9 & 961 & 510 & 90 & 420 & 29 & $5 \cdot 7$ & 0 & & 29 & $6 \cdot 9$ & $10 \cdot 2$ & $15 \cdot 7$ \\
\hline 16 & 1050 & 589 & 115 & 474 & 33 & $5 \cdot 6$ & 0 & & 33 & $7 \cdot 0$ & $18 \cdot 8$ & $13 \cdot 8$ \\
\hline 23 & 1141 & 564 & 144 & 420 & 31 & $5 \cdot 5$ & 0 & & 31 & $7 \cdot 4$ & $11 \cdot 7$ & $18 \cdot 0$ \\
\hline 30 & 1087 & 507 & 103 & 404 & 22 & $4 \cdot 3$ & 1 & $1 \cdot 0$ & 21 & $5 \cdot 2$ & $13 \cdot 6$ & $16 \cdot 2$ \\
\hline July 7 & 1252 & 558 & 181 & 377 & 28 & $5 \cdot 0$ & & & 28 & $7 \cdot \overline{4}$ & $18 \cdot 0$ & $17 \cdot 2$ \\
\hline 14 & 1175 & 540 & 128 & 412 & 13 & $2 \cdot 4$ & & & 13 & $3 \cdot 2$ & $18 \cdot 6$ & $23 \cdot 0$ \\
\hline 21 & 1261 & 591 & 146 & 445 & 21 & $3 \cdot 6$ & & & 21 & $4 \cdot \overline{7}$ & $18 \cdot 7$ & $16 \cdot 8$ \\
\hline 28 & 1327 & 620 & 167 & 453 & 29 & $4 \cdot 7$ & & & 29 & $6 \cdot 4$ & $16 \cdot 3$ & $17 \cdot 9$ \\
\hline Allg. 4 & 1133 & 469 & 100 & 369 & 19 & $4 \cdot 1$ & & & 19 & $5 \cdot 1$ & $12 \cdot 3$ & $21 \cdot 5$ \\
\hline 11 & 1070 & 494 & 128 & 366 & 26 & $5 \cdot 3$ & & & 26 & $7 \cdot 1$ & $14 \cdot 9$ & $24 \cdot 7$ \\
\hline 18 & 1411 & 552 & 138 & 414 & 38 & 6.9 & & & 38 & $9 \cdot 2$ & $20 \cdot 8$ & $20 \cdot 7$ \\
\hline 25 & 1272 & 554 & 165 & 389 & 24 & $4 \cdot 3$ & & & 24 & $6 \cdot 2$ & $20 \cdot 0$ & $17 \cdot 5$ \\
\hline Sept. 1 & 1630 & 722 & 225 & 497 & 38 & $5 \cdot 3$ & 2 & 0.9 & 36 & $7 \cdot 2$ & $15 \cdot 9$ & $24 \cdot 7$ \\
\hline 8 & 1607 & 723 & 168 & 555 & $4 \tilde{0}$ & $6 \cdot 2$ & & & 45 & $8 \cdot \overline{1}$ & $16 \cdot 2$ & $21 \cdot 2$ \\
\hline 15 & 1031 & 516 & 119 & 397 & 22 & $4 \cdot 3$ & & & 22 & $5 \cdot 5$ & $13 \cdot 9$ & $18 \cdot 2$ \\
\hline 22 & 1841 & 822 & 163 & 659 & 34 & $4 \cdot 1$ & & & 34 & $5 \cdot 2$ & $11 \cdot 1$ & $19 \cdot 8$ \\
\hline 29 & 1396 & 650 & 136 & 514 & 25 & $3 \cdot 8$ & & & 25 & $4 \cdot 9$ & $16 \cdot 3$ & $19 \cdot 2$ \\
\hline Oct. 6 & 2460 & 1196 & 240 & 956 & 32 & $2 \cdot 7$ & 2 & 0.8 & 30 & $3 \cdot 1$ & $16 \cdot 6$ & $26 \cdot 3$ \\
\hline 13 & 3226 & 1574 & 404 & 1170 & 62 & $3 \cdot 9$ & 1 & 0.25 & 61 & $5 \cdot 2$ & $12 \cdot 9$ & $29^{\cdot 4}$ \\
\hline 20 & 1886 & 808 & 285 & 523 & 27 & $\mathbf{3} \cdot \mathbf{3}$ & & & 27 & $5 \cdot 2$ & $12 \cdot 0$ & $37 \cdot 9$ \\
\hline
\end{tabular}




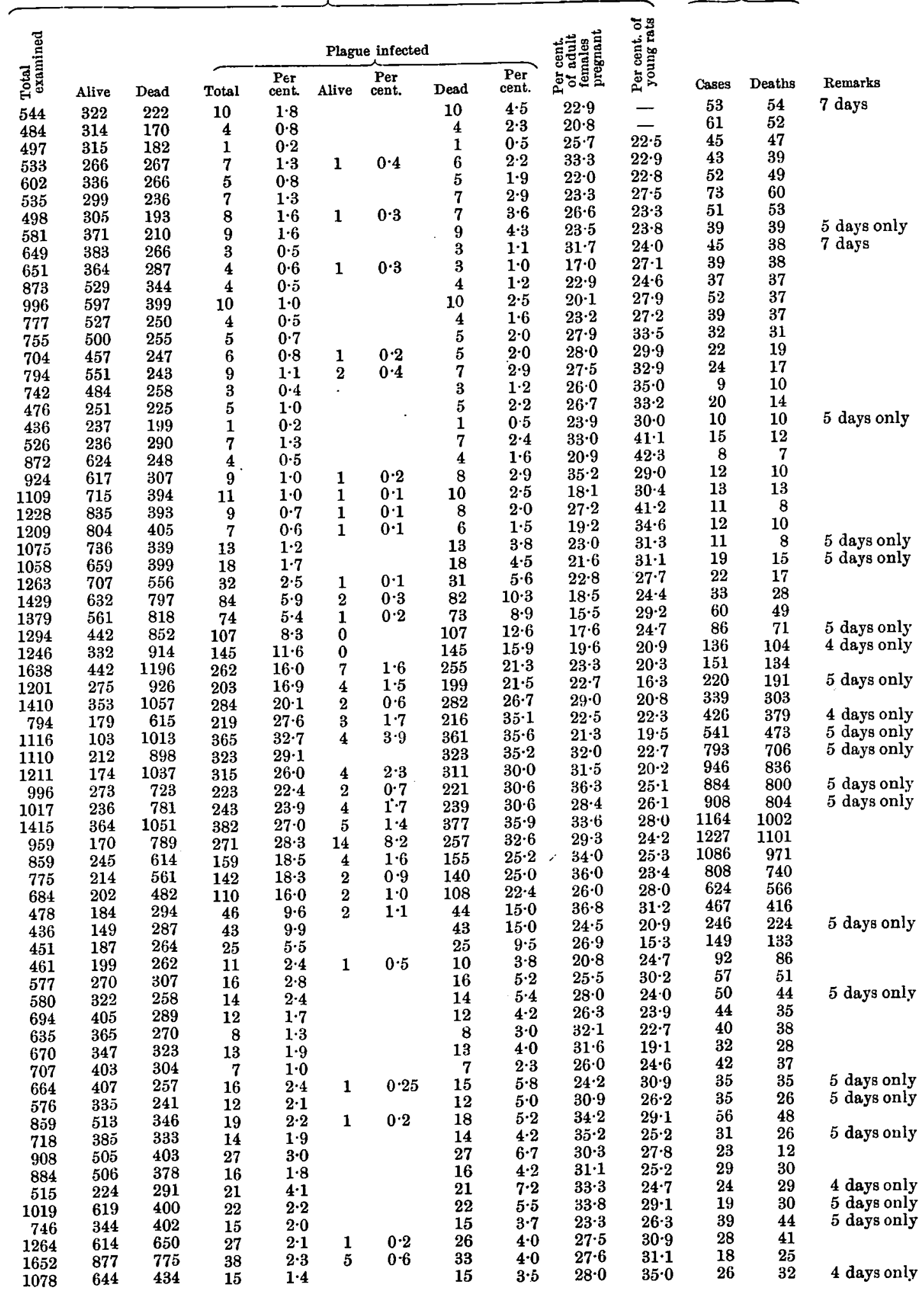


I obtained the following results :-

(1) Human plague with rattus plague in previous week. $r=9305 \pm 011$.

(2) Human plague with rattus plague in 2nd previous week. $r=9407 \pm .0096$.

(3) Human plague with rattus plague, 3rd previous week. $r=9206 \pm 0128$.

(4) Human plague with rattus plague, 4th previous week. $r=887 \pm 018$.

The difference between (1) and (2) is $0102 \pm 0146$; between (2) and (3) $.0201 \pm 016$; between (3) and (4) $0336 \pm 0221$.

The differences between the correlation coefficient for the same week and (1), (2), (3) and (4) are $\cdot 0504 \pm \cdot 021 ; \cdot 0606 \pm \cdot 021 ; \cdot 0405 \pm \cdot 0224 ; \cdot 0069 \pm \cdot 0257$, respectively.

A comparison of these differences with their "probable errors" makes it clear that with one doubtful exception, there is no real increase in the correlation when we go back in this way. In the case of (2) $r$ differs from the value previously obtained by nearly three times the "probable error" of the difference; that is to say, there is some evidence that human plague incidence in any given week is most closely associated with rattus plague incidence in the next week but one before. But if we adopt as a criterion of significance an increase of three times the "probable error," and most biometricians consider this best, the difference is within the limit. The evidence on this point is therefore merely suggestive, not convincing.

The inferences which may, I think, be drawn from this analysis are :-

(1) There is an extremely close relationship between the incidence of plague in man and plague in $M$. rattus.

(2) There is no undoubtedly significant difference between the results obtained by correlating human plague returns with those of rattus for the same and four preceding weeks. One value alone approaches the limit.

(3) The correlation between plague in man and plague in $M$. decumanus is probably spurious, depending on the correlation between plague in decumanus and in rattus. 